\title{
Regulation of checkpoint kinase signalling and tumorigenesis by the NF-kB regulated gene, CLSPN
}

Jill E. Hunter ${ }^{1}$, Jacqueline A. Butterworth ${ }^{1}$, Helene Sellier ${ }^{1}$, Saimir Luli $^{2}$, Achilleas Floudas ${ }^{2}$, Adam J. Moore ${ }^{1}$, Huw D. Thomas ${ }^{3}$, Kirsteen J. Campbell ${ }^{4}$, Niall S. Kenneth ${ }^{1}$, Robson T. Chiremba $^{1}$, Dina Tiniakos ${ }^{2}$, Andrew M. Knight ${ }^{2}$, Benjamin E. Gewurz ${ }^{5}$, Fiona Oakley ${ }^{2}$, Michelle D. Garrett ${ }^{6,7}$, lan Collins ${ }^{7}$, and Neil D. Perkins ${ }^{1^{*}}$

\author{
${ }^{1}$ Institute for Cell and Molecular Biosciences \\ ${ }^{2}$ Institute of Cellular Medicine \\ ${ }^{3}$ Northern Institute for Cancer Research \\ Faculty of Medical Sciences \\ Newcastle University \\ Newcastle Upon Tyne, NE2 4HH, UK \\ ${ }^{4}$ The Beatson Institute for Cancer Research \\ Glasgow, G61 1BD, UK \\ ${ }^{5}$ Brigham and Women's Hospital, \\ Boston, MA 02115, USA \\ ${ }^{6}$ School of Biosciences, University of Kent \\ Canterbury, CT2 7NJ, UK \\ ${ }^{7}$ The Institute of Cancer Research \\ Sutton, SM2 5NG, UK \\ * corresponding author \\ Tel. 01912088866 \\ Fax. 01912087424 \\ Email:neil.perkins@ncl.ac.uk
}

Running Title: NF-KB regulation of CHK1 inhibitor sensitivity

Word count: 


\begin{abstract}
Inhibition of the tumour promoting activities of NF-KB by cell signalling pathways has been proposed as a natural mechanism to limit the development of cancer. However, there has been a lack of evidence for these effects in vivo. Here we report that RelA ${ }^{T 505 A}$ mice, where a CHK1 targeted Thr505 phosphosite is mutated to alanine, display earlier onset of MYC driven lymphoma than wild type littermates. We describe a positive feedback loop in which the NF-kB subunits RelA and c-Rel, in a manner dependent upon RelA Thr505 phosphorylation, drive the expression of the ATR checkpoint kinase regulator Claspin in response to DNA replication stress in cancer cells. This in turn is required for maintenance of $\mathrm{CHK} 1$ activity. Loss of a single allele of the Clspn gene in mice is sufficient to drive earlier tumorigenesis and low levels of CLSPN mRNA expression are associated with worse survival in some forms of human cancer. We propose that loss of this pathway early in tumorigenesis promotes cancer development through increased genomic instability. However, in malignant cancer cells it can help promote their addiction to the checkpoint kinase signalling required for the maintenance of genomic integrity. Importantly, disruption of this pathway leads to resistance of cells to treatment with $\mathrm{CHK} 1$ inhibitors. Claspin expression could therefore act as a biomarker for responsiveness of patients to CHK1 inhibitors and provide a potential pathway for the development of tumour resistance.
\end{abstract}

Keywords: NF-KB, Claspin, CHK1, lymphoma, CHK1 inhibitor 


\section{Introduction}

The Nuclear Factor kB (NF-kB) family of transcription factors, comprising RelA/p65, RelB, cRel, p50/p105 (NF-kB1) and p52/p100 (NF-KB2), are important regulators of cancer cell biology (Perkins, 2012). Through their ability to regulate a wide variety of genes associated with inflammation, proliferation, apoptosis and metastasis, aberrant NF-KB subunit activity can promote the growth, survival and spread of tumour cells (Perkins, 2012). However, many in vivo studies have relied upon mutation or deletion of subunits of the IKB Kinase (IKK) complex, which drives activation of the NF-KB pathway but has also been reported to have many other functions (Hinz and Scheidereit, 2014). By contrast, the functions of specific NF-KB subunits have often not been explored. Indeed, while there is often an assumption that NF-KB is an obligate tumour promoter, tumour suppressor like characteristics have been identified in vitro that are rarely examined using in vivo models (Perkins, 2012). For example in cell lines, in response to inducers of DNA replication stress, NF-kB can have a pro-apoptotic function (Campbell et al., 2006; Msaki et al., 2011; Rocha et al., 2005; Wu and Miyamoto, 2008).

Given the many diverse roles of the NF-KB pathway, dissecting the complexity of its role in different contexts and diseases can be challenging. In particular, mouse gene knockouts of NF-kB will remove many functions simultaneously and are thus a crude tool to analyse the contribution of different, sometimes apparently opposing activities. By contrast, knockin mutations of NF-KB subunits in mice that inactivate, for example, specific sites of post-translational modifications, can potentially reveal aspects of their behaviour not seen with knockouts, inhibition through RNA interference, or expression of the inhibitor $\operatorname{lkB} \alpha$ (Riedlinger et al., 2018). An example of this is the RelA ${ }^{T 505 A}$ mouse (Moles et al., 2016). Previously this laboratory has shown that in cell lines, CHK1 can phosphorylate the RelA Cterminal transactivation domain at Thr505 (T505), resulting in inhibition of tumour promoting activities of NF-KB, including resistance to apoptosis, autophagy and cell proliferation/migration (Campbell et al., 2006; Msaki et al., 2011; Rocha et al., 2003; Rocha et al., 2005). However, the in vivo significance of these effects was not known. Therefore to learn more about this we created a knock-in mouse model in which the RelA Thr 505 
residue (504 in the mouse) is mutated to Ala (T505A). Importantly, and consistent with our model for the function of RelA T505 phosphorylation, we previously reported that this mutation led to earlier onset of hepatocellular carcinoma ( $\mathrm{HCC})$ in vivo using the $\mathrm{N}$ nitrosodiethylamine (DEN) model (Moles et al., 2016). However, the mechanisms leading to this effect in vivo were not clear. Therefore, in this study, to better understand the basis of why inactivating RelA T505 phosphorylation leads to earlier onset of cancer, we decided to investigate this pathway in the context of oncogene driven DNA replication stress. We chose the $\mathrm{E} \mu$-Myc mouse model of B-cell lymphoma to perform these experiments since it is a wellestablished and highly characterised system (Harris et al., 1988). Moreover, over-expression of the oncogene c-Myc is a feature of many types of cancer and results in DNA replication stress leading to genomic instability and tumorigenesis (Dominguez-Sola and Gautier, 2014; Maya-Mendoza et al., 2015; Rohban and Campaner, 2015). Since DNA replication stress leads to activation of the checkpoint kinases Ataxia Telangiectasia and Rad3 Related (ATR) and $\mathrm{CHK} 1$, given our previous observations, this had the potential to be an ideal model system to further explore the functional role of RelA T505 phosphorylation.

Here we report that mutation of RelA at T505 also leads to earlier onset of lymphoma

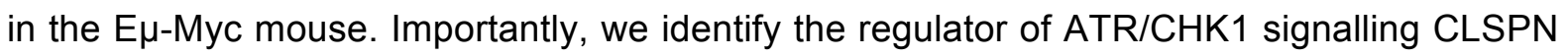
(Claspin) gene as an important effector of both the RelA and c-Rel NF-kB subunits in response to DNA replication stress in cancer. In $R e / A^{T 505 A}$ and $c-R e l$ null mice, we demonstrate reduced levels of CLSPN expression, leading to reduced levels of CHK1 activity. This in turn, leads to resistance of these cells to treatment with a highly selective and specific CHK1 inhibitor, a result with important implications for the use of such compounds in the clinic. Moreover, for the first time, we demonstrate that loss of a single allele of CLSPN is sufficient to drive early tumorigenesis in mice and that low CLSPN transcript levels are associated with significantly reduced survival of human patients with certain types of cancer. 


\section{Results}

\section{RelA T505 phosphorylation is required for pro-apoptotic effects of NF-kB following DNA replication stress}

RelA Thr 505 (T505) phosphorylation has been shown to induce a pro-apoptotic form of NF$\mathrm{KB}$ following stimulation with the chemotherapeutic drug and DNA cross-linker cisplatin (Campbell et al., 2006; Msaki et al., 2011). However, these experiments were based on exogenous expression of wild type (WT) and T505A RelA mutants in either human cell lines or Rela ${ }^{-/-}$immortalised mouse embryonic fibroblasts (MEFs). Therefore, to confirm the role of endogenous RelA T505 phosphorylation as a regulator of the NF-kB response to DNA damage we generated immortalised and primary MEFs from RelA $A^{T 505 A}$ mice and matching WT littermates. Importantly, and in agreement with the previous data, mutation of endogenous RelA at T505 strongly protected cells from cisplatin-induced apoptosis (Fig. 1A \& $B, S 1 A)$. Induction of p53 protein in response to cisplatin treatment was not significantly affected in early passage RelA $A^{T 505 \mathrm{~A}}$ immortalised MEFs (Fig. 1A). Western blot analysis revealed no significant effects on the other NF-kB subunits in the RelA ${ }^{T 505 A}$ MEFs (Fig S1B).

We extended this analysis to other inducers of DNA damage and similarly the RelA T505A MEFs again displayed less apoptosis in response to the DNA crosslinker mitomycin C and hydroxyurea, an inhibitor of ribonucleotide reductase, both of which are inducers of DNA replication stress (Fig. 1C). By contrast, there was no significant difference in apoptosis between WT and RelA ${ }^{T 505 A}$ MEFs when treated with etoposide, a Topoisomerase II inhibitor, or with SN38, a Topoisomerase I inhibitor and the active metabolite of camptothecin (Fig. 1C).

Since the RelA T505 residue can be phosphorylated by the checkpoint kinase CHK1 following replication stress (Rocha et al., 2005), we were interested in whether the RelA T505A mutation would also affect cell survival in response to treatment with CHK1 inhibitors, an important class of novel cancer therapeutics currently in clinical trials (Carrassa and Damia, 2017). Interestingly, in both cell viability and clonogenic survival assays the RelA ${ }^{T 505 A}$ MEFs were significantly more resistant to the CHK1 inhibitor CCT244747 (Fig. 1D \& E) 
(Walton et al., 2012), and the structurally unrelated CHK1 inhibitor MK8776 (Fig. S1C) (Daud et al., 2015; Guzi et al., 2011) compared with matched WTs.

Taken together these results confirm and extend the original observation that phosphorylation at the RelA T505 residue is an important regulator of the cellular response to inducers of DNA replication stress. Furthermore, they demonstrate that the $R e I A^{T 505 A}$ mouse is a suitable model to interrogate the function of NF-KB in this context in vivo in a manner that cannot be performed with RelA knockout mice or other NF-kB pathway mutants.

\section{Mutation of ReIA T505 results in earlier onset of E $\mu$-Myc driven lymphoma}

Given our data supporting a critical role for RelA T505 phosphorylation as a regulator of how cells respond to DNA replication stress we decided to investigate its function in the context of c-Myc driven cancer. Over-expression of c-Myc is a feature of many types of cancer and results in DNA replication stress leading to genomic instability and tumorigenesis

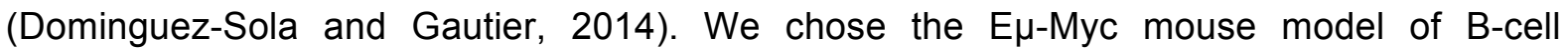
lymphoma to perform these experiments since it is a well-established and highly characterised system (Harris et al., 1988).

Based on our data in Fig 1, our prediction was that the RelA T505A mutation should lead to earlier onset of lymphomagenesis and indeed homozygous $\mathrm{E} \mu-\mathrm{Myc} / \mathrm{Rela}^{T 505 A}$ mice had a significantly shorter overall survival (median survival 83.5 days) when compared with the E $\mu$-Myc mice (median survival 122 days) (Fig. 2A). Moreover, consistent with RelA T505 phosphorylation being a regulator of the response to DNA replication stress, we observed significantly higher levels of $\gamma \mathrm{H} 2 \mathrm{AX}$, a marker of DNA damage and genomic instability, in $\mathrm{E} \mu-$ Myc/Rela ${ }^{T 505 A}$ lymphomas (Figs. 2B-D).

Further analysis of the lymphoma cells from $\mathrm{E} \mu-\mathrm{Myc} / R_{\mathrm{Re}}{ }^{T 505 A}$ mice did not reveal any significant differences in the expression of NF-KB anti-apoptotic target gene $B c l-x L$ (Bc/2/1) (Fig S2A). Nor did we observe differences in expression of the pro-apoptotic gene Bax between WT E $\mu-M y c$ and $\mathrm{E} \mu-\mathrm{Myc} /$ Rela $^{T 505 A}$ Iymphomas (Fig. S2B). Furthermore, flow cytometric analysis revealed that the percentages of B and T lymphocyte sub-populations, 
along with macrophage and dendritic cell populations, were similar in WT and RelA $A^{T 505 A}$ mice, indicating that a fundamental difference in the immune system of these mice was unlikely to be the cause of the earlier onset of lymphoma observed in $\mathrm{E} \mu-\mathrm{Myc} / \mathrm{Re} / \mathrm{a}^{T 505 A}$ mice (Fig. S2C and Suppl Table 1). Western blot analysis showed no significant effects on RelA and c-Rel levels in EM-Myc/Rela ${ }^{T 505 A}$ cells, although apparently raised levels of RELB and reduced processing of $\mathrm{p} 105$ to $\mathrm{p} 50$ were observed (Fig. S2D).

\section{$\mathrm{E} \mu-\mathrm{Myc} / \mathrm{Rela}^{T 505 A}$ and $\mathrm{E} \mu-\mathrm{Myc} / \mathrm{C}-\mathrm{Re}^{-/-}$lymphomas exhibit a defect in CHK1 signalling}

Development of lymphoma in the E $\mu$-Myc model requires DNA mutations leading to, for example, loss of function of the ARF/p53 tumour suppressor pathway (Eischen et al., 1999). This suggested that the increased genomic instability seen in the E $\mu-M y c / R e l a^{T 505 A}$ lymphomas could provide a potential explanation for the earlier lymphoma onset observed. We therefore decided to examine the ATR/CHK1 DNA replication stress response pathway in more detail. Significantly, levels of CHK1 phosphorylated at Ser345, a marker for its activation by ATR, were reduced in $\mathrm{E} \mu-\mathrm{Myc} / \mathrm{Rela}^{T 505 A}$ cells (Fig. $2 \mathrm{E}$ and see also $4 \mathrm{C}$ ). These effects did not result from problems with extract preparation since analysis of the same extracts revealed unchanged or increased levels of phospho-ERK, JNK and p38 MAP kinase together with RELA phosphorylated at Ser536 (Fig. 2E and S2E). Unfortunately, our phospho-RELA T505 antibody does not work well with extracts from mouse tissues, meaning we could not confirm phosphorylation at this site.

In a parallel series of experiments we have also found that knockout of the c-Rel NFKB subunit results in earlier lymphoma onset in the $\mathrm{E} \mu-\mathrm{Myc}$ model (Hunter et al., 2016). We were therefore interested in whether $\mathrm{E} \mu-\mathrm{Myc} / \mathrm{c}-\mathrm{ReI}^{-{ }^{-}}$lymphoma cells would also display loss of CHK1 activity. Interestingly, western blot analysis also demonstrated a lower level of Ser345 phosphorylated CHK1 in E $\mu-M y c / c-R e r^{--}$cells (Fig. 2F). These results indicated that, surprisingly, $\mathrm{E} \mu-\mathrm{Myc} / R_{\mathrm{Re}} \mathrm{a}^{\mathrm{T505A}}$ and $\mathrm{E} \mu-\mathrm{Myc} / \mathrm{C}-\mathrm{Rel}^{-/-}$lymphomas share a common and intrinsic defect in CHK1 kinase signalling. 


\section{$\mathrm{E} \mu-\mathrm{Myc} / \mathrm{c}-\mathrm{Re}^{-/}$and $\mathrm{E} \mu-\mathrm{Myc} / \operatorname{Rela}^{\mathrm{T} 505 \mathrm{~A}}$ lymphoma cells are resistant to $\mathrm{CHK} 1$ inhibition}

Disruption of the DNA damage response, frequently seen as a consequence of genetic mutation, can lead to more rapid onset of tumorigenesis (Campaner and Amati, 2012). However, inhibiting those pathways that are still intact provides a potential therapeutic strategy for targeting tumours that have become dependent on their activity (Garrett and Collins, 2011). For this reason, inhibitors of ATR and CHK1 represent a potential new class of anti-cancer therapies, and are currently in clinical trials (Carrassa and Damia, 2017).

Given the apparent defect in CHK1 kinase signalling in $\mathrm{E} \mu-\mathrm{Myc} / \mathrm{Re} / a^{T 505 A}$ and $\mathrm{E} \mu$ $\mathrm{Myc} / \mathrm{c}-\mathrm{Re}^{-/}$lymphomas, we hypothesised that a consequence would be altered sensitivity to CHK1 inhibition in vivo, similar to the increased resistance we had seen in RelA ${ }^{T 505 A}$ MEFs (Figs 1D \& E, S2C). The CHK1 inhibitor CCT244747 has shown efficacy in a transgenic model of MYCN-driven neuroblastoma (Walton et al., 2012). Moreover, we have previously shown that the related CHK1 inhibitor CCT245737 inhibits the growth of re-implanted WT EH-Myc cells (Walton et al., 2015).

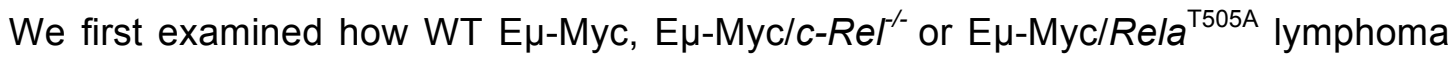
cells responded to treatment with CCT244747 for 96 hours ex vivo. Consistent with this hypothesis, we observed small but significant differences, with WT cells having reduced viability relative to $\mathrm{E} \mu-\mathrm{Myc} / \mathrm{c}-\mathrm{Re}^{-/-}$or $\mathrm{E} \mu-\mathrm{Myc} / \mathrm{Rela}^{\mathrm{T} 505 \mathrm{~A}}$ tumour cells (Fig. 3A). We next evaluated the effectiveness of CCT244747 in vivo by analysing its effect on the growth of five transplanted WT E $\mu-\mathrm{Myc}, \mathrm{E} \mu-\mathrm{Myc} / \mathrm{c}-\mathrm{Re}^{-/}$and $\mathrm{E} \mu-\mathrm{Myc} / R e l a^{T 505 A}$ tumours. Each tumour was implanted into six syngeneic $\mathrm{C} 57 \mathrm{BI} / 6$ recipient mice and three were treated orally with СCT244747 once a day for nine days, while three received a vehicle control (implantation and dosing schematic shown in Fig. 3B). After the 9-day course of treatment, we observed

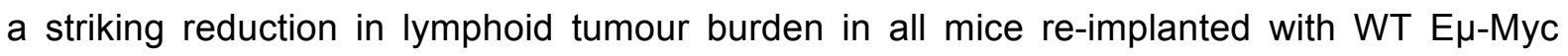
tumours (Figs. 3C \& D, S3A-F). Some splenomegaly was observed in mice treated with ССT244747 (Fig. 3D) but other, non-lymphoid organs were unaffected by the drug (not shown). By contrast, both $\mathrm{E} \mu-\mathrm{Myc} / \mathrm{c}-\mathrm{Re}^{-/}$and $\mathrm{E} \mu-\mathrm{Myc} / \mathrm{Rela}^{\mathrm{T} 505 \mathrm{~A}}$ transplanted tumours were largely resistant to CCT244747 treatment (Figs. 3C \& D, S3A-F), consistent with the ex vivo

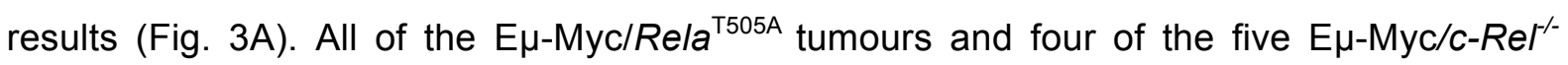


tumours showed no significant reduction in lymphoid tumour burden after CCT244747 treatment, whereas one tumour exhibited a partial response with a reduction in tumours of

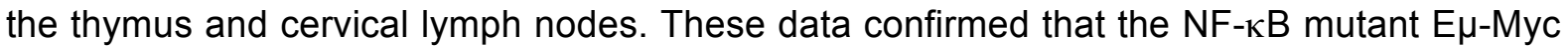
tumours have disrupted checkpoint kinase signalling pathway, bypassing a requirement for CHK1 activation, thus rendering them insensitive to the CHK1 inhibitor.

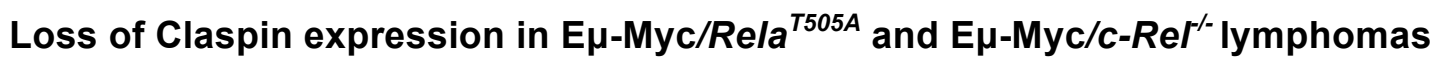

We next investigated the mechanistic basis of the loss of CHK1 activity in the NF-KB mutated cells. A number of proteins are known to regulate the DNA replication stress checkpoint response to oncogene activation, which includes the coregulators ATRIP, Claspin (encoded by the Clspn gene in mice), TopBP1 and Rad17 that are all required for ATR mediated activation of CHK1 (Fig 4A) (Errico and Costanzo, 2012). qRT-PCR analysis of RNA extracted from E $\mu$-Myc lymphoma cells revealed that of these genes, only Clspn expression was affected by loss of c-Rel or the RelA T505A mutation (Fig. 4B and S4A-E).

By contrast, Clspn levels were similar in normal B-cells from WT, RelA ${ }^{T 505 A}$ and $c-R e I^{-/}$mice (Fig. S5A \& B) suggesting that it is a NF-KB target gene only under certain conditions, such as oncogene (e.g. MYC) induced DNA replication stress. Claspin is an adaptor protein associated with DNA replication forks that is required for ATR dependent phosphorylation of CHK1 following DNA replication stress and other forms of DNA damage. Claspin can also function as a sensor to monitor the integrity of DNA replication forks through binding to branched DNA structures (Azenha et al., 2017; Chini and Chen, 2004; Errico and Costanzo, 2012; Kumagai and Dunphy, 2003). Claspin inactivation contributes to malignant transformation of cell lines by oncogenic viruses (Hein et al., 2009; Koganti et al., 2014; Spardy et al., 2009) such as human papillomavirus. HPV-E7 protein can induce Claspin degradation and thus bypass cellular checkpoints allowing the virus to replicate in the presence of DNA damage, (Spardy et al., 2009). Proteolytic degradation of Claspin has also been shown to disrupt ATR/CHK1 signalling and promote EBV transformation of primary Bcells (Koganti et al., 2014). Consequently, it has been suggested that Claspin inactivation 
could be an essential event during carcinogenesis (Azenha et al., 2017), although evidence for this at the genetic level has not been established. Moreover, Rad17, a vital component of the replication stress response has previously been reported as a putative tumour suppressor in murine lymphoma (Bric et al., 2009), indicating that this pathway is essential for the maintenance of genome integrity.

In human cell lines derived from solid tumours, the CLSPN gene has previously been shown to be a direct c-Rel target gene (Kenneth et al., 2010). To extend this analysis we extracted data from a published ChIP-seq analysis of the EBV-transformed human lymphoblastoid B-cell line (LCL) GM12878 (Zhao et al., 2014). This demonstrated that the CLSPN promoter region can potentially be a target of all NF-kB subunits in B-cells, including RelA and c-Rel (Fig. S5C).

Western blot analysis confirmed that there was a correlation between low Clspn mRNA levels and low Claspin protein levels in WT E $\mu$-Myc cells (Fig. 4C). Moreover Claspin protein levels were reduced in both $\mathrm{E} \mu-\mathrm{Myc} / \mathrm{Rela}^{T 505 A}$ and $\mathrm{E} \mu-\mathrm{Myc} / \mathrm{crel}^{-/}$lymphoma cells, although one $\mathrm{E} \mu-\mathrm{Myc} / \mathrm{Rela}^{T 505 A}$ sample displayed aberrantly high levels of protein despite low mRNA levels (Fig. 4C). Claspin protein levels are also regulated by proteolysis and this result suggests that some tumour cells overcome the reduction of mRNA expression through increased protein stability (Koganti et al., 2014; Yuan et al., 2014; Zhu et al., 2014). NF-kB regulation of Clspn gene expression therefore provides one potential explanation for the defects in CHK1 activity we observed in $\mathrm{E} \mu-\mathrm{Myc} / \mathrm{Re} \mathrm{a}^{T 505 A}$ and $\mathrm{E} \mu-\mathrm{Myc} / \mathrm{c}-\mathrm{Re}^{-/}$lymphomas.

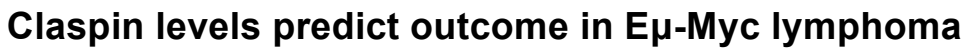

In our analysis of CHK1 phosphorylation we noticed that this was highly variable in the WT

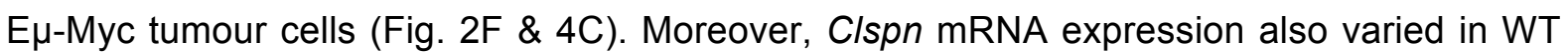
E $\mu$-Myc cells, with a population showing very low levels of expression similar to that seen in $\mathrm{E} \mu-\mathrm{Myc} / \mathrm{Rela}^{\mathrm{T505A}}$ and $\mathrm{E} \mu-\mathrm{Myc} / \mathrm{c}-\mathrm{Rel}^{--}$cells (Fig. 4B). We concluded that if low levels of Claspin and $\mathrm{CHK} 1$ activity in the $c-\mathrm{Re}^{H^{-}}$and $\mathrm{Rela}^{\mathrm{T505A}}$ cells were leading to earlier onset of disease then this would also be seen in this population of WT E $\mu$-Myc cells with low Clspn 
mRNA levels. To test this hypothesis, we analysed the survival of the two populations of E $\mu$ Myc mice identified with Clspn mRNA expression either below or above the median level (Fig. S5D). Importantly, this revealed that low levels of this transcript were associated with significantly earlier onset of lymphoma (median onset 82 versus 138 days) (Fig. 5A). This was almost identical to that found in $\mathrm{E} \mu$-Myc mice lacking c-Rel (median 79 days) or to that seen in Rela ${ }^{T 505 A}$ mutant mice (median 83.5 days). By contrast, analysis of below and above the median mRNA levels of Atr, Atrip, Topbp1, Rad17 and Chek1 showed no correlation with the survival times of E $\mu$-Myc mice (Fig. S4A-E).

\section{Claspin is a novel prognostic indicator in breast and gastric cancer}

This data suggested that a failure to induce Claspin expression in tumour cells leads to a defective oncogene-induced DNA damage response and increased genomic instability, which will contribute to the earlier onset of disease. We therefore next investigated whether CLSPN mRNA levels might also predict progression of human cancer. Analysis of some previous gene expression studies of human B-cell lymphomas (e.g. (Hummel et al., 2006)) is complicated by an older Affymetrix microarray probe (219621_at) being designed to an incorrect Genbank entry for the sequence in the 3' untranslated region of the human CLSPN mRNA. However, using more recent publicly available datasets on KM Plotter (Lanczky et al., 2016) and Human Protein Atlas (proteinatlas.org), we were able to assess the prognostic implications of Claspin expression in many different types of human cancer (summarised in Table S2). Strikingly, analysis of breast, stomach, head \& neck, rectal and gastric cancer patients revealed that low levels of CLSPN transcripts were significantly associated with a poor prognosis in the disease (Fig. 5B, Table S2), just as we had observed in our mouse model (Fig. 5A). However, this was not the case in all tumour types and in some cases, such as lung, liver and pancreatic cancers, the opposite effect was observed (Table S2). An indication of why this might be the case came from further analysis of the breast cancer data. Here, we found that low CLSPN mRNA expression was also associated with poor survival in patients with mutant p53 but that in patients with WT p53 the opposite effect was seen (Fig. 5B). Similarly, with HER2 positive patients, low CLSPN mRNA expression again 
correlated with poor survival and this effect was lost in HER2 negative patients (Fig. S5E). This indicates a more complex situation where the consequences of high or low Claspin expression will depend on other mutation events in the tumour. Nonetheless, these data suggest that Claspin levels may be prognostic for some classes of cancer and importantly could influence the response to therapy, particularly of checkpoint kinase inhibitors, in human patients.

\section{Primary $\mathrm{Clspn}^{+/}$cells have a defect in the replication stress signalling pathway}

Our data suggested that reduced Claspin levels could explain the results seen in $\mathrm{E} \mu$ Myc/Rela ${ }^{T 505 A}$ and $\mathrm{E} \mu-\mathrm{Myc} / \mathrm{c}-\mathrm{Re}^{\gamma^{-}}$lymphoma cells. However, this data was largely correlative and we wished to directly test whether reduced Claspin levels alone can be sufficient to affect the response to CHK1 inhibition and enhance tumorigenesis. We therefore decided to examine these effects in Clspn knockout mice (purchased from the UC Davis KOMP Repository). In these studies heterozygous knockout Clspn mice were used since, similar to other mice with knockouts of genes associated with replication stress, such as Atr' (O'Driscoll, 2009) and Chek1' (Liu et al., 2000), homozygous loss of the Clspn gene is embryonic lethal at E10.5 (our observation and http://www.mousephenotype.org/data/genes/MGl:2445153). We generated independent isolates of $\mathrm{Clspn}^{+/-}$and WT primary ear fibroblasts (EFs) and showed that Claspin protein levels were reduced in the $\mathrm{Clspn}^{+/}$cells, but that the protein levels of other pathway components, ATR and CHK1 were unaffected (Fig. S6A). Importantly, and consistent with our earlier data, $\mathrm{Clspn}^{+/-}$EFs were more resistant to CHK1 inhibition, compared to their WT counterparts (Fig 5C and S6B).

\section{Aged $\mathrm{Clspn}^{+/}$mice develop spontaneous lymphoid tumours}

To investigate whether reduced levels of Claspin would lead to lymphomagenesis, we aged a colony of $\mathrm{Clspn}^{+/-}$mice. Strikingly, we observed tumours of the mesenteric lymph node in five of the nine $\mathrm{Clspn}^{+/-}$mice we aged to 18 months of age (Fig. 5D - F), and in two 
of these mice there was further lymphoid disease burden as well as tumours of the small intestine/colon (Fig S6C). There were no overt signs of cancer, at either the macro- or microscopic level in any of the age-matched WT littermates (Fig 5D-F, S6C). Interestingly, the mesenteric lymph node appeared larger at all time points at which animals were harvested (Fig S6D \& E) suggesting that the malignant cells home to this location and proliferate in situ thus resulting in the tumour burden seen in Fig 5D-F. No overall differences were seen with other lymph nodes (Figs S6F-H).

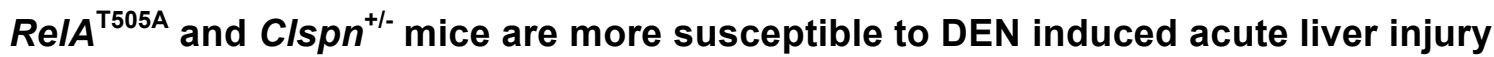

The data from aged $\mathrm{Clspn}^{+/}$mice suggested that reduced Claspin levels could lead to earlier onset of tumorigenesis in other contexts. However due to a number of ethical and technical problems associated with the difficulty of generating enough $\mathrm{E} \mu-\mathrm{Myc}_{\mathrm{C}} \mathrm{Clspn}{ }^{+/-}$mice to perform an adequately powered study (see E $\mu$-Myc mouse section of Methods), we decided investigate this further using the $\mathrm{N}$-nitrosodiethylamine (DEN) induced model of hepatocellular carcinoma (Heindryckx et al., 2009), where we had already established an effect of the RelA T505A mutation (Moles et al., 2016). We first challenged both the RelA ${ }^{\text {T505A }}$ and the Clspn ${ }^{+/-}$mice with an acute dose of DEN (Fig. 6A). DEN is a DNA alkylating agent and following acute administration, will promote hepatocyte death followed by compensatory proliferation. This compensatory proliferation following $\mathrm{DEN}$-induced injury is critical for tumour formation in this model. We had previously observed that livers from RelA ${ }^{T 505 A}$ mice exhibited increased proliferation following acute DEN treatment (Moles et al., 2016). Given our data from the $\mathrm{E} \mu$-Myc model, which indicated that mice with reduced Claspin levels would be more susceptible to genomic instability, we hypothesised that similar to $\mathrm{RelA}{ }^{\mathrm{T} 505 \mathrm{~A}}$ mice, $\mathrm{Clspn}^{+/-}$mice would be more susceptible to acute liver injury induced by DEN.

Following acute DEN administration, we observed a decrease in Clspn transcript levels after 24 hours, which in wild type mice returned to untreated levels after 48 hours.. However, in the RelA ${ }^{T 505 A}$ mice, this recovery was significantly reduced (Fig. 6B). 
Consistent with our hypothesis that Clspn transcript levels are regulated by RelA in a T505 dependent manner following DNA damage, acute DEN administration resulted in significant decreases in body weight of both the $\operatorname{RelA}^{\mathrm{T505A}}$ (Fig 6C) and Clspn ${ }^{+/-}$(Fig 6D) mice, compared with their respective WT counterparts, suggestive of greater damage and parenchyma loss. Consistent with this, the liver to bodyweight ratio in both $\operatorname{Rel}^{\mathrm{T} 505 \mathrm{~A}}$ (Fig 6E) and $\mathrm{Clspn}^{+/-}$(Fig 6F) mice at both time points post DEN administration was also significantly reduced. This decrease in the liver to bodyweight ratio is suggestive of increased hepatocyte damage, which was confirmed by the increased presence of $\gamma \mathrm{H} 2 \mathrm{AX}$ staining, a marker of DNA damage in $\mathrm{Re}^{\mathrm{T}} \mathrm{A}^{\mathrm{T} 05 \mathrm{~A}}$ (Fig 6G) and $\mathrm{Clspn}^{+/-}$(Fig 6H) compared to WT control mice following DEN. These results confirm that the reduction in Claspin expression in both the RelA ${ }^{T 505 A}$ and $\mathrm{Clspn}^{+/-}$mice can have important consequences for how cells cope with DNA damage.

\section{Earlier onset of liver cancer in $\mathrm{Clspn}^{+/-}$mice}

We next investigated whether reduced Claspin levels would affect tumorigenesis in the chronic model of DEN-induced HCC. DEN was administered to 15-day-old WT and Clspn ${ }^{+/-}$ mice and tumour growth was evaluated after 30 weeks. At this point tumours start to become visible on the liver surface in WT mice and therefore, similar to our study using the RelA ${ }^{T 505 A}$ mice (Moles et al., 2016) this is the optimal time to investigate if disruption of the Clspn gene resulted in earlier onset of tumorigenesis. To longitudinally assess liver cancer growth, we developed a novel in vivo method, utilizing $800 \mathrm{CW}$ 2-deoxyglugose (800 CW 2$D G)$, to track disease progression in live animals by exploiting the elevated rate of glycolysis in tumour cells, even in anaerobic conditions (Rajendran et al., 2004). Using this approach, we were able to initially observe that at 28 weeks after DEN administration, the fluorescent signal in the Clspn ${ }^{+/-}$livers was higher than in the WTs suggesting earlier onset of tumorigenesis (Fig. 7B). This was confirmed at 30 weeks, when the mice were imaged again (Fig. 7B). Following imaging, the mice were euthanised and macroscopic liver tumours were counted and also imaged ex vivo. This confirmed that the $\mathrm{Clsph}^{+/-}$mice had significantly 
higher fluorescent signal in the livers ex vivo (Fig. 7C) and this corresponded to a significantly increased number of visible liver tumours (Fig.7D \& E, S7A).

Detailed histological analysis of liver tissue sections confirmed the visible differences in tumour numbers between $\mathrm{Clspn}^{+/-}$mice and WT mice (Fig. 7F, S7B). Interestingly, while the numbers of adenomas are broadly equivalent between the two mice strains ( 17 foci from 11 WT mice, 16 foci from $13 \mathrm{Clspn}^{+/-}$mice), the more malignant hepatocellular carcinoma numbers were dramatically different. Here the $13 \mathrm{Clsph}^{+/-}$mice had 23 hepatocellular carcinomas, including one grade II HCC, versus only six seen in the WT mice (Figs. 7F, $\mathrm{S} 9 \mathrm{~B})$. This result was strikingly similar to that we had previously reported in $R e / A^{T 505 A}$ mice (Moles et al., 2016), indicating that NF-KB regulation of Claspin levels provides an explanation, at least in part, for the ability of this transcription factor to regulate onset and progression of DEN-induced HCC. 


\section{Discussion}

It has been known for some time that DNA damage activated checkpoint kinases can regulate NF-KB, either through activation or inhibition of IKB kinase activity or direct phosphorylation of NF-KB subunits (Campbell et al., 2004; Hinz et al., 2010; Rocha et al., 2005; Sabatel et al., 2012; Schmitt et al., 2011; Wu and Miyamoto, 2008; Wu et al., 2010). However, it is less well established whether NF-KB itself regulates the DNA damage response and if this has any role in tumorigenesis. Previously, the Rocha lab demonstrated that in a variety of human and mouse cell lines, IKK $\beta$ and c-Rel regulate the CLSPN gene independently of the cell cycle (Kenneth et al., 2010). As a consequence they observed reduced $\mathrm{CHK} 1$ activity in response to ultraviolet light and hydroxyurea in which IKK/C-Rel activity was inhibited. However, this study did not examine the significance of this pathway in vivo nor any potential role in tumorigenesis. Here we have both confirmed and significantly extended these findings. We demonstrate that in two distinct mouse models, the RelA ${ }^{T 505 A}$ knockin mouse and the $c-\mathrm{Rel}^{--}$mouse, there is significant loss of Claspin expression and

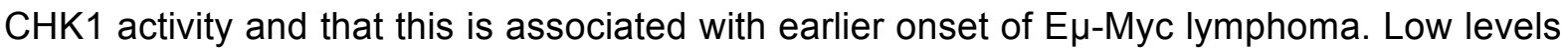
of CLSPN expression are also associated with reduced survival in some human forms of cancer (Fig. 5B, S5E, Table S2). Supporting this hypothesis we find that heterozygous knockout Clspn mice spontaneously develop B-cell lymphoma and treatment of these mice with the DEN carcinogen leads to earlier, more aggressive HCC. We propose that in the early stages of tumorigenesis, CLSPN is an NF-KB target gene that through promoting checkpoint kinase activation helps prevent further genomic instability and cancer development resulting from DNA replication stress (Fig. 8).

Our results also imply a distinct role for NF-KB in the context of c-Myc driven cancer. Much of the research in the role of NF-KB in cancer has focussed either on its role in inflammation or haematological malignancies where activating mutations often lead to aberrant activity. However, there has been little analysis of its role in other types of the disease, such as c-Myc-driven lymphomas, with a normal, unmutated NF-kB pathway. We recently investigated the role of the c-Rel NF-KB subunit in the E $\mu$-Myc model (Hunter et al., 2016). Here we found that surprisingly and in contrast to the expected result, E $\mu-M y c / c-R e r^{--}$ 
mice displayed earlier onset of lymphoma that correlated with loss of the expression of the B-cell tumour suppressor BTB and CNC homology 2 (Bach2) (Hunter et al., 2016). Moreover, tumour suppressor-like activity has also been described for RelA in Myc driven lymphoma (Chien et al., 2011). Here, shRNA depletion of RelA was found not to affect progression of established lymphomas but did result in resistance to cyclophosphamide treatment due to an impaired induction of cell senescence (Chien et al., 2011). Similarly, inhibition of NF-KB through expression of a degradation resistant form of the inhibitor IKB $\alpha$,

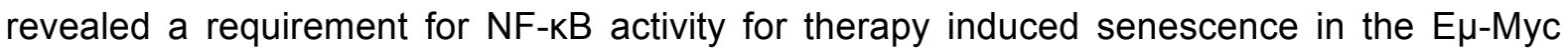
mouse model of B-cell lymphoma (Jing et al., 2011). c-Myc can also inhibit expression of NF-KB2 (p100/p52), and loss of this NF-KB subunit in the E $\mu-M y c$ mouse model resulted in impaired apoptosis and moderately earlier onset of disease (Keller et al., 2010). By contrast,

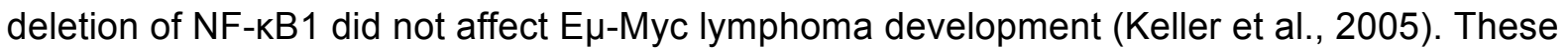
results imply a more complicated role for NF-KB subunits in Myc driven lymphoma than the tumour promoting activities usually associated with these transcription factors.

Although early clinical trials for CHK1 inhibitors have encountered problems these appear to result from off-target effects of these compounds (Carrassa and Damia, 2017) and newer more specific compounds entering clinical trials are not anticipated to encounter these issues (Blackwood et al., 2013; McNeely et al., 2014). Our results suggest that Claspin mRNA or protein levels could act as a biomarker for the use of CHK1 inhibitors in the clinic, although to date we have been unable to identify an anti-human Claspin antibody with sufficient specificity. Although CLSPN mutations are relatively rare in human patients they have been reported (Erkko et al., 2008; Zhang et al., 2009) and may also serve as a potential biomarker, but as yet this has not been investigated. Our studies have therefore identified a potential pathway through which tumours might become resistant to CHK1 inhibitors, either through reduced Claspin expression, mutations within the CLSPN gene and other regulators of $\mathrm{CHK} 1$ activity or within the NF-KB subunits that regulate their expression. These results also imply that in cells with low Claspin and CHK1 activity and displaying CHK1 inhibitor resistance, an alternative cell signalling pathway has become activated to allow the tumour to survive the on going genomic instability caused by DNA replication 
stress. Future studies identifying this pathway could lead to therapeutic strategies for patients developing resistance to CHK1 inhibitors.

Our analysis showed that in human breast, gastric and other cancer samples, low CLSPN mRNA expression correlated with reduced survival (Fig. 5B, S5E, Table S2). It is interesting to note that studies have shown that following double strand breaks Claspin can associate with BRCA1, a known breast cancer tumour suppressor, and is required for its phosphorylation by ATR (Lin et al., 2004; Yoo et al., 2006). Another report also suggested that high Claspin protein expression through stabilization by the deubiquitinase, USP20, correlated with better prognosis in gastric cancer (Wang et al., 2017). However, in other tumour types our analysis indicated the opposite effect, with low levels of CLSPN expression being associated with better survival (Table S2). These contrasting effects can be explained by the many roles Claspin has in DNA repair pathways that are distinct from its role in DNA replication. For example, Claspin is known to have a role in homologous recombination (Lin et al., 2004), mismatch repair (Liu et al., 2010) and nucleotide excision repair (PraetoriusIbba et al., 2007), and therefore its role may depend on which pathway tumour cells are most dependent on, or become activated by, a given therapeutic regimen. Moreover, our data (Figs $5 \& 8$ ) suggest that Claspin loss or haplo-insufficiency is required at the point of tumour initiation in order to drive tumorigenesis but other tumours may downregulate, or fail to activate Claspin, at later time points as a consequence of tumour progression.

Taken together our data describe a previously unappreciated pathway through which NF-KB can function as a tumour suppressor and prevent cancer development. In this model, the NF-kB subunits RelA and c-Rel, in a manner dependent upon RelA T505 phosphorylation, drive the expression of Claspin in response to oncogene induced DNA replication stress. This in turn drives CHK1 activity, which early in tumorigenesis will inhibit cancer development through preventing the genomic instability required for additional genetic mutations. However, in malignant tumours, this pathway can help promote their addiction to the checkpoint kinase signalling required for the maintenance of genomic integrity and cancer cell survival. In our study, disruption of this pathway leads both to the earlier onset of cancer and to $\mathrm{CHK} 1$ inhibitor resistance. These results have important 
bioRxiv preprint doi: https://doi.org/10.1101/358291; this version posted June 28,2018 . The copyright holder for this preprint (which was not certified by peer review) is the author/funder. All rights reserved. No reuse allowed without permission.

implications in the development of resistance in cancer patients treated with $\mathrm{CHK} 1$ inhibitors: they could lead both to the identification of cohorts likely to respond better to drug treatment as well as the development of alternative therapies in low responders and patients where resistance has developed. 


\section{Methods}

\section{Ethics statement}

All mouse experiments were approved by Newcastle University's Animal Welfare and Ethical Review Board. All procedures, including the of breeding genetically modified mice, were carried out under project and personal licences approved by the Secretary of State for the Home Office, under the United Kingdom's 1986 Animal (Scientific Procedures). Animals were bred in the Comparative Biology Centre, Newcastle University animal unit, according to the FELASA Guidelines.

\section{Mouse models}

RelA ${ }^{T 505 A}$ knock in mice were generated by Taconic Artemis (Germany) using C57BI/6 ES cells (Moles et al., 2016), c-Rer ${ }^{-/}$mice were provided by Dr Fiona Oakley (Newcastle University). Е $\mu$-Myc mice were purchased from The Jackson Laboratory, Maine, USA. C57BI/6 mice used for re-implantation studies were purchased from Charles River (UK). Male $\mathrm{E} \mu$-Myc transgenic mice that were used as breeding stock were omitted from the survival analysis. $\mathrm{Clspn}^{+/}$mice were generated by the Knockout Mouse Project using C57BI/6 ES cells, and obtained via RIKEN (Saitama, Japan). Clspn ${ }^{+/}$mice were maintained on a pure $\mathrm{C} 57 \mathrm{BI} / 6 \mathrm{n}$ background. In all experiments, the relevant pure C57BI/6 (WT) strain was used as a control. No blinding of groups in mouse studies was performed. All mice were designated to an experimental group dependent on their genotype.

\section{Drugs and compounds}

CCT244737 was synthesized as described (Walton et al., 2012). MK8776 was purchased from Stratech (Ely, UK). Etoposide was purchased from Scientific Lab Supplies (Nottingham, UK), SN38 and Mitomycin C were obtained from R\&D systems (Abingdon, UK). All other compounds were purchased from Sigma Aldrich. 


\section{Generation of Mouse Embryo Fibroblasts (MEFs)}

Heterozygote RelA ${ }^{T 505 A}$ mice were bred to produce a mixture of WT and RelA ${ }^{T 505 A}$ homozygote littermates. MEFs were isolated as follows. Internal torso connective tissue from 13.5-day embryos was washed in sterile PBS and minced in 1x Trypsin (Invitrogen) for 15 $\min$ at $37^{\circ} \mathrm{C}$. Following repeated pipetting to break up large tissue fragments, the cell pellet was re-suspended in DMEM (Lonza) supplemented with 20\% Fetal Bovine Serum (FBS) (Gibco, Paisley, UK) and 50U/ml penicillin/streptomycin (Lonza), and incubated at $37^{\circ} \mathrm{C}$ in a $5 \% \mathrm{CO}_{2}$ humidified atmosphere. Once cells reached $90 \%$ confluency, they were subcultured in $75 \mathrm{~cm}^{2}$ flasks and considered as passage 1 . Cells were then cultured following the standard 3T3 protocol (Todaro and Green, 1963). Cells were considered immortalised beyond passage 14, but not used in experiments beyond passage 25 .

\section{Generation of Ear Fibroblasts}

Ear Fibroblasts (EFs) were generated as previously described (Jurk et al., 2014). Briefly, ear punch biopsies (two per mouse) were transported and stored in DMEM containing $10 \%$ FBS on ice. Punches were washed three times with serum-free DMEM, finely cut and incubated for $2 \mathrm{hrs}$ at $37^{\circ} \mathrm{C}$ in $2 \mathrm{mg} / \mathrm{ml}$ collagenase A (Sigma Aldrich) in DMEM. A single-cell suspension was obtained by repeated pipetting and passing through a $25 \mathrm{G}$ needle. Cells were centrifuged for $10 \mathrm{~min}$ at $95 \mathrm{xg}$ and cultured in Advanced DMEM/F-12 (DMEM, Invitrogen) plus 10\% FBS, 50U/ml penicillin/streptomycin (Lonza), $2 \mathrm{mM} \mathrm{L-}$ glutamine (Lonza) at $37^{\circ} \mathrm{C}$ in a $5 \% \mathrm{CO}_{2}$ humidified atmosphere. Each isolate was derived from a separate mouse.

\section{Apoptosis assays}

RelA ${ }^{T 505 A}$ or WT MEFs were grown in 96-well plates and treated for $24 \mathrm{~h}$ with the appropriate concentration of Cisplatin (4 $\mu \mathrm{g} / \mathrm{ml})$, Etoposide (15 $\mu \mathrm{M})$, Hydroxyurea $(0.5 \mathrm{mM})$, SN38 (5 $\mu \mathrm{M})$ or Mitomycin C $(1 \mu \mathrm{g} / \mathrm{ml})$. Cells were then harvested, lysed and assayed for Caspase-3 
activity using the CaspACE Assay System (Promega, Southampton, UK), according to manufacturer's guidelines. Samples were normalized to their protein concentration using the Pierce BCA Protein Assay Kit (ThermoFisher Scientific, UK).

\section{Cell viability assays}

Freshly isolated $\mathrm{E} \mu-\mathrm{Myc}, \mathrm{E} \mu-\mathrm{Myc} / R e / A^{T 505 A}$ or $\mathrm{E} \mu-\mathrm{Myc} / \mathrm{c}-\mathrm{Re}^{-{ }^{--}}$tumour cells $\left(5 \times 10^{5}\right.$ per well), immortalized WT or RelA ${ }^{T 505 A}$ MEFs $\left(5 \times 10^{3}\right)$ or primary WT or $C / s p n^{+/-}$ear fibroblasts $\left(2.5 \times 10^{4}\right)$ per well were seeded into 96 -well plates. Increasing concentrations of the novel CHK1 inhibitor, CCT244747 (ICR, Sutton, UK), or MK8776 (Stratech, Ely, UK) or solvent controls were added to three replicate wells. After $96 \mathrm{hrs}$, viability was quantified using the PrestoBlue Cell Viability Reagent (ThermoFisher Scientific, UK), according to manufacturer's instructions.

\section{Cell survival assays}

Exponentially growing immortalized WT or RelA ${ }^{T 505 \mathrm{~A}}$ MEFs were treated for $24 \mathrm{~h}$ with $1 \mu \mathrm{M}$ or $5 \mu \mathrm{M}$ CHK1 inhibitor, CCT244747 (ICR, Sutton, UK), or MK8776 (Stratech, Ely, UK) or solvent controls before re-seeding onto Petri dishes at known cell number $(1000,2500$ or 5000 cells/dish). Colonies were fixed 14 days later with methanol:acetic acid (3:1) and stained with $0.4 \%(\mathrm{w} / \mathrm{v})$ Crystal Violet. Cloning efficiencies were normalized to untreated controls.

\section{Gene expression analysis using quantitative real-time PCR}

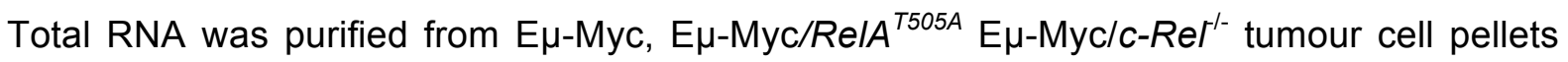
using the PeqGold total RNA extraction kit (Peqlab). From appropriate liver samples, total RNA was extracted from snap-frozen tissues by homogenisation using Precellys 24 ceramic mix bead tubes (Stretton Scientific Ltd) in a Precellys 24 benchtop homogeniser (Stretton Scientific Ltd) at $6500 \mathrm{rpm}$ for $30 \mathrm{~s}$. Following this, samples were passed through 
Qiashredders (Qiagen, Crawley, UK) and RNA was purified using the Qiagen RNeasy mini kit according to manufacturer's instructions.

RNA was measured for purity and concentration with the NanoDrop1000 (ThermoFisher Scientific) and reverse transcribed using the Quantitect Reverse transcription Kit (Qiagen) according to manufacturer's instructions. Quantitative real-time PCR was performed on 20ng cDNA, in triplicate, using predesigned Quanititect Primer assays (Qiagen) to the following murine genes; Clspn, Atr, Atrip, Rad17, Topbp1, Chek1. These samples were run and analysed on a Rotor-gene Q system (Qiagen), using murine Gapdh primers as an internal control. All CT values were normalised to Gapdh levels.

\section{Caspase- 3 assay}

Both adherent and floating cells were harvested by centrifugation, and cell pellets were washed in ice-cold PBS. Caspase activity was analysed with the CaspasACE ${ }^{\mathrm{TM}}$ colorimetric assay kit (Promega) using $25 \mu \mathrm{g}$ of protein extract following the manufacturer's instructions. Protein quantification was undertaken using the bicinchoninic acid (BCA) protein assay (Thermo-scientific, Rockland, USA)Absorbance at $405 \mathrm{~nm}$ is directly proportional to Caspase-3 specific activity.

\section{Western blotting}

Whole cell extracts were prepared from $\mathrm{E} \mu-\mathrm{Myc}, \mathrm{E} \mu-\mathrm{Myc} / \mathrm{Re} / A^{T 505 A}$ or $\mathrm{E} \mu-\mathrm{Myc} / \mathrm{c}-\mathrm{Re}{ }^{-/}$tumour cell suspensions or extracted direct from snap frozen pieces of tumour or liver tissue. Snap frozen tumour or tissue was lysed in PhosphoSafe ${ }^{\text {ТМ }}$ Extraction Reagent using the Precellys24 ceramic mix bead tubes (Stretton Scientific Ltd) in a Precellys $₫ 24$ homogeniser (Stretton Scientific Ltd) at $6500 \mathrm{rpm}$ for 30s, then extracted according to the PhosphoSafe ${ }^{\mathrm{TM}}$ Extraction Reagent manufacturer's instructions. In the case of tumour cell suspensions, cell pellets were washed with ice-cold PBS, and lysed using PhosphoSafe ${ }^{\mathrm{TM}}$ Extraction Reagent (Merck-Millipore, Watford, UK), according to manufacturer's protocols. Protein quantification was undertaken using the BCA protein assay, and samples resolved by standard denaturing SDS-PAGE gels. Samples were transferred onto PVDF membrane (Merck-Millipore) before 
being probed with the primary antibody. Horseradish peroxidase-conjugated secondary antibodies (anti-mouse; Sigma (UK), anti-rabbit; Sigma, UK) and enhanced chemiluminscence reagent (Thermo-scientific, UK) were used for detection.

\section{Immunohistochemistry}

Formalin-fixed tumour or liver tissues were paraffin-embedded sections and serial sections cut by the Molecular Pathology Node, Cellular Pathology, Royal Victoria Infirmary, Newcastle-Upon-Tyne. H\&E staining was also undertaken by the Molecular Pathology Node.

Formalin-fixed paraffin-embedded tumour and liver sections were dewaxed and hydrated. Endogenous peroxidase activity was blocked with hydrogen peroxide and antigen retrieval was achieved using $1 \mathrm{mM}$ EDTA. Tissue was blocked using an Avidin/Biotin Blocking Kit (Vector Laboratories, Peterborough, UK) followed by $20 \%$ swine serum in PBS and then incubated with primary antibodies overnight at $4{ }^{\circ} \mathrm{C}$. The following day slides were washed and incubated with biotinylated swine anti-rabbit (Dako, UK) followed by Vectastain Elite ABC Reagent (Peterborough, UK). Antigens were visualised using $D A B$ peroxidase substrate kit and counterstained with Mayer's haematoxylin. Immuno-stained cells were imaged using a DFC310 FX microscope (Leica Microsystems) and the images blinded (coded) prior to analysis by an independent party. At least 5 images per tissue at $\times 10$ magnification were analysed using brown/blue pixel intensity using Adobe Photoshop.

\section{Antibodies}

Antibodies used were c-Rel (sc-71 Santa Cruz), c-Myc (sc-42 Santa Cruz), RelA (sc-372 Santa Cruz), RelB (4954 Cell Signaling), p105/p50 (ab7971 Abcam), p100/p52 (4882 Cell Signaling), $\beta$-Actin (A5441 Sigma), CHK1 (phospho S345) (2341 Cell Signaling), CHK1 (2360 Cell Signaling) RelA (phospho 536) (3031 Cell Signaling), active caspase 3 (9664 Cell Signaling), PCNA (ab64100), yH2AX (9718 Cell Signaling) and CD45R (ab18197). 
Antibodies to the murine form of Claspin was generated by Moravian Biotechnologies. Antirabbit IgG (A6154Sigma and 7074 Cell Signaling) and anti-mouse IgG (A9044 Sigma) HRP-linked secondary antibodies were used for western blot detection.

\section{E $\mu-M y c$ mice studies}

$\mathrm{E} \mu-\mathrm{Myc} / R e / A^{\mathrm{T} 505 \mathrm{~A}+/}$ offspring were generated by mating $T 505 \mathrm{~A}$ female mice with $\mathrm{E} \mu-\mathrm{Myc}$ male mice, further $\mathrm{E} \mu-\mathrm{Myc} / \mathrm{Re} / A^{\mathrm{T} 505 \mathrm{~A}}$ mice were generated by crossing $\mathrm{E} \mu-\mathrm{Myc} / \mathrm{T} 505 A^{+/}$ males with $T 505 A$ female mice. Only group housed $\mathrm{E} \mu-\mathrm{Myc} / \mathrm{Re} / \mathrm{A}^{\mathrm{T505A}}$ males were included as the cohort for this analysis to minimise any potential effects from environmental and endogenous estrogens. E $\mu-\mathrm{Myc} / \mathrm{c}-\mathrm{Re}^{+/-}$offspring were generated by mating $c-R e I^{-/}$female mice with $\mathrm{E} \mu-\mathrm{Myc}$ male mice, further $\mathrm{E} \mu-\mathrm{Myc} / \mathrm{c}-\mathrm{Re}^{--}$mice were generated by crossing $\mathrm{E} \mu-$ $\mathrm{Myc} / \mathrm{c}-\mathrm{Re} \mathrm{I}^{+/-}$males with $\mathrm{c}-\mathrm{Re} \mathrm{I}^{-/}$female mice. To perform survival analysis, E $\mu-\mathrm{Myc}$ transgenic mice were monitored daily and were sacrificed at pre-determined end-points, defined as the animal becoming moribund, losing bodyweight/condition and/or having palpable tumour burden at any lymphoid organ site.

Survival analysis (Kaplan Meier analysis) was carried out using GraphPad Prism (Version 5.0) and significance determined using the log-rank (Mantel-Cox) test. Moribund mice were necropsied and single cell suspensions were prepared from tumour-bearing organs. Briefly, lymph nodes, spleen or thymus were homogenised through a cell strainer, and single cell suspension collected in DMEM (Lonza) supplemented with $10 \%$ FBS, $5 \mathrm{mM}$ L-glutamine, $5 \mathrm{mM}$ sodium pyruvate, $1 \mu \mathrm{M}$ L-asparagine and $50 \mu \mathrm{M} \beta$-mercaptoethanol (Sigma Aldrich). These cell suspensions were then used for downstream analyses or frozen in $90 \% \mathrm{FBS} / 10 \%$ DMSO for long-term storage and transplantation.

Technical note: This study does not include analysis of survival in $\mathrm{E} \mu-\mathrm{Myc} / \mathrm{Clspn}^{+/-}$mice. We were advised that the Director of the Newcastle University Faculty of Medical Sciences Comparative Biology Centre had serious ethical and 3 Rs concerns with this option, due to the number of mice required to generate a sufficiently powered cohort of male $E \mu$ - 
$\mathrm{Myc} / \mathrm{Clspn}^{+/-}$mice. Female $\mathrm{Clspn}^{+/-}$mice have reduced litter sizes (2 versus 5 for wild type mice in 100 days), lengthened time to first litter (44.5 days versus 22 days for wild type mice) and reduced average pups per litter (3.8 versus 7.2 for wild types). E $\mu$-Myc mice can only be bred as heterozygote transgenes (homozygous are non viable) and E $\mu$-Myc females cannot be used to carry litters due to the early onset of disease. Consequently only 1 in 16 of the $\mathrm{Cs}_{\mathrm{p}} \mathrm{ph}^{+/-}$mice (female) $\mathrm{x}$ Het Eu-Myc mice (male) would be male and have the $\mathrm{E} \mu$ $\mathrm{Myc} / \mathrm{Clsph}^{+/-}$genotype. We would therefore only obtain a suitable male mouse approximately once every four successful matings.

\section{Reimplantation studies}

For tumour therapy studies, $2 \times 10^{6} \mathrm{E} \mu-\mathrm{Myc}, \mathrm{E} \mu-\mathrm{Myc} / \mathrm{Re} / A^{\mathrm{T} 505 \mathrm{~A}}$ or $\mathrm{E} \mu-\mathrm{Myc} / \mathrm{c}-\mathrm{Re}^{-/}$tumour cells from male mice were transplanted intravenously (IV) via the lateral tail vein into 8-week old male C57BL/6 recipients. Mice were monitored daily using parameters such as their bodyweight and food and water consumption to assess disease progression. Mice were necropsied when they became moribund and the tumour burden assessed.

Oral administration of the CHK1 inhibitor, CCT244747, prepared as previously described (Lainchbury et al., 2012) (ICR, Sutton, UK), or vehicle control (65\% PEG-400, 20\% Tween-20, 10\% $\mathrm{H}_{2} \mathrm{O}, 5 \%$ DMSO (all Sigma Aldrich)) was initiated when tumours became palpable (approximately 10 days after inoculation of $\mathrm{E} \mu-\mathrm{Myc}$ or $\mathrm{E} \mu-\mathrm{Myc} / \mathrm{Re} / \mathrm{A}^{\mathrm{T} 505 \mathrm{~A}}$ cells, and 20 days after inoculation of $\mathrm{E} \mu-\mathrm{Myc} / \mathrm{c}-\mathrm{Rel}^{-/}$cells). CCT244747 was given as a single agent, bolus dose (100 mg/kg p.o.) for 9 consecutive days. Lymphoid tumour burden and final tumour weights were measured at necropsy 24 hours after the final dose.

\section{In-vivo models of liver injury and hepatocellular cancer}

$80 \mathrm{mg} / \mathrm{kg}$ DEN in $0.9 \%$ saline was administered intraperitoneally (IP) to 8 week old male mice for the acute liver injury studies. In this case mice were humanely killed $24 \mathrm{~h}$ or $48 \mathrm{~h}$ post-DEN and tissues collected. In order to induce liver cancer, day 15 mice were given 
$30 \mathrm{mg} / \mathrm{kg}$ DEN in $0.9 \%$ saline by IP injection. For this model, in vivo imaging was performed at both 28 weeks and prior to harvest at 30 weeks. $20 \mathrm{nmol} 800 \mathrm{CW}$ 2-deoxyD-glucose (Licor, UK) was administered IV via the lateral tail vein, $24 \mathrm{~h}$ prior to imaging at 740/800nm on the IVIS Spectrum system (Perkin Elmer) under isoflurane anaesthesia. Mice were humanely killed, and liver tissue was harvested and imaged ex vivo at 30 weeks post DEN.

\section{ChIP-Seq}

ChIP Seq data shown here was extracted from a previously published analysis of the EBVtransformed lymphoblastoid B-cell line (LCL) GM12878 using validated anti-RelA, RelB, cRel, p52 and p50 antibodies (Zhao et al., 2014). GM12878 are one of three ENCODE project Tier 1 cell lines. It is an original HapMap cell line used in many genetic studies including the 1000 Genomes Project and has a relatively normal karyotype. Reads from all ChIP-seq experiments were mapped to the hg19/GRCh37 build of the human genome using the UCSC genome browser. NF-KB ChIP-seq datasets have been published (gene expression omnibus, accession code GSE55105) (Zhao et al., 2014).

\section{$\gamma \mathrm{H} 2 \mathrm{AX}$ Immunostaining by flow cytometry}

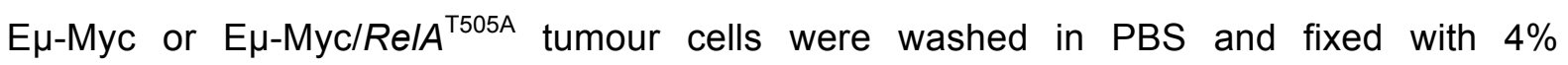
formaldehyde before permeabilisation with $0.1 \%$ Triton. Cells were then stained with either $\gamma \mathrm{H} 2 \mathrm{AX}-\mathrm{FITC}$ conjugated antibody (560445 BD Biosciences, UK) or IgG-FITC conjugated control antibody (557782 BD Biosciences, UK) before a $2 \mathrm{hr}$ incubation protected from the light. Cells were then resuspended in DAPI staining buffer and analysed using the FACS Canto III (BD Biosciences) and DIVA (BD Biosciences) software.

\section{Analysis of immune cell populations}

Spleens, lymph nodes, blood and peritoneal fluids were isolated. For blood samples, red blood cell lysis was performed prior to cell acquisition using FACS lysis buffer (Becton 
Dickinson) according to manufacturer's instructions. Murine tissue single cell suspensions were generated followed by incubation with anti-Fc receptor blocking antibody (antiCD16/CD32 clone 2.4G2, BD Pharmingen). Distinction between live and apoptotic/necrotic cells was performed based on staining with LIVE/DEAD Aqua (Life Technologies). For cell surface marker detection cells were stained with a combination of FITC, PE, APC, PerCPCy5.5, APC-Cy7 conjugated monoclonal antibodies (BD Pharmigen). For detection of Foxp3, intracellular staining was performed using a Fix/Perm kit (eBiosciences). See Table S1 for additional antibody information. All Samples were acquired using a three laser FACS Canto II (BD Bioscience) and the data was subsequently analysed using FlowJo (version 9 or X; Treestar, USA).

\section{Statistical analysis}

GraphPad Prism software (http://www.graphpad.com, V6.0) was used for statistical analysis.

Except where stated in figure legends, Mantel-Cox and unpaired t-tests were used to calculate $P$ values ( $P$ values of $p<0.05$ were considered significant). 


\section{Acknowledgments}

We would like to thank Sonia Rocha, Derek Mann, Claire Richardson, Elaine Willmore and all members of the NDP laboratory for helpful advice and assistance. We also thank Drs. Luis Barrera and Hufeng Zhou for assistance with bioinformatics analysis and $\mathrm{Dr}$ Thomas Matthews (Institute of Cancer Research, London) for synthesis of CCT244747. JEH is funded by Cancer Research UK grant C1443/A22095 and has previously received funding from Leukemia Lymphoma Research grant 11022 and Cancer Research UK grant C1443/A12750. JAB, HS and AJM were funded by the Wellcome Trust grant 094409. The IVIS $^{\circledR}$ Spectrum was funded by Welcome Trust Equipment grant 087961 . BEG is funded by US National Institutes of Health (grant Al137337) and by a Burroughs Wellcome Medical Scientist career award. IC and MDG receive funding from Cancer Research UK grant number C309/A11566. 


\section{Author contributions}

JEH: performed majority of experimental work. Contributed to design of experiments and manuscript writing.

JAB: performed experiments with WT and ReIA ${ }^{\text {T505A }}$ MEFs, assisted with procedures involving $\mathrm{E} \mu-\mathrm{Myc}$ mice

HS: assisted with procedures involving $\mathrm{E} \mu-\mathrm{Myc}$ and $\mathrm{CLSPN}^{+-}$mice. Performed $\gamma \mathrm{H} 2 \mathrm{AX}$ flow cytometry experiments.

SL: assisted with procedures involving imaging and liver in vivo models.

AF \& AMK: performed analysis of immune cells in RelA ${ }^{T 505 A}$ mice.

AJM, NSK \& RTC: contributed to experimental work.

HDT: provided training and assisted with lymphoma re-implantation studies.

KJC: provided advice on working with $\mathrm{E} \mu-\mathrm{Myc}$ mice, assisted with data analysis and manuscript writing.

BEG: performed analysis of ChIP-Seq data. Assisted with manuscript writing.

FO: assisted with liver in vivo models and performed pathological analysis of DEN treated tumours. Assisted with manuscript writing.

MDG and IC: provided CCT244747 CHK1 inhibitor and contributed to the design and analysis of experiments. Assisted with manuscript writing.

NDP: contributed to design of experiments and manuscript writing.

Conflict of Interest Disclosures: IC and MDG are current or former employees of The Institute of Cancer Research, which has a commercial interest in CHK1 inhibitors. The other authors disclose no conflicts of interest. 


\section{Figure legends}

Figure 1. RelA T505 phosphorylation is required for pro-apoptotic effects of NF-kB

\section{following DNA replication stress}

(A \& B) RelA ${ }^{T 505 A}$ MEFs are resistant to Cisplatin induced apoptosis. Western blot analysis of full length and cleaved CASPASE 3 in (A) immortalised or (B) primary wild type (WT) and RelA T505A MEFs after treatment with the DNA damaging agent, Cisplatin $(4 \mu \mathrm{g} / \mathrm{ml})$.

(C) RelA ${ }^{T 505 A}$ MEFs are resistant to apoptosis resulting from treatment with inducers of DNA replication stress. CASPASE 3 activity assay in immortalised WT and RelA ${ }^{T 505 A}$ MEFs after treatment with Cisplatin $(4 \mu \mathrm{g} / \mathrm{ml})$, Mitomycin C $(1 \mu \mathrm{g} / \mathrm{ml})$., Hydroxyurea $(0.5 \mathrm{mM})$, Etoposide $(15 \mu \mathrm{M})$ and the active metabolite of Camptothecin, SN38 $(5 \mu \mathrm{M})$. All drugs were added for 16 hours before analysis apart from SN38 (48 hours). Results shown are the mean + SEM from 3 separate repeat experiments.

(D) RelA ${ }^{T 505 \mathrm{~A}}$ MEFs are resistant to $\mathrm{CHK} 1$ inhibitor treatment. Cell viability (Prestoblue assay) in WT and RelA ${ }^{T 505 A}$ MEFs following treatment with increasing concentrations of the CHK1 inhibitor, CCT244747 for 72 hours.

(E) Increased clonogenic survival in Re/A ${ }^{T 505 A}$ MEFs following $\mathrm{CHK} 1$ inhibitor treatment Clonogenic survival in WT and ReIA ${ }^{T 505 A}$ MEFs following either treatment with either $1 \mu \mathrm{M}$ $\left(p=0.0052{ }^{* *}\right.$ Unpaired Student's t-test $)$ or $5 \mu \mathrm{M}(p=0.0208$ * Unpaired Student's t-test $)$ of the CHK1 inhibitor, CCT244747 for 24 hours.

\section{Figure 2. The RelA T505A mutation leads to earlier onset of lymphoma, genomic} instability and a defect in CHK1 activation

(A) Earlier inset of lymphoma in $\mathrm{E} \mu-\mathrm{Myc} / \mathrm{Re} \mathrm{a}^{T 505 A}$ mice. Kaplan Meier survival curves for $\mathrm{E} \mu-\mathrm{Myc}(\mathrm{n}=27)$ and homozygous $\mathrm{E} \mu-\mathrm{Myc} / \mathrm{Rela}^{T 505 A}$ male mice $(\mathrm{n}=11)$. Survival is significantly shorter in $\mathrm{E} \mu-\mathrm{Myc} / \mathrm{Re} / A^{\mathrm{T} 505 \mathrm{~A}}$ mice $\left(\mathrm{p}=0.0001^{* * *}\right.$ Mantel-Cox test) and hazard ratio (HR) analysis indicates that these mice are at 7.5 times greater risk of dying earlier due to lymphoma compared with $\mathrm{E} \mu$-Myc mice. The median survival for each genotype is indicated. 
(B-D) Increased genomic instability in lymphomas from $\mathrm{E} \mu-\mathrm{Myc} / \mathrm{Re}^{\mathrm{T505A}}$ mice. Flow cytometric analysis (B) of B cells prepared from $\mathrm{E} \mu-\mathrm{Myc}$ and $\mathrm{E} \mu-\mathrm{Myc} / \mathrm{Rela}^{\mathrm{T505A}}$ spleens and stained for $\gamma \mathrm{H} 2 \mathrm{AX}$, a marker of DNA damage $\left(\mathrm{p}=0.0018^{* *}\right.$ Unpaired Student's t-test).

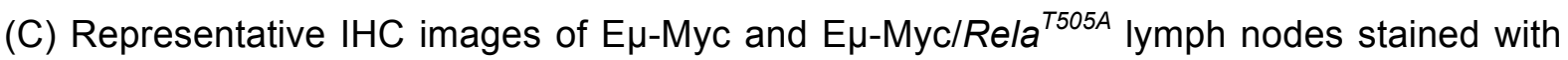
an antibody against $\gamma \mathrm{H} 2 \mathrm{AX}$ and counterstained with heamatoxylin. Brown staining indicates cells positive for $\gamma \mathrm{H} 2 \mathrm{AX}$. Quantification of $\gamma \mathrm{H} 2 \mathrm{AX}$ positive pixels by $\mathrm{IHC}$ analysis (D) in $\mathrm{E} \mu-$ Myc and E $\mu-M y c / R e l a^{T 505 A}$ lymph nodes. Each dot represents one mouse and at least blinded 5 fields of view were analysed per mouse $\left(p=0.0114{ }^{*}\right.$ Unpaired Student's t-test). The red dot in each case illustrates the mouse shown in (C).

(E \& F) E $\mu-M y c / R e l a^{T 505 A}$ lymphomas have a defect in $\mathrm{CHK} 1$ activation. Western blot analysis of phospho-S345 CHK1, CHK1, RELA and phospho-S536 RELA in snap frozen tumour extracts prepared from $\mathrm{E} \mu-\mathrm{Myc}$ and $E \mu-M y c / R e l a^{T 505 A}$ mouse inguinal lymph nodes and spleens. Red dots in scatter plots in (B) and (D) indicate the mice used for protein analysis.

(F) E $\mu-M y c / c-R e r^{-/}$lymphomas also have a defect in CHK1 activation. Western blot analysis of phospho-S345 CHK1 and CHK1using extracts prepared from E $\mu-M y c$ and E $\mu-M y c / c-R e r^{--}$ tumorigenic spleens.

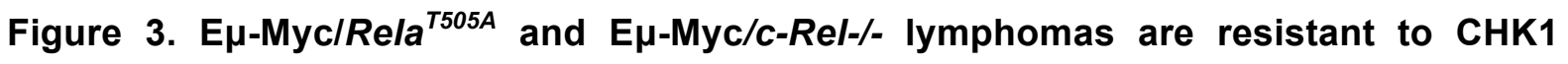
inhibition

(A) E $\mu-M y c / c-R e I^{--}$and $\mathrm{E} \mu-M y c / R e l a^{T 505 A}$ lymphoma cells are resistant to $\mathrm{CHK} 1$ inhibition ex

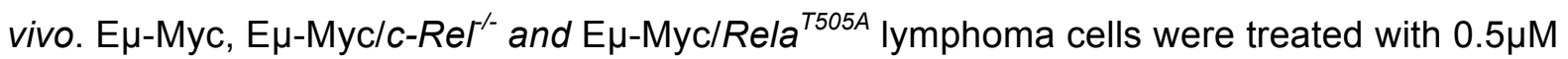
or $1 \mu \mathrm{M}$ CCT244747 (or vehicle control) for 96 hours ex vivo. WT E $\mu$-Myc tumour cells show a reduced cell viability compared with the $\mathrm{E} \mu-\mathrm{Myc} / \mathrm{c}-\mathrm{Re}{ }^{-/}$or $\mathrm{E} \mu-\mathrm{Myc} / \mathrm{Re} / \mathrm{A}^{\mathrm{T505A}}$ tumour cells at all doses of CCT244747 tested.

(B) Schematic of the in vivo study using the CHK1 inhibitor, CCT244747. 5 lymphomas of each genotype were reimplanted separately into 6 syngeneic recipient C57BI/6 mice. 
Lymphomas were allowed to develop and when palpable 3 were treated with CCT244747 (100 mg/kg p.o), and 3 with vehicle control, for 9 days.

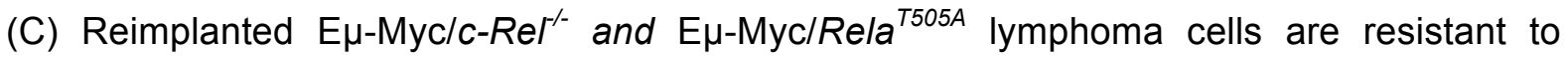
$\mathrm{CHK} 1$ inhibition in vivo. Line graphs showing the mean response of the five reimplanted $\mathrm{E} \mu$ -

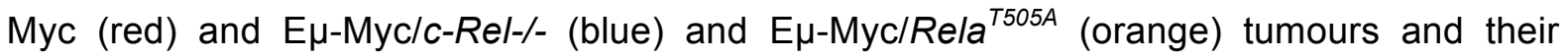
response to ССТ244747. A response was defined as a significant reduction (or increase) in tumour burden $(p<0.05)$ using unpaired Student's t-tests. The complete data set is summarised in (D). ' + ' indicates one experiment where treatment was stopped after 7 days and the mice were humanely killed at this timepoint due to the disease burden in these mice.

(D) Table showing the response of 5 re-implanted $\mathrm{E} \mu-\mathrm{Myc}, \mathrm{E} \mu-\mathrm{Myc}_{\mathrm{c}}-\mathrm{Rel}^{--}$and $\mathrm{E} \mu-$ Myc/Rela ${ }^{T 505 A}$ tumours to CCT244747, in all sites where lymphoid tumour burden is anticipated in this model.

Figure 4. $\mathrm{E} \mu-\mathrm{Myc} / \mathrm{c}-\mathrm{Re}^{-/}$and $\mathrm{E} \mu-\mathrm{Myc} / \mathrm{RelA}^{\mathrm{T} 505 \mathrm{~A}}$ Iymphomas fail to induce Claspin expression

(A) Schematic diagram illustrating the activation of CHK1 by ATR following DNA damage or replication stress, and the role of Claspin as an essential adaptor protein.

(B) Reduced Clspn mRNA expression in $\mathrm{E} \mu-\mathrm{Myc} / \mathrm{c}-\mathrm{Re}^{\gamma^{-/}}$and $\mathrm{E} \mu-\mathrm{Myc} / \mathrm{Rela}^{\mathrm{T505A}}$ lymphomas. qRT-PCR data showing relative Clspn mRNA expression in tumorigenic spleens from $\mathrm{E} \mu$ -

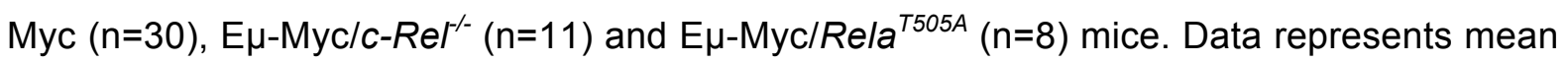
\pm SEM. $\mathrm{p}^{\star *}<0.01$ (Unpaired Student's t-test), each point is an individual mouse.

(C) Claspin protein expression is also reduced in $\mathrm{E} \mu-\mathrm{Myc} / \mathrm{C}-\mathrm{Re}^{-/-}$and $\mathrm{E} \mu-\mathrm{Myc} / \mathrm{Re} / \mathrm{a}^{T 505 \mathrm{~A}}$ lymphomas. Western blot analysis of Claspin using extracts prepared from $\mathrm{E} \mu-\mathrm{Myc}, \mathrm{E} \mu-$ $\mathrm{Myc} / \mathrm{c}-\mathrm{Re} \mathrm{I}^{-/}$or $\mathrm{E} \mu-\mathrm{Myc} / \mathrm{Re}^{\mathrm{T505A}}$ tumorigenic spleens. Accompanying scatter plot illustrates which wild type mice with either high (o) or low (x) Clspn mRNA expression were used for protein analysis. 


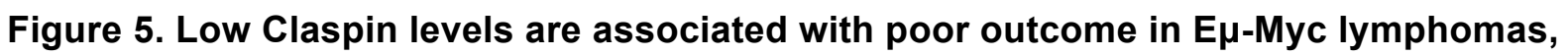
human breast cancers and lead to spontaneous B-cell lymphoma in aged $\mathrm{Clspn}^{+/-}$ mice.

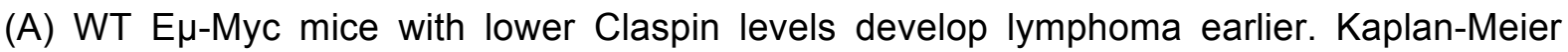
survival analysis of WT E $\mu$-Myc mice comparing above and below median level expression of Clspn mRNA. Table detailing the survival of $\mathrm{E} \mu-\mathrm{Myc}$ and $\mathrm{E} \mu-\mathrm{Myc} / \mathrm{c}-\mathrm{Rel}^{--}$mice as described previously in (Hunter et al., 2016).

(B) Low CLSPN mRNA levels are associated with poor survival in breast cancer patients with mutant p53. Kaplan-Meier survival analysis of breast cancer datasets from KM Plotter with differing levels of CLSPN mRNA (auto select best cutoff). Patients with low CLSPN mRNA levels have significantly shorter overall survival $(p=0.0000054$ Mantel-Cox test, HR

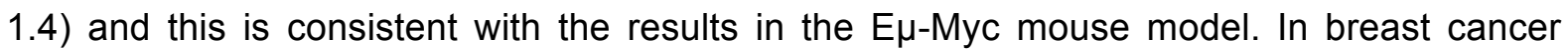
patients with mutant p53 mutant breast cancer low CLSPN levels also have significantly shorter overall survival ( $p=0.00015$ Mantel-Cox test, HR 3.6), while the situation is reversed in breast cancer patients with WT p53 ( $p=0.0033$ Mantel-Cox test, HR 2.6).

(C) Primary fibroblasts from $\mathrm{Clspn}^{+/-}$mice are resistant to $\mathrm{CHK} 1$ inhibition. Cell viability (Prestoblue assay) in WT and $\mathrm{Clspn}^{+-}$primary ear fibroblasts (EFs) following treatment with increasing concentrations of the CHK1 inhibitor, CCT244747.

(D - F) 18 month old $\mathrm{Clspn}^{+/}$spontaneously develop B-cell lymphoma. (D) Weight of the mesenteric lymph nodes from 18 month old WT and $\mathrm{CLSPN}^{+-}$mice. (E) Representative images of the mesenteric lymph node from two 18 month old WT and two 18 month old WT $\mathrm{Clspn}^{+-}$mice. (F) Representative H \& E stained sections of the mesenteric lymph node from 18 month old WT and $\mathrm{Clspn}^{+-}$mice. Red dots in scatter plot in (D) indicate samples used in $(E)$ and $(F)$.

Figure 6: $\operatorname{RelA}^{T 505 A}$ and $\mathrm{Clspn}^{+/-}$mice are more susceptible to DEN induced acute liver injury 
(A) Schematic diagram illustrating the acute DEN in vivo study in WT, RelA ${ }^{T 505 A}$ or Clspn ${ }^{+/-}$ mice. $80 \mathrm{mg} / \mathrm{kg}$ DEN in $0.9 \%$ saline was administered IP to 8 week old male mice. $24 \mathrm{~h}$ or 48h post-DEN mice were humanely killed and tissues collected.

(B) Clspn mRNA levels recover more slowly in RelA ${ }^{T 505 A}$ mice. qRT-PCR data showing relative Clspn mRNA expression in livers from WT and RelA ${ }^{T 505 A}$ mice $24 \mathrm{~h}$ or $48 \mathrm{~h}$ post DEN injury. Data represents mean \pm SEM. $\mathrm{p}^{*}<0.05$ (Unpaired Student's t-test).

(C \& D) $\operatorname{RelA}^{\mathrm{T} 505 \mathrm{~A}}$ and $\mathrm{Clspn^{+/- }}$ mice show similar increased body weight loss after acute DEN treatment. Percentage change in bodyweight in WT, RelA ${ }^{T 505 A}$ (C) and $\mathrm{Clspr}^{+/-}$(D) mice $24 \mathrm{~h}$ or $48 \mathrm{~h}$ post DEN injury. Data represents mean \pm SEM. $\mathrm{p}^{*}<0.05, p<0.01^{* *}, p<0.001^{* * *}$ (Unpaired Student's t-test).

(E \& F) RelA ${ }^{T 505 A}$ and $C / s p n^{+/-}$mice show similar increased liver damage after acute DEN treatment. Liver:body weight ratio at $24 \mathrm{~h}$ and $48 \mathrm{~h}$ post DEN injury in male WT, RelA ${ }^{T 505 \mathrm{~A}}$ (E) and $\mathrm{Clspn}^{+/-}(\mathrm{F})$.

$(\mathrm{G} \& \mathrm{H}) \mathrm{Re} / \mathrm{A}^{\mathrm{T} 505 \mathrm{~A}}$ and $\mathrm{Clspn^{+/- }}$ mice both show increased levels of DNA damage after acute DEN treatment. Quantification of $\gamma \mathrm{H} 2 \mathrm{AX}$ positive pixels by IHC analysis in WT, RelA ${ }^{\mathrm{T} 505 \mathrm{~A}}$ and $\mathrm{Clspn}^{+/-}(\mathrm{H})$ livers either $24 \mathrm{~h}$ or $48 \mathrm{~h}$ post DEN injury. Each dot represents one mouse and at least blinded 5 fields of view were analysed per mouse. Data represents mean \pm SEM. $p<0.001^{* * *} p>0.0001^{* * *}$ (Unpaired Student's t-test) Representative images are shown, with red dots in scatter plots indicating representative images chosen.

Figure 7: Earlier onset of DEN induced hepatocellular carcinoma in $\mathrm{Clspn}^{+/-}$mice $^{-}$

(A) Schematic diagram illustrating the chronic DEN in vivo study in WT and Clspn ${ }^{+-}$mice. 15 day old mice were given $30 \mathrm{mg} / \mathrm{kg}$ DEN in $0.9 \%$ saline by IP injection. Black arrow indicates DEN administration, blue arrows indicate imaging timepoints and the red arrow indicates the time of study termination. 
(B) In vivo imaging using fluorescent 2-DG reveals increased tumour growth in $\mathrm{Clspn}^{+/-}$mice. Quantification of the in vivo fluorescent signal from the abdominal region of either WT or $\mathrm{Clspn}^{+/-}$mice either $28 \mathrm{w}$ or $30 \mathrm{w}$ post DEN administration. Data represents mean \pm SEM. $p<0.05 *$ (Unpaired Student's t-test). Representative images are shown with red dots in scatter plots indicating representative samples chosen.

(C) Quantification of the ex vivo fluorescent signal from the livers of either WT or Clspn ${ }^{+/-}$ mice excised $30 \mathrm{w}$ post DEN administration. Data represents mean \pm SEM. $p<0.05$ * (Unpaired Student's t-test) Representative images are shown with red dots in scatter plots indicating representative samples chosen.

(D \& E) Livers from $\mathrm{Clspn}^{+/-}$mice show increased numbers of visible tumours. Numbers of macroscopic tumours visible in WT and $\mathrm{Clspn}^{+/-}$livers 30 weeks after DEN administration were counted (D). Data represents mean \pm SEM. $p<0.05^{*}$ (Unpaired Student's t-test) Representative images (E) of livers in WT and $C / s p n^{+/-}$livers 30 weeks after DEN administration. Red dots in (D) scatter plots indicate liver images chosen.

(F) DEN treated $\mathrm{Clspn}^{+/-}$mice have increased numbers of hepatocellular carcinoma. Histological quantification of tumours and classified as either hepatocellular adenomas or carcinomas in liver sections from DEN-treated WT and $\mathrm{Clspn}^{+/-}$mice. An expert pathologist scored the pathology. Data represents mean \pm SEM. $p<0.05^{*}, p<0.01^{* *}$ (Unpaired Student's t-test).

Figure 8. Schematic model illustrating NF-KB regulation of Claspin expression in cancer. Our data describe a positive feedback loop in which CHK1 phosphorylation of RelA at T505, together with the NF-KB subunit c-Rel, drives the expression of the ATR checkpoint kinase regulator Claspin in response to DNA replication stress in cancer cells. This in turn is required for maintenance of $\mathrm{CHK} 1$ activity. We propose that loss of this pathway early in tumorigenesis promotes cancer development through increased genomic instability. However, in malignant cancer cells it can help promote their addiction to the checkpoint 
bioRxiv preprint doi: https://doi.org/10.1101/358291; this version posted June 28,2018 . The copyright holder for this preprint (which was not certified by peer review) is the author/funder. All rights reserved. No reuse allowed without permission.

kinase signalling required for the maintenance of genomic integrity. Importantly, disruption of this pathway leads to resistance of cells to treatment with $\mathrm{CHK} 1$ inhibitors. 


\section{Supplementary Figure Legends}

\section{Figure S1:}

(A) RelA ${ }^{T 505 A}$ MEFs are resistant to Cisplatin induced apoptosis. CASPASE 3 activity assay in immortalised WT and RelA ${ }^{T 505 A}$ MEFs after 16 hours treatment with Cisplatin $(4 \mu \mathrm{g} / \mathrm{ml})$, Results shown are the mean + SEM from 3 separate repeat experiments. This is an independent isolate of the WT and Rela ${ }^{T 505 A}$ MEFs to that used in Figure 1.

(B) Western blot analysis of the NF-KB subunits, c-REL, RELA, RELB, p100/p52, p50 together with c-MYC in extracts prepared from WT and Rela ${ }^{T 505 A}$ MEFs.

(C) Increased clonogenic survival in RelA ${ }^{T 505 A}$ MEFs following CHK1 inhibitor treatment Clonogenic survival in WT and RelA ${ }^{T 505 A}$ MEFs following either treatment with either $1 \mu \mathrm{M}$ $\left(p=0.0032{ }^{* *}\right.$ Unpaired Student's t-test) or $5 \mu \mathrm{M}(p=0.0504$ Unpaired Student's t-test) of the CHK1 inhibitor, MK8776.

\section{Figure S2:}

$(A \& B)$ There is no significant change in $\mathrm{Bcl}-\mathrm{xL}(\mathrm{Bc/2/1})$ or Bax mRNA levels between $\mathrm{E} \mu$ Myc and E $\mu-M y c / R e l a^{T 505 A}$ lymphomas. qRT-PCR data showing relative Bc/2/1 (A) or Bax (B) mRNA expression in tumorigenic spleens from $\mathrm{E} \mu-\mathrm{Myc}$ and $\mathrm{E} \mu-\mathrm{Myc} / \mathrm{Re}_{\mathrm{a}}{ }^{T 505 \mathrm{~A}}$ mice. Data represents mean \pm SEM, each point is an individual mouse.

(C) Table detailing the cell numbers in spleen and inguinal lymph nodes from WT and Rela ${ }^{T 505 A}$ mice. No significant difference was observed using a two-tailed Students t-test.

(D) Western blot analysis of the NF-kB subunits, c-REL, RELA, RELB, p100/p52, p50 together with c-MYC in extracts prepared from E $\mu-M y c$ and $E \mu-M y c / R e l a^{T 505 A}$ mouse tumorigenic spleens.

(E) Western blot analysis of the phospho p38 (Thr180, Tyr182), p38, phospho JNK (Thr183, Tyr185) JNK, phospho ERK (Thr202, Tyr204) or ERK in snap frozen tumours extracts prepared from $\mathrm{E} \mu-\mathrm{Myc}$ and $\mathrm{E} \mu-\mathrm{Myc} / R_{\mathrm{Re}} \mathrm{a}^{T 505 A}$ mouse inguinal lymph nodes and spleens.

Figure S3: 


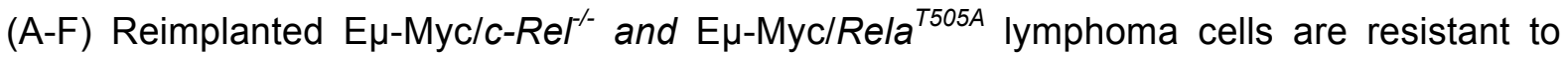
CHK1 inhibition in vivo. Representative data from one $\mathrm{E} \mu-\mathrm{Myc}$ or one $\mathrm{E} \mu-\mathrm{Myc} / \mathrm{c}-\mathrm{ReI}^{-/}$or one E $\mu$-Myc/Rela ${ }^{T 505 A}$ tumour re-implanted into six C57BI/6 mice and treated with CCT244747 $(n=3)$, or vehicle control $(n=3)$. Two organ sites are shown; cervical lymph nodes $(A-C)$ and brachial lymph nodes (D-F), and in the case of all E $\mu$-Myc tumours, lymphoid tumour burden was significantly reduced by CCT244747 (data shown are mean \pm SEM, $\mathrm{p}^{*}<0.05, \mathrm{p}^{* *}<0.01$,

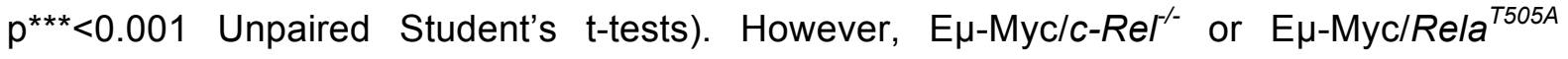
lymphoid tumour burden was not significant affected by CCT244747 (data shown are mean \pm SEM).

\section{Figure S4:}

(A-E) Other components of the ATR/CHK1 signalling pathway are not affected in E $\mu$-Myc/c$\mathrm{Rel}^{--}$and $\mathrm{E} \mu$-Myc/Rela ${ }^{T 505 A}$ mice and do not correlate with onset of lymphoma. QRT-PCR data showing relative $\operatorname{Atr}(\mathrm{A}), \operatorname{Rad17}(\mathrm{B}), \operatorname{Atrip}(\mathrm{C}), \operatorname{Topbp} 1$ (D) and Chek1 (E) expression in tumorigenic spleens from $\mathrm{E} \mu-\mathrm{Myc}$ (for $\mathrm{c}-\mathrm{Rel}$ analysis $\mathrm{n}=20 \mathrm{~A}-\mathrm{D}, \mathrm{n}=11 \mathrm{E}$, for Rela ${ }^{T 505 A}$ analysis $n=13$ A-D, $n=6 E), E \mu-M y c / c-R e H^{--}(n=11)$ and $E \mu-M y c / R e l a^{T 505 A}(n=8)$ mice. Right hand panel (A-E) shows Kaplan-Meier survival analysis of $E \mu$-Myc mice with below and above the median levels of Atr, Rad17, Atrip, Topbp1 and Chek1 mRNA ( $\mathrm{n}=20$ mice), and Topbp1 $(\mathrm{n}=11$ mice). No correlation with overall survival is seen.

\section{Figure S5:}

(A \& B) Clspn mRNA levels are not affected in non-tumorigenic B-cells from $c-\operatorname{Rel}^{-/}(A)$ or Rela $^{T 505 A}$ (B) mice. qRT-PCR data showing relative Clspn expression in purified splenic Bcells from C57BI/6 $(n=6)$ and $\mathrm{crel}^{-/}(n=7)$ mice. Data represents mean \pm SEM. Analysed using Unpaired Student's t-test.

(C) The CLSPN gene is a NF-KB target gene in B-cell lymphoma. ChIP Seq data showing NF-KB subunit binding to the human CLSPN gene promoter in the EBV-transformed lymphoblastoid B-cell line (LCL) GM12878. 
(D) Scatter plot showing how E $\mu$-Myc mice were stratified into those expressing below or above the median levels of Clspn mRNA in tumours, as well as $\mathrm{E} \mu-\mathrm{Myc}_{\mathrm{C}}-\mathrm{Rel}^{--}$and $\mathrm{E} \mu$ Myc/Rela ${ }^{T 505 A}$ mice. Analysed using an ONE-way Anova with Sidak post-hoc test

(E) Low CLSPN mRNA levels are associated with poor survival in HER2 positive breast cancer patients. Kaplan-Meier survival analysis of breast cancer datasets from KM Plotter with differing levels of CLSPN mRNA (auto select best cutoff). Patients with low CLSPN levels have significantly shorter overall survival in HER2 positive patients $(p=0.0033$ MantelCox test, HR 2.6). In HER2 negative breast cancer patients, CLSPN mRNA levels do not predict outcome in this context ( $p=0.33$ Mantel-Cox test, HR 1.19).

\section{Figure S6:}

(A) Western blot analysis of Claspin, ATR and CHK1 in two independent isolates of WT and $\mathrm{Clspn}^{+/-}$Ear Fibroblasts (EFs).

(B) Primary fibroblasts from $\mathrm{Clspn}^{+/-}$mice are resistant to $\mathrm{CHK} 1$ inhibition. Cell viability (Prestoblue assay) in WT and $\mathrm{Clspn}^{+/}$primary ear fibroblasts (EFs) following treatment with increasing concentrations of the CHK1 inhibitor, СCT244747. This is an independent isolate of EFs to those used in Figure 5C.

(C) 18 month old $\mathrm{Clspn}^{+/}$spontaneously develop B-cell lymphoma. Table summarizing the

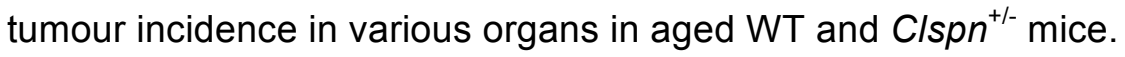

$(\mathrm{D}-\mathrm{H})$ Weight of the indicated lymph nodes from 12 month old $(\mathrm{D}, \mathrm{F}-\mathrm{H})$ and 6 month old $(E)$ WT and $\mathrm{Clspn}^{+/-}$mice

\section{Figure S7:}

(A) Liver:body weight ratio at 30weks post DEN treatment in male WT and $\mathrm{Clspn}^{+/-}$mice. Analysed using Unpaired Student's t-test. (B) Representative IHC images from 30 week DEN treated WT animals. The images show the presence of adenomas but not hepatocellular carcinomas in these animals.

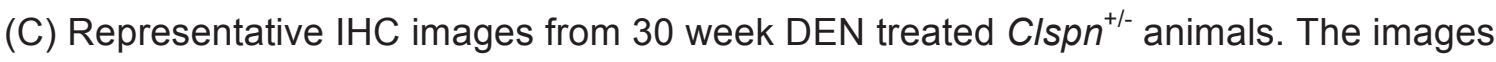
show the presence of hepatocellular carcinomas (HCC) in these animals, including a Grade II HCC. Red arrows denote the presence of proteoglycans and black arrows denote the 
bioRxiv preprint doi: https://doi.org/10.1101/358291; this version posted June 28,2018 . The copyright holder for this preprint (which was

not certified by peer review) is the author/funder. All rights reserved. No reuse allowed without permission.

presence of mitotic bodies. 


\section{References}

Azenha, D., Lopes, M.C., and Martins, T.C. (2017). Claspin functions in cell homeostasis-A link to cancer? DNA Repair (Amst) 59, 27-33.

Blackwood, E., Epler, J., Yen, I., Flagella, M., O'Brien, T., Evangelista, M., Schmidt, S., Xiao, Y., Choi, J., Kowanetz, K., et al. (2013). Combination drug scheduling defines a "window of opportunity" for chemopotentiation of gemcitabine by an orally bioavailable, selective ChK1 inhibitor, GNE-900. Mol Cancer Ther 12, 1968-1980.

Bric, A., Miething, C., Bialucha, C.U., Scuoppo, C., Zender, L., Krasnitz, A., Xuan, Z., Zuber, J., Wigler, M., Hicks, J., et al. (2009). Functional identification of tumor-suppressor genes through an in vivo RNA interference screen in a mouse lymphoma model. Cancer Cell $16,324-335$.

Campaner, S., and Amati, B. (2012). Two sides of the Myc-induced DNA damage response: from tumor suppression to tumor maintenance. Cell Div 7, 6.

Campbell, K.J., Rocha, S., and Perkins, N.D. (2004). Active repression of antiapoptotic gene expression by RelA(p65) NF-kappa B. Mol Cell 13, 853-865.

Campbell, K.J., Witty, J.M., Rocha, S., and Perkins, N.D. (2006). Cisplatin mimics ARF tumor suppressor regulation of RelA (p65) nuclear factor-kappaB transactivation. Cancer Res 66, 929-935.

Carrassa, L., and Damia, G. (2017). DNA damage response inhibitors: Mechanisms and potential applications in cancer therapy. Cancer Treat Rev 60, 139-151.

Chien, Y., Scuoppo, C., Wang, X., Fang, X., Balgley, B., Bolden, J.E., Premsrirut, P., Luo, W., Chicas, A., Lee, C.S., et al. (2011). Control of the senescence-associated secretory phenotype by NF-\{kappa\}B promotes senescence and enhances chemosensitivity. Genes Dev.

Chini, C.C., and Chen, J. (2004). Claspin, a regulator of CHK1 in DNA replication stress pathway. DNA Repair (Amst) 3, 1033-1037.

Daud, A.I., Ashworth, M.T., Strosberg, J., Goldman, J.W., Mendelson, D., Springett, G., Venook, A.P., Loechner, S., Rosen, L.S., Shanahan, F., et al. (2015). Phase I dose-escalation trial of checkpoint kinase 1 inhibitor MK-8776 as monotherapy and in combination with gemcitabine in patients with advanced solid tumors. J Clin Oncol 33, 1060-1066.

Dominguez-Sola, D., and Gautier, J. (2014). MYC and the control of DNA replication. Cold Spring Harb Perspect Med 4.

Eischen, C.M., Weber, J.D., Roussel, M.F., Sherr, C.J., and Cleveland, J.L. (1999). Disruption of the ARF-Mdm2-p53 tumor suppressor pathway in Myc-induced lymphomagenesis. Genes Dev 13, 2658-2669.

Erkko, H., Pylkas, K., Karppinen, S.M., and Winqvist, R. (2008). Germline alterations in the CLSPN gene in breast cancer families. Cancer letters 261, 93-97.

Errico, A., and Costanzo, V. (2012). Mechanisms of replication fork protection: a safeguard for genome stability. Critical reviews in biochemistry and molecular biology 47, 222-235.

Garrett, M.D., and Collins, I. (2011). Anticancer therapy with checkpoint inhibitors: what, where and when? Trends Pharmacol Sci 32, 308-316. 
Guzi, T.J., Paruch, K., Dwyer, M.P., Labroli, M., Shanahan, F., Davis, N., Taricani, L., Wiswell, D., Seghezzi, W., Penaflor, E., et al. (2011). Targeting the replication checkpoint using SCH 900776, a potent and functionally selective CHK1 inhibitor identified via high content screening. Mol Cancer Ther 10, 591-602.

Harris, A.W., Pinkert, C.A., Crawford, M., Langdon, W.Y., Brinster, R.L., and Adams, J.M. (1988). The $\mathrm{E}$ mu-myc transgenic mouse. A model for high-incidence spontaneous lymphoma and leukemia of early B cells. J Exp Med 167, 353-371.

Hein, J., Boichuk, S., Wu, J., Cheng, Y., Freire, R., Jat, P.S., Roberts, T.M., and Gjoerup, O.V. (2009). Simian virus 40 large $\mathrm{T}$ antigen disrupts genome integrity and activates a DNA damage response via Bub1 binding. J Virol 83, 117-127.

Heindryckx, F., Colle, I., and Van Vlierberghe, H. (2009). Experimental mouse models for hepatocellular carcinoma research. International journal of experimental pathology 90, 367386.

Hinz, M., and Scheidereit, C. (2014). The IkappaB kinase complex in NF-kappaB regulation and beyond. EMBO Rep 15, 46-61.

Hinz, M., Stilmann, M., Arslan, S.C., Khanna, K.K., Dittmar, G., and Scheidereit, C. (2010). A cytoplasmic ATM-TRAF6-cIAP1 module links nuclear DNA damage signaling to ubiquitin-mediated NF-kappaB activation. Mol Cell 40, 63-74.

Hummel, M., Bentink, S., Berger, H., Klapper, W., Wessendorf, S., Barth, T.F., Bernd, H.W., Cogliatti, S.B., Dierlamm, J., Feller, A.C., et al. (2006). A biologic definition of Burkitt's lymphoma from transcriptional and genomic profiling. The New England journal of medicine 354, 2419-2430.

Hunter, J.E., Butterworth, J.A., Zhao, B., Sellier, H., Campbell, K.J., Thomas, H.D., Bacon, C.M., Cockell, S.J., Gewurz, B.E., and Perkins, N.D. (2016). The NF-kappaB subunit c-Rel regulates Bach2 tumour suppressor expression in B-cell lymphoma. Oncogene 35, 34763484.

Jing, H., Kase, J., Dorr, J.R., Milanovic, M., Lenze, D., Grau, M., Beuster, G., Ji, S., Reimann, M., Lenz, P., et al. (2011). Opposing roles of NF-\{kappa $\}$ B in anti-cancer treatment outcome unveiled by cross-species investigations. Genes Dev.

Jurk, D., Wilson, C., Passos, J.F., Oakley, F., Correia-Melo, C., Greaves, L., Saretzki, G., Fox, C., Lawless, C., Anderson, R., et al. (2014). Chronic inflammation induces telomere dysfunction and accelerates ageing in mice. Nat Commun 2, 4172.

Keller, U., Huber, J., Nilsson, J.A., Fallahi, M., Hall, M.A., Peschel, C., and Cleveland, J.L. (2010). Myc suppression of Nfkb2 accelerates lymphomagenesis. BMC cancer 10, 348.

Keller, U., Nilsson, J.A., Maclean, K.H., Old, J.B., and Cleveland, J.L. (2005). Nfkb 1 is dispensable for Myc-induced lymphomagenesis. Oncogene 24, 6231-6240.

Kenneth, N.S., Mudie, S., and Rocha, S. (2010). IKK and NF-kappaB-mediated regulation of Claspin impacts on ATR checkpoint function. Embo J 29, 2966-2978.

Koganti, S., Hui-Yuen, J., McAllister, S., Gardner, B., Grasser, F., Palendira, U., Tangye, S.G., Freeman, A.F., and Bhaduri-McIntosh, S. (2014). STAT3 interrupts ATR-CHK1 signaling to allow oncovirus-mediated cell proliferation. Proc Natl Acad Sci U S A 111, 4946-4951.

Kumagai, A., and Dunphy, W.G. (2003). Repeated phosphopeptide motifs in Claspin mediate the regulated binding of CHK1. Nat Cell Biol 5, 161-165. 
Lainchbury, M., Matthews, T.P., McHardy, T., Boxall, K.J., Walton, M.I., Eve, P.D., Hayes, A., Valenti, M.R., de Haven Brandon, A.K., Box, G., et al. (2012). Discovery of 3alkoxyamino-5-(pyridin-2-ylamino)pyrazine-2-carbonitriles as selective, orally bioavailable CHK1 inhibitors. J Med Chem 55, 10229-10240.

Lanczky, A., Nagy, A., Bottai, G., Munkacsy, G., Szabo, A., Santarpia, L., and Gyorffy, B. (2016). miRpower: a web-tool to validate survival-associated miRNAs utilizing expression data from 2178 breast cancer patients. Breast Cancer Res Treat 160, 439-446.

Lin, S.Y., Li, K., Stewart, G.S., and Elledge, S.J. (2004). Human Claspin works with BRCA1 to both positively and negatively regulate cell proliferation. Proc Natl Acad Sci U S A 101, 6484-6489.

Liu, Q., Guntuku, S., Cui, X.S., Matsuoka, S., Cortez, D., Tamai, K., Luo, G., CarattiniRivera, S., DeMayo, F., Bradley, A., et al. (2000). CHK1 is an essential kinase that is regulated by Atr and required for the G(2)/M DNA damage checkpoint. Genes Dev 14, 14481459.

Liu, Y., Fang, Y., Shao, H., Lindsey-Boltz, L., Sancar, A., and Modrich, P. (2010). Interactions of human mismatch repair proteins MutSalpha and MutLalpha with proteins of the ATR-CHK1 pathway. J Biol Chem 285, 5974-5982.

Maya-Mendoza, A., Ostrakova, J., Kosar, M., Hall, A., Duskova, P., Mistrik, M., MerchutMaya, J.M., Hodny, Z., Bartkova, J., Christensen, C., et al. (2015). Myc and Ras oncogenes engage different energy metabolism programs and evoke distinct patterns of oxidative and DNA replication stress. Mol Oncol 9, 601-616.

McNeely, S., Beckmann, R., and Bence Lin, A.K. (2014). CHEK again: revisiting the development of CHK1 inhibitors for cancer therapy. Pharmacol Ther 142, 1-10.

Moles, A., Butterworth, J.A., Sanchez, A., Hunter, J.E., Leslie, J., Sellier, H., Tiniakos, D., Cockell, S.J., Mann, D.A., Oakley, F., et al. (2016). A RelA(p65) Thr505 phospho-site mutation reveals an important mechanism regulating NF-kappaB-dependent liver regeneration and cancer. Oncogene 35, 4623-4632.

Msaki, A., Sanchez, A.M., Koh, L.F., Barre, B., Rocha, S., Perkins, N.D., and Johnson, R.F. (2011). The role of RelA (p65) threonine 505 phosphorylation in the regulation of cell growth, survival, and migration. Mol Biol Cell 22, 3032-3040.

O'Driscoll, M. (2009). Mouse models for ATR deficiency. DNA Repair (Amst) 8, 13331337.

Perkins, N.D. (2012). The diverse and complex roles of NF-kappaB subunits in cancer. Nature Reviews Cancer 12, 121-132.

Praetorius-Ibba, M., Wang, Q.E., Wani, G., El-Mahdy, M.A., Zhu, Q., Qin, S., and Wani, A.A. (2007). Role of Claspin in regulation of nucleotide excision repair factor DDB2. DNA Repair (Amst) 6, 578-587.

Rajendran, J.G., Mankoff, D.A., O'Sullivan, F., Peterson, L.M., Schwartz, D.L., Conrad, E.U., Spence, A.M., Muzi, M., Farwell, D.G., and Krohn, K.A. (2004). Hypoxia and glucose metabolism in malignant tumors: evaluation by $[18 \mathrm{~F}]$ fluoromisonidazole and [18F]fluorodeoxyglucose positron emission tomography imaging. Clin Cancer Res 10, 22452252 . 
Riedlinger, T., Haas, J., Busch, J., van de Sluis, B., Kracht, M., and Schmitz, M.L. (2018). The Direct and Indirect Roles of NF-kappaB in Cancer: Lessons from Oncogenic Fusion Proteins and Knock-in Mice. Biomedicines 6.

Rocha, S., Campbell, K.J., and Perkins, N.D. (2003). p53- and Mdm2-independent repression of NF-kappa B transactivation by the ARF tumor suppressor. Mol Cell 12, 15-25.

Rocha, S., Garrett, M.D., Campbell, K.J., Schumm, K., and Perkins, N.D. (2005). Regulation of NF-kappaB and p53 through activation of ATR and CHK1 by the ARF tumour suppressor. Embo J 24, 1157-1169.

Rohban, S., and Campaner, S. (2015). Myc induced replicative stress response: How to cope with it and exploit it. Biochim Biophys Acta 1849, 517-524.

Sabatel, H., Di Valentin, E., Gloire, G., Dequiedt, F., Piette, J., and Habraken, Y. (2012). Phosphorylation of p65(RelA) on Ser(547) by ATM represses NF-kappaB-dependent transcription of specific genes after genotoxic stress. PLoS One 7, e38246.

Schmitt, A.M., Crawley, C.D., Kang, S., Raleigh, D.R., Yu, X., Wahlstrom, J.S., Voce, D.J., Darga, T.E., Weichselbaum, R.R., and Yamini, B. (2011). p50 (NF-kappaB1) is an effector protein in the cytotoxic response to DNA methylation damage. Mol Cell 44, 785-796.

Spardy, N., Covella, K., Cha, E., Hoskins, E.E., Wells, S.I., Duensing, A., and Duensing, S. (2009). Human papillomavirus 16 E7 oncoprotein attenuates DNA damage checkpoint control by increasing the proteolytic turnover of claspin. Cancer Res 69, 7022-7029.

Todaro, G.J., and Green, H. (1963). Quantitative studies of the growth of mouse embryo cells in culture and their development into established lines. J Cell Biol 17, 299-313.

Walton, M.I., Eve, P.D., Hayes, A., Henley, A.T., Valenti, M.R., De Haven Brandon, A.K., Box, G., Boxall, K.J., Tall, M., Swales, K., et al. (2015). The clinical development candidate CCT245737 is an orally active CHK1 inhibitor with preclinical activity in RAS mutant NSCLC and Emicro-MYC driven B-cell lymphoma. Oncotarget.

Walton, M.I., Eve, P.D., Hayes, A., Valenti, M.R., De Haven Brandon, A.K., Box, G., Hallsworth, A., Smith, E.L., Boxall, K.J., Lainchbury, M., et al. (2012). CCT244747 is a novel potent and selective CHK1 inhibitor with oral efficacy alone and in combination with genotoxic anticancer drugs. Clin Cancer Res 18, 5650-5661.

Wang, C., Yang, C., Ji, J., Jiang, J., Shi, M., Cai, Q., Yu, Y., Zhu, Z., and Zhang, J. (2017). Deubiquitinating enzyme USP20 is a positive regulator of Claspin and suppresses the malignant characteristics of gastric cancer cells. Int J Oncol.

Wu, Z.H., and Miyamoto, S. (2008). Induction of a pro-apoptotic ATM-NF-kappaB pathway and its repression by ATR in response to replication stress. Embo J 27, 1963-1973.

Wu, Z.H., Wong, E.T., Shi, Y., Niu, J., Chen, Z., Miyamoto, S., and Tergaonkar, V. (2010). ATM- and NEMO-dependent ELKS ubiquitination coordinates TAK1-mediated IKK activation in response to genotoxic stress. Mol Cell 40, 75-86.

Yoo, H.Y., Jeong, S.Y., and Dunphy, W.G. (2006). Site-specific phosphorylation of a checkpoint mediator protein controls its responses to different DNA structures. Genes Dev 20, 772-783.

Yuan, J., Luo, K., Deng, M., Li, Y., Yin, P., Gao, B., Fang, Y., Wu, P., Liu, T., and Lou, Z. (2014). HERC2-USP20 axis regulates DNA damage checkpoint through Claspin. Nucleic acids research 42, 13110-13121. 
Zhang, J., Song, Y.H., Brannigan, B.W., Wahrer, D.C., Schiripo, T.A., Harris, P.L., Haserlat, S.M., Ulkus, L.E., Shannon, K.M., Garber, J.E., et al. (2009). Prevalence and functional analysis of sequence variants in the ATR checkpoint mediator Claspin. Molecular cancer research : MCR 7, 1510-1516.

Zhao, B., Barrera, L.A., Ersing, I., Willox, B., Schmidt, S.C., Greenfeld, H., Zhou, H., Mollo, S.B., Shi, T.T., Takasaki, K., et al. (2014). The NF-kappaB genomic landscape in lymphoblastoid B cells. Cell Rep 8, 1595-1606.

Zhu, M., Zhao, H., Liao, J., and Xu, X. (2014). HERC2/USP20 coordinates CHK1 activation by modulating CLASPIN stability. Nucleic acids research 42, 13074-13081. 
Hunter et al., Figure 1

A

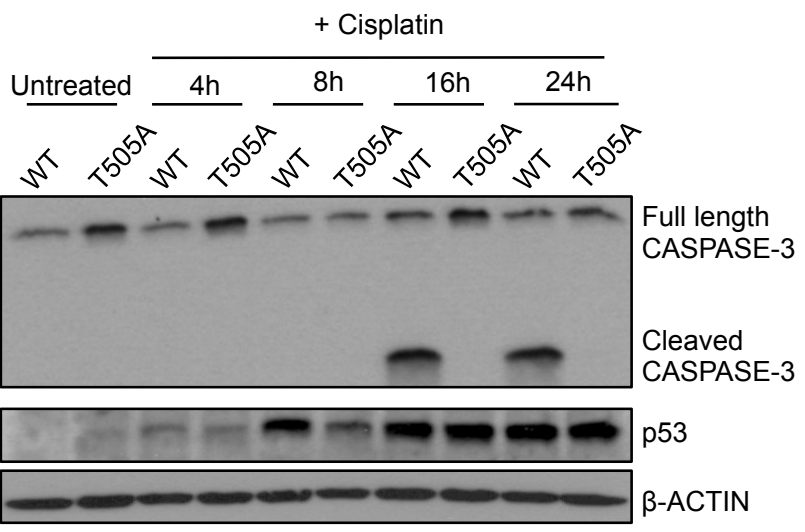

pMEFs

B

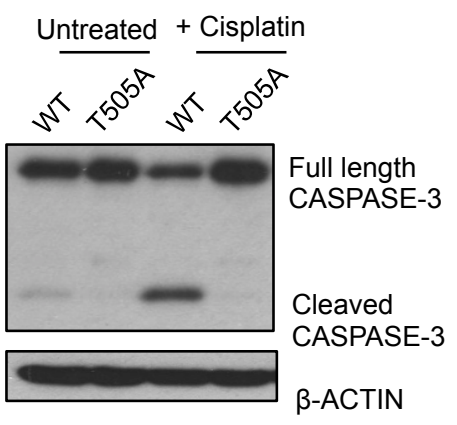

E

Clonogenic survival (MEFs)

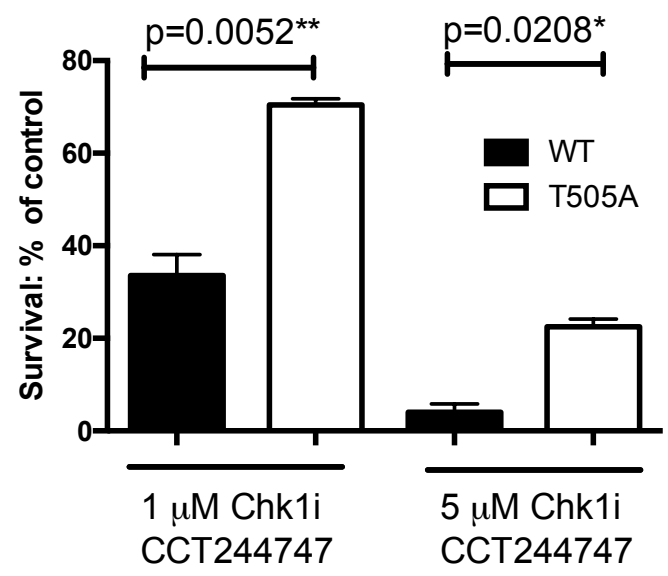

C

MEFs

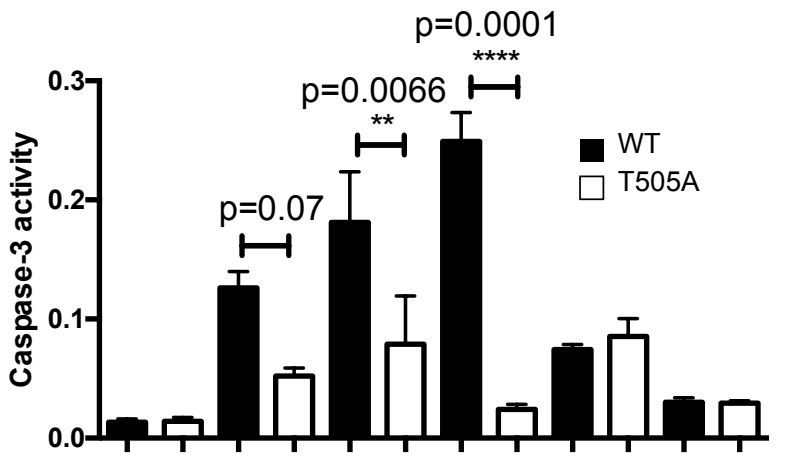

Cisplatin

Mitomycin C

Hydroxyurea

Etoposide SN38

D

Cell viability - MEFs

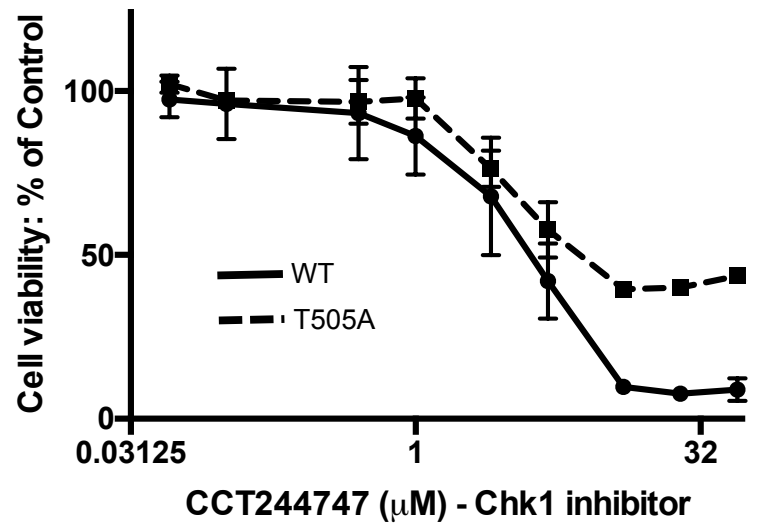


Hunter et al., Figure 2

A

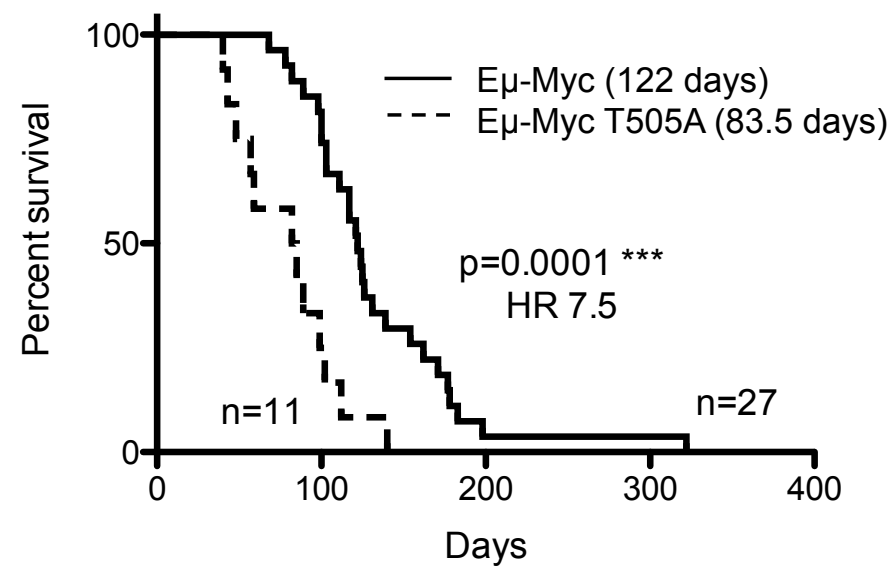

C
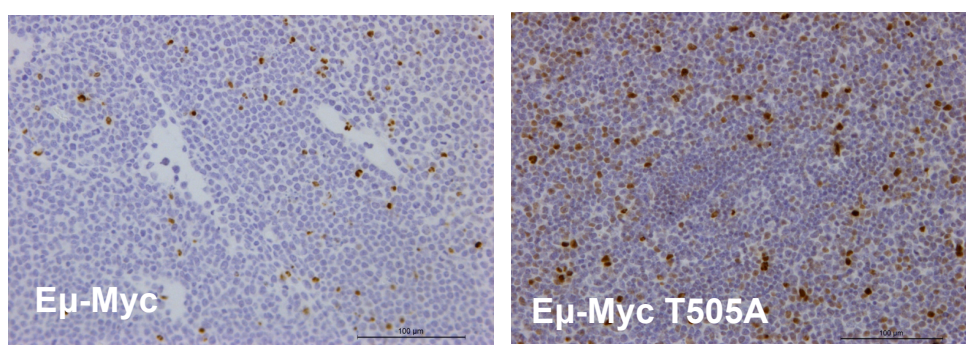

B

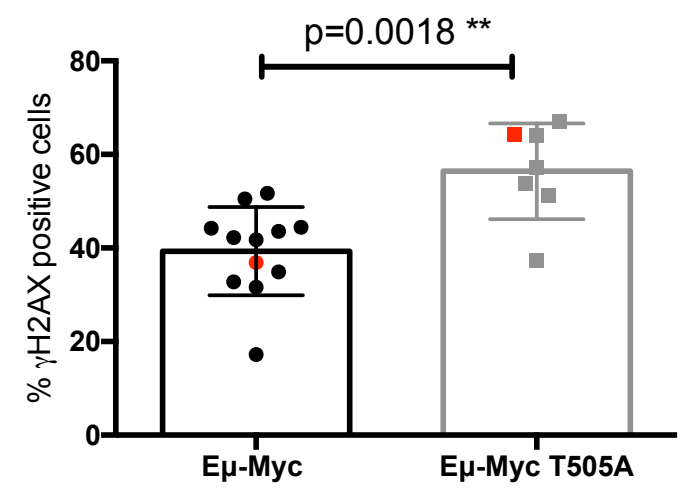

$\mathrm{IHC}$ analysis

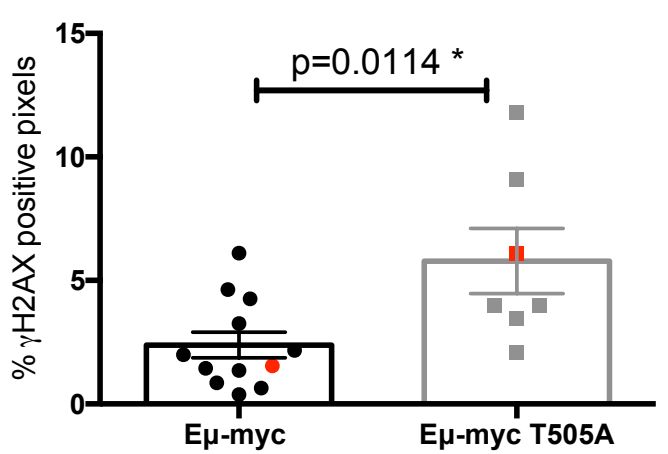

E

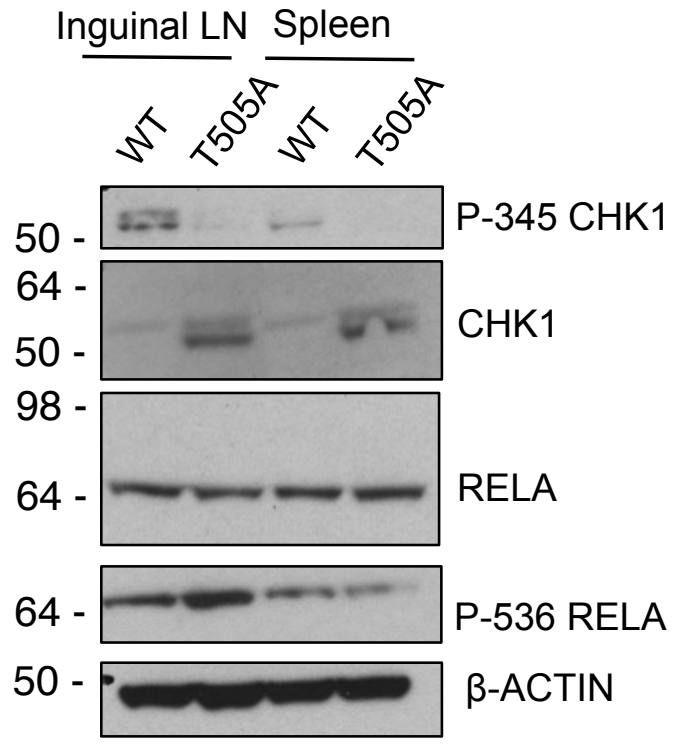

F

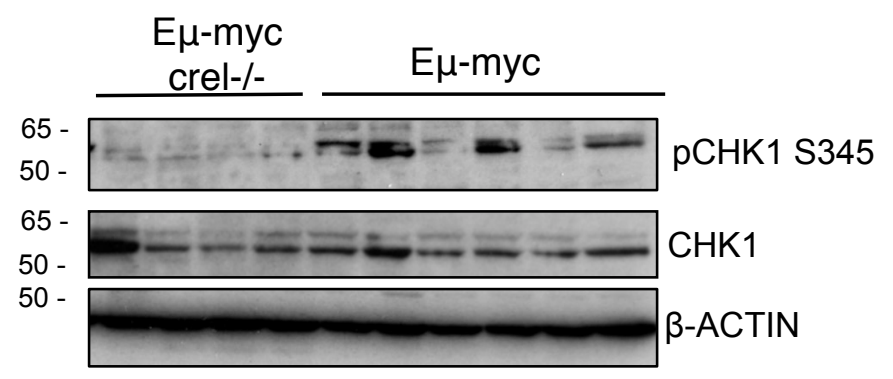




\section{Hunter et al., Figure 3}

A

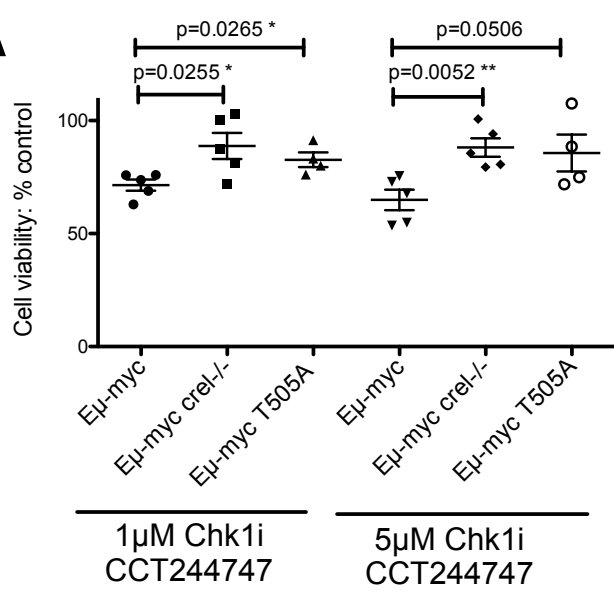

B

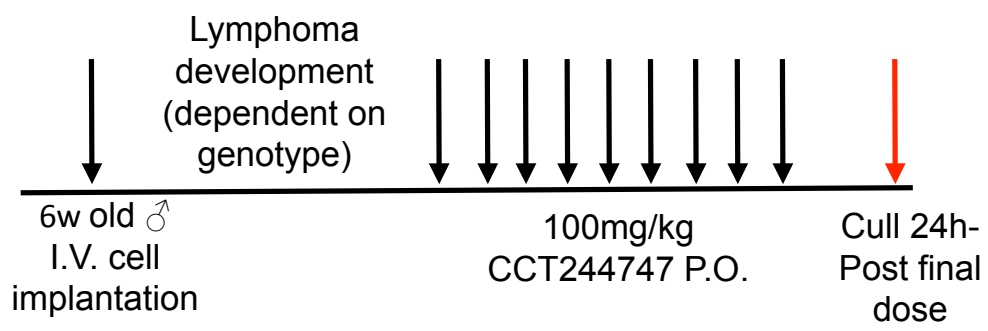

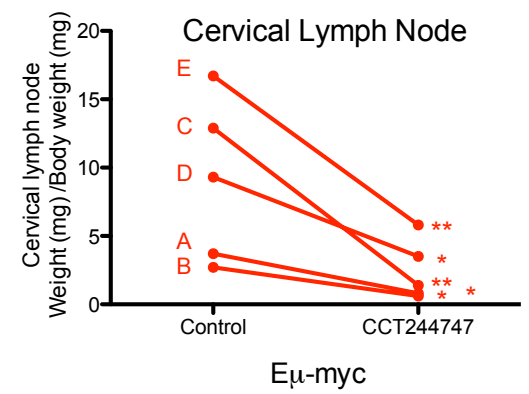

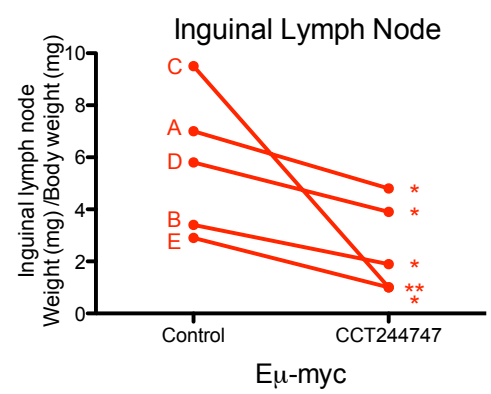

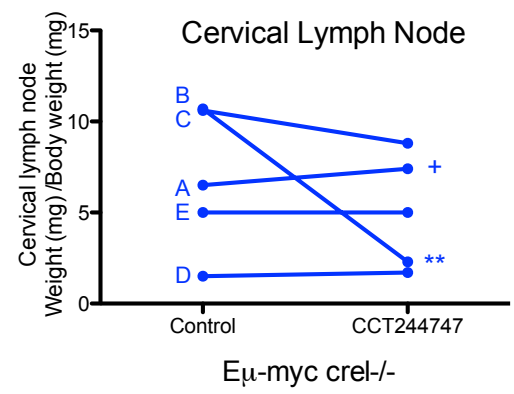

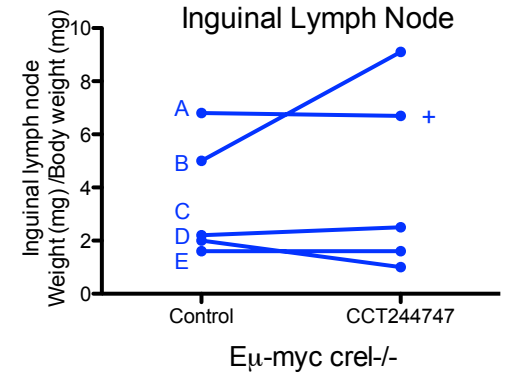

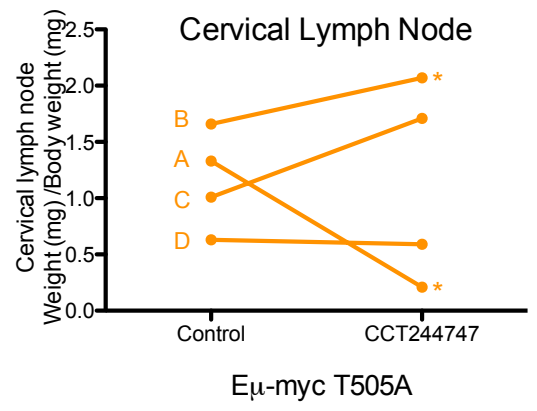

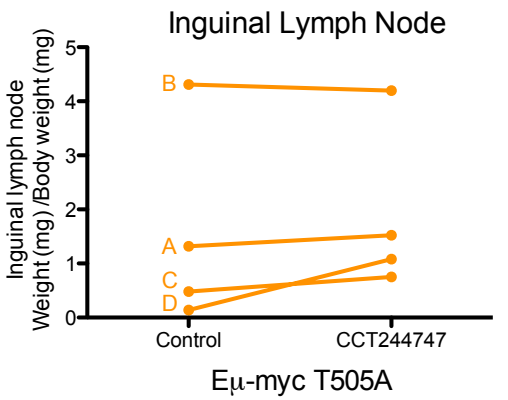

D

\begin{tabular}{|c|c|c|c|}
\hline & \multicolumn{3}{|c|}{ 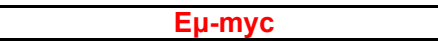 } \\
\hline Organ & $\begin{array}{l}\text { Decrease } \\
\text { tumour } \\
\text { burden }\end{array}$ & $\begin{array}{c}\text { No } \\
\text { response }\end{array}$ & $\begin{array}{l}\text { Increase } \\
\text { tumour } \\
\text { burden }\end{array}$ \\
\hline Inguinal LN & $5 / 5$ & $0 / 5$ & $0 / 5$ \\
\hline Brachial LN & $5 / 5$ & $0 / 5$ & $0 / 5$ \\
\hline $\begin{array}{c}\text { Mesenteric } \\
\text { LN }\end{array}$ & $5 / 5$ & $0 / 5$ & $0 / 5$ \\
\hline Spleen & $0 / 5$ & $4 / 5$ & $1 / 5$ \\
\hline Thymus & $5 / 5$ & $0 / 5$ & $0 / 5$ \\
\hline Cervical LN & $5 / 5$ & $0 / 5$ & $0 / 5$ \\
\hline & \multicolumn{3}{|c|}{ E $\mu$-myc crel--/- } \\
\hline Inguinal LN & $0 / 5$ & $4 / 5$ & $1 / 5$ \\
\hline Brachial LN & $0 / 5$ & $4 / 5$ & $1 / 5$ \\
\hline $\begin{array}{c}\text { Mesenteric } \\
\text { LN }\end{array}$ & $0 / 5$ & $5 / 5$ & $0 / 5$ \\
\hline Spleen & $1 / 5$ & $4 / 5$ & $0 / 5$ \\
\hline Thymus & $1 / 5$ & $4 / 5$ & $0 / 5$ \\
\hline Cervical LN & $1 / 5$ & $4 / 5$ & $0 / 5$ \\
\hline & \multicolumn{3}{|c|}{ Eц-myс T505A } \\
\hline Inguinal LN & $0 / 4$ & $4 / 4$ & $0 / 4$ \\
\hline Brachial LN & $0 / 4$ & $4 / 4$ & $0 / 4$ \\
\hline $\begin{array}{c}\text { Mesenteric } \\
\text { LN }\end{array}$ & $0 / 4$ & $4 / 4$ & $0 / 4$ \\
\hline Spleen & $0 / 4$ & $4 / 4$ & $0 / 4$ \\
\hline Thymus & $1 / 4$ & $3 / 4$ & $0 / 4$ \\
\hline Cervical LN & $1 / 4$ & $2 / 4$ & $1 / 4$ \\
\hline
\end{tabular}


Hunter et al., Figure 4

A

DNA damage/

Replication stress

TopBP1

\section{ATR}

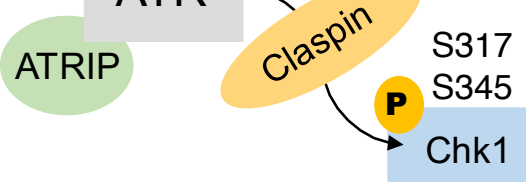

B

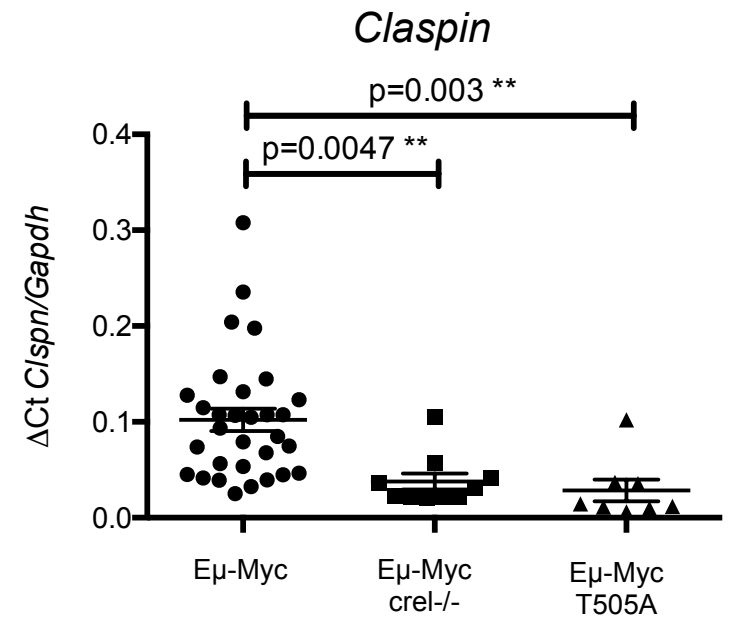

C
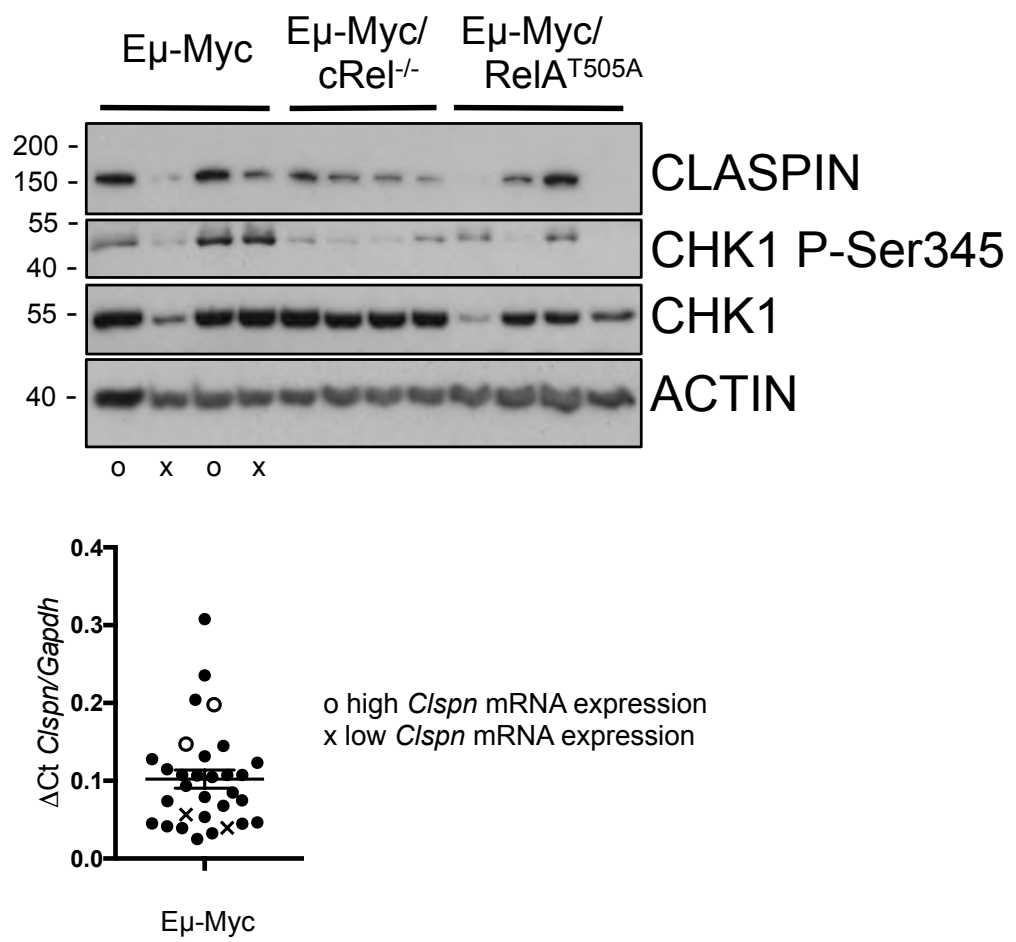


\section{Hunter et al., Figure 5}

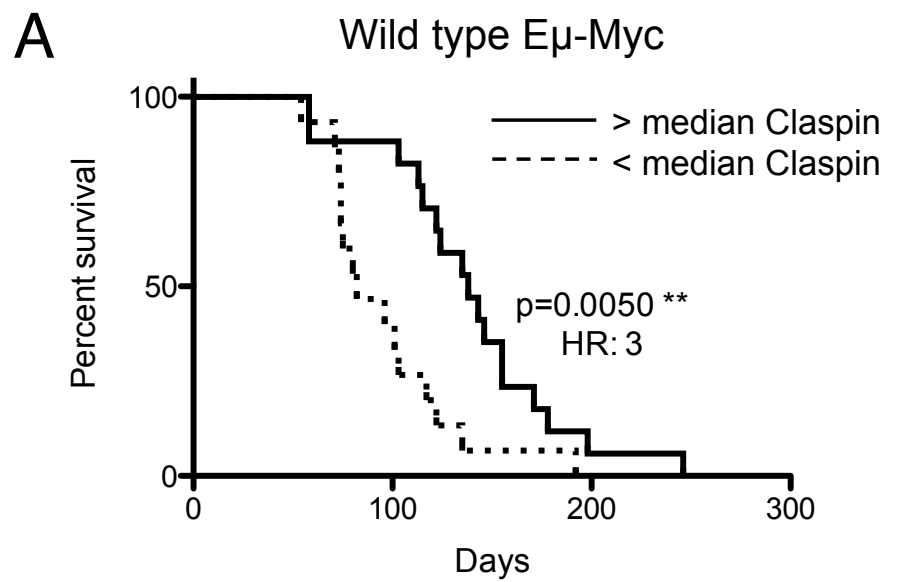

\begin{tabular}{|c|c|}
\hline Cohort & $\begin{array}{l}\text { Median } \\
\text { survival }\end{array}$ \\
\hline $\mathrm{E} \mu$-myc $>$ median & 138 days \\
\hline E $\mu$-myc <median & 82 days \\
\hline Eu-myc crel-/- & 79 days \\
\hline 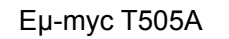 & 83.5 days \\
\hline
\end{tabular}

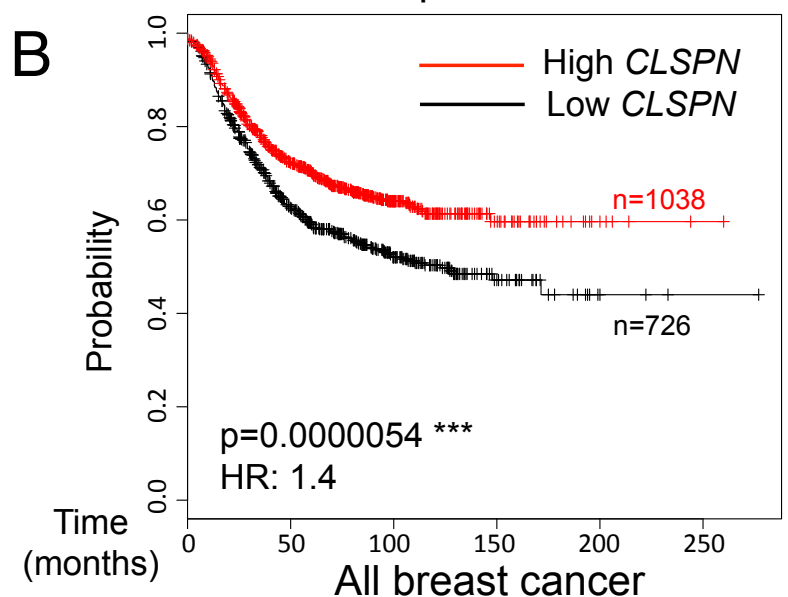

C
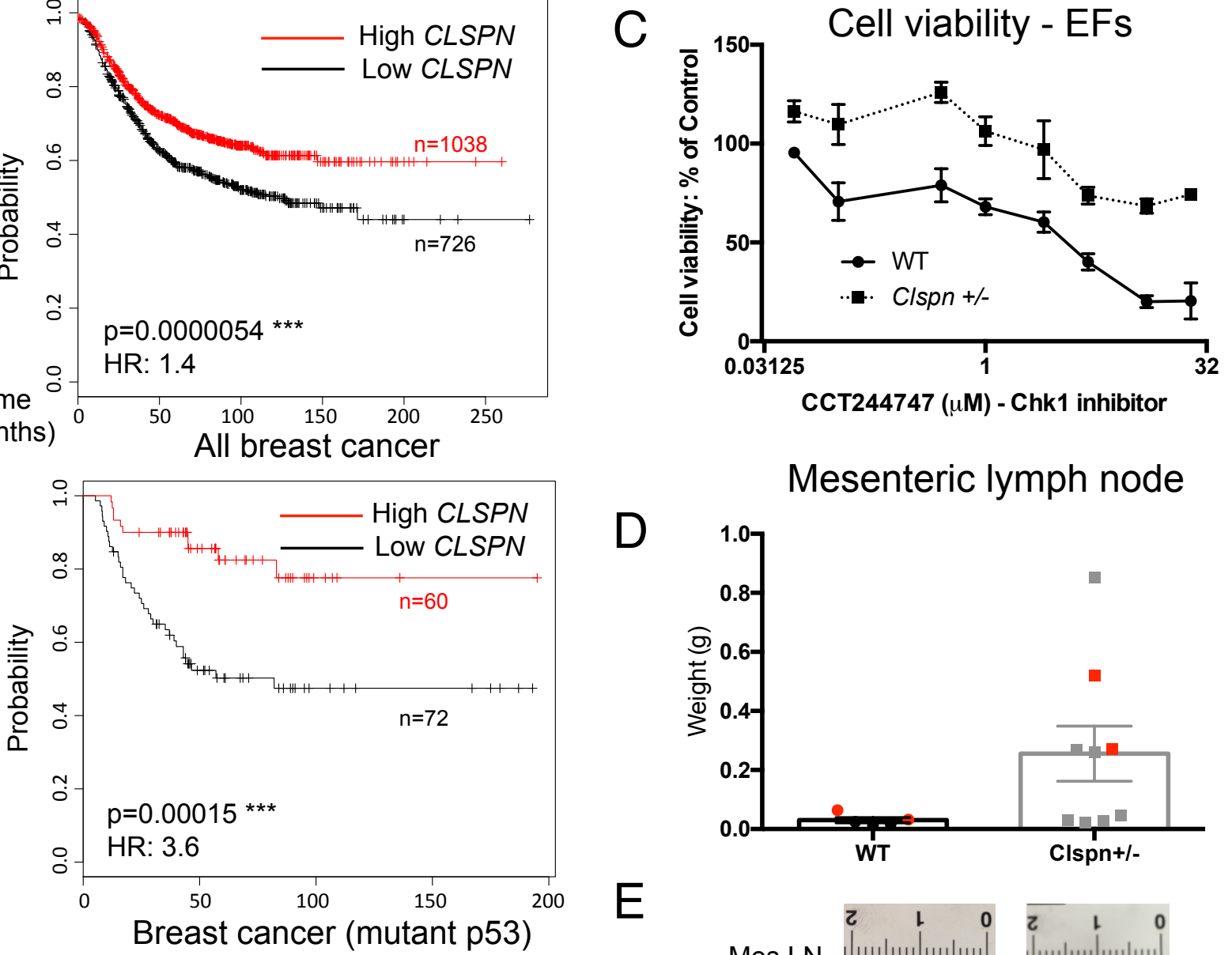

Mesenteric lymph node

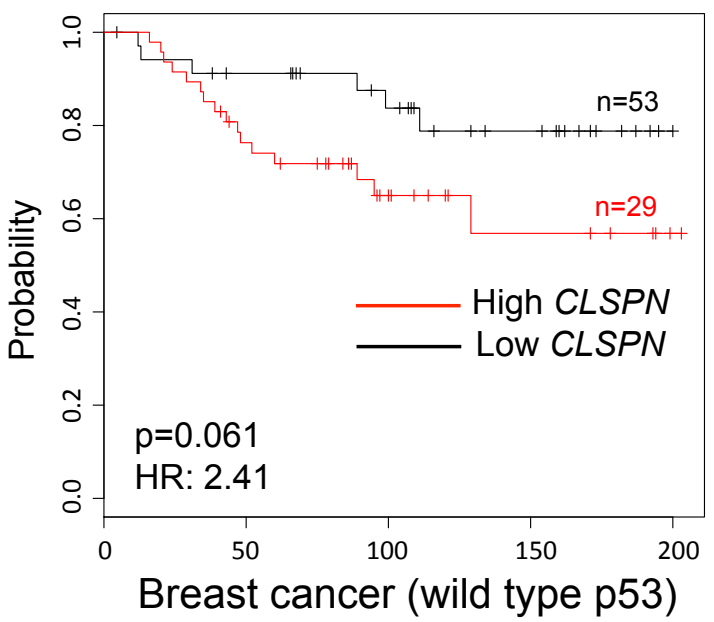

D

E

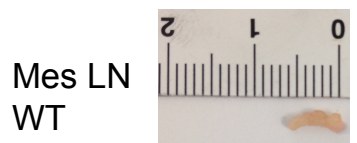

Mes LN

Clspn+/-

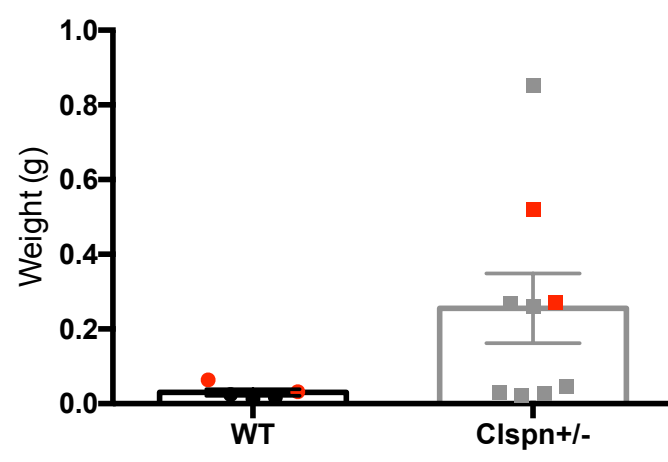

F
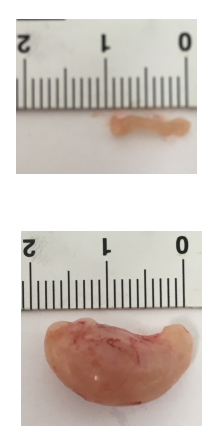
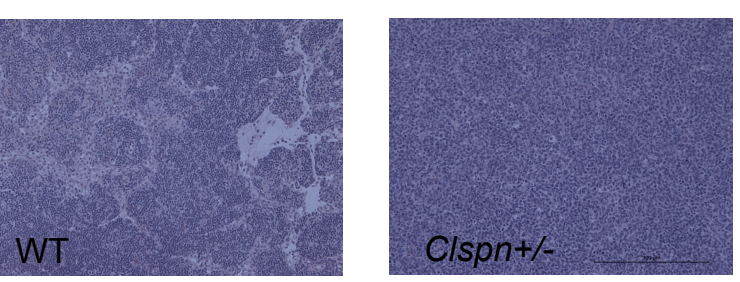
Hunter et al., Figure 6

A

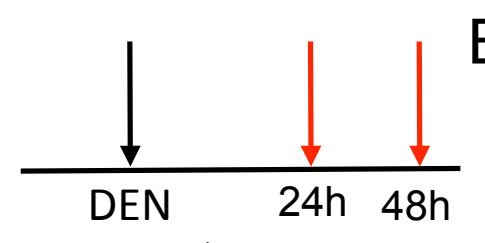

B

\section{Claspin}

$8 \mathrm{w}$ old $\widehat{O}$

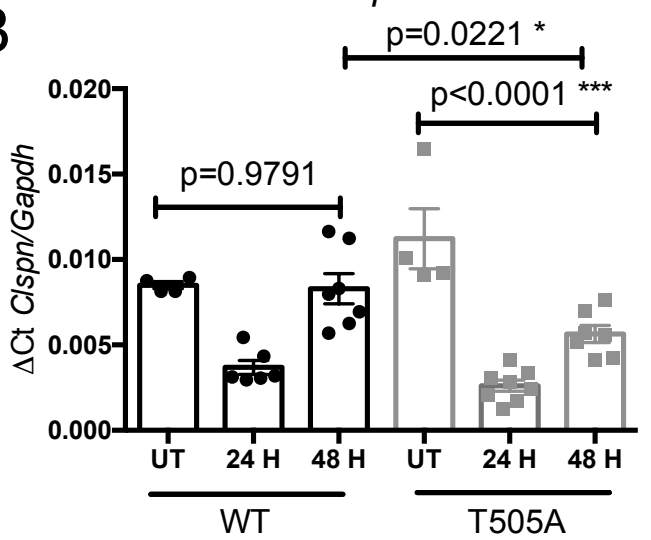

C
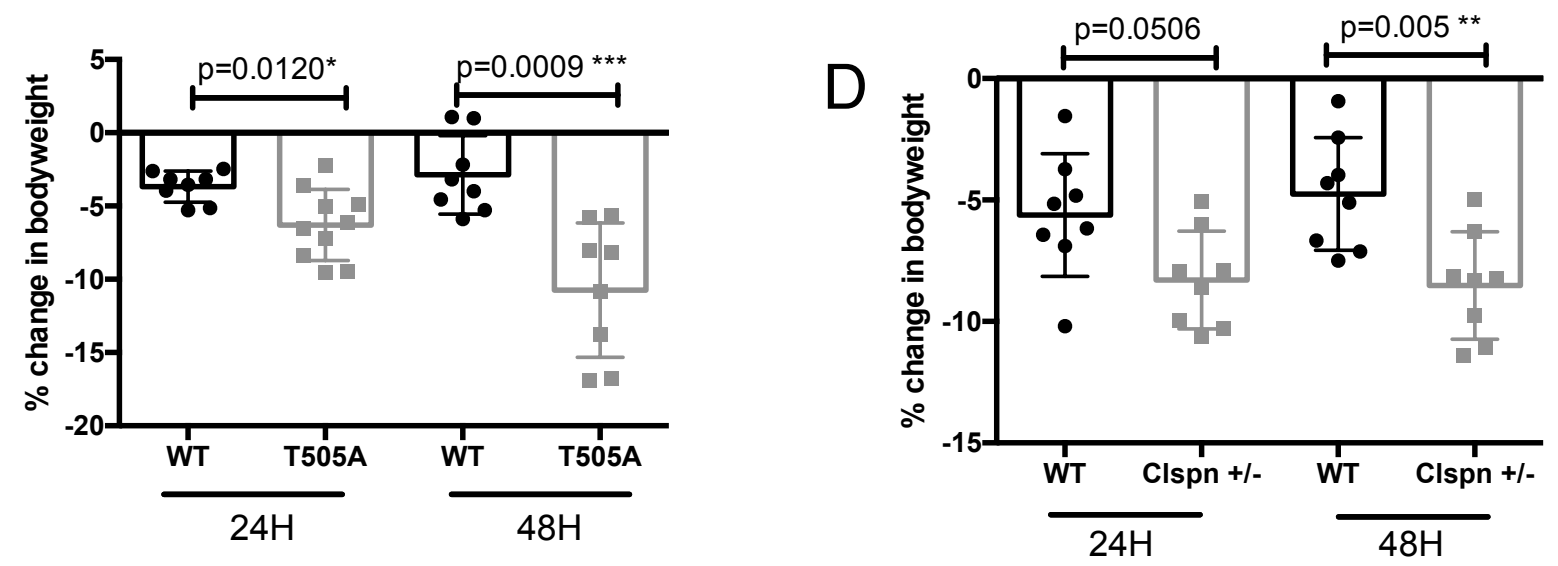

E

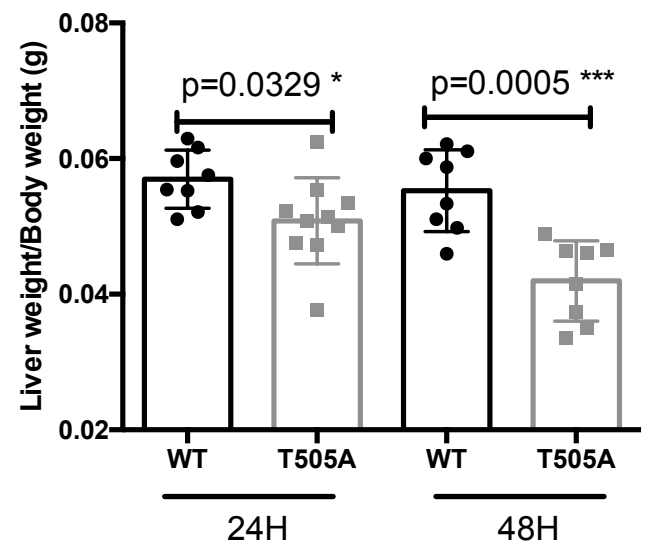

F

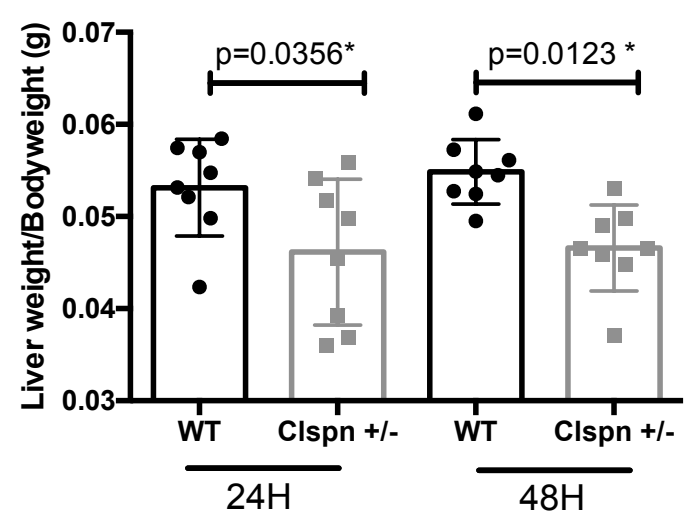

G

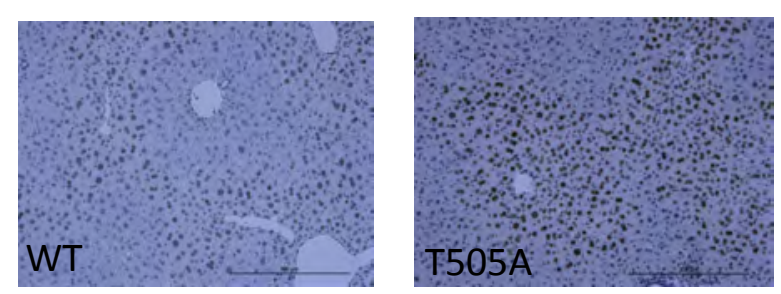

$\mathrm{H}$
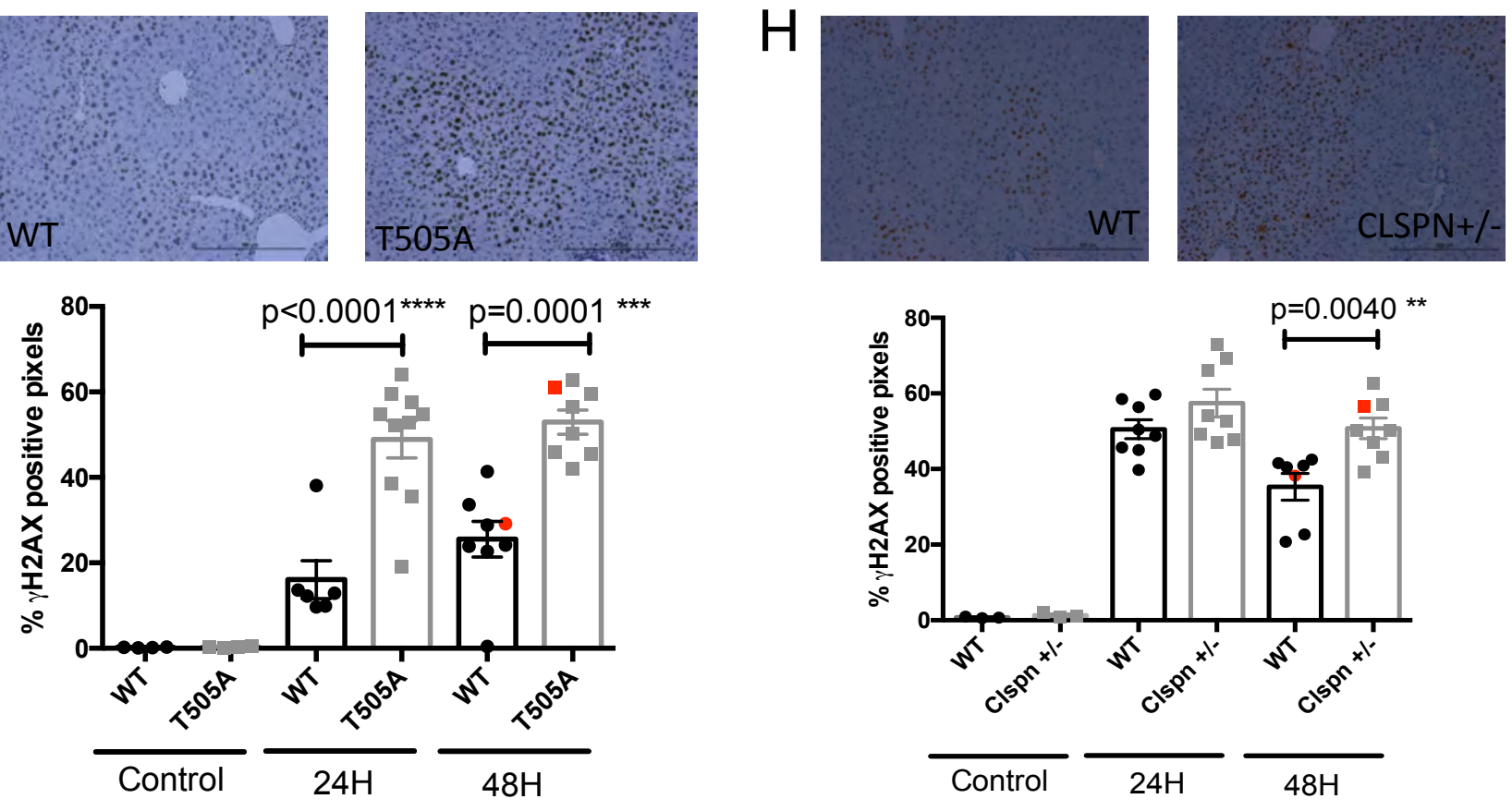
Hunter et al., Figure 7

A

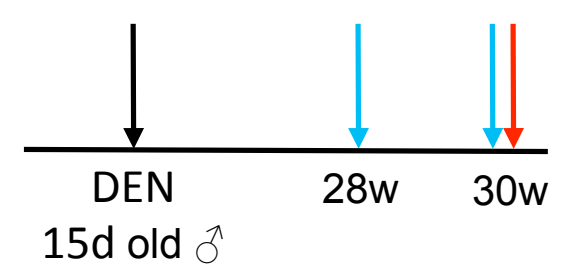

B
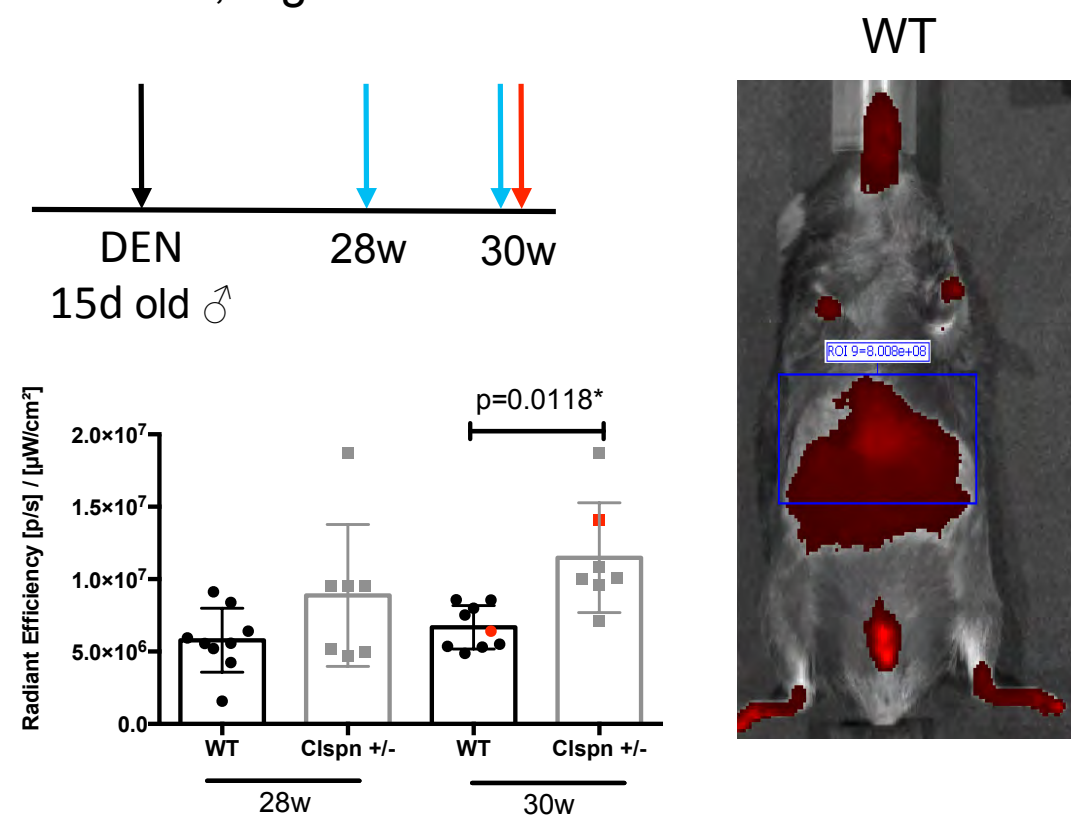

Clspn+/-

C
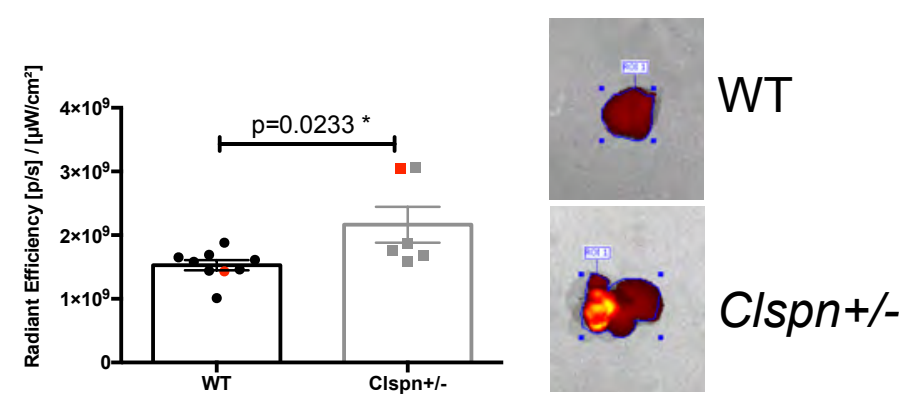

D

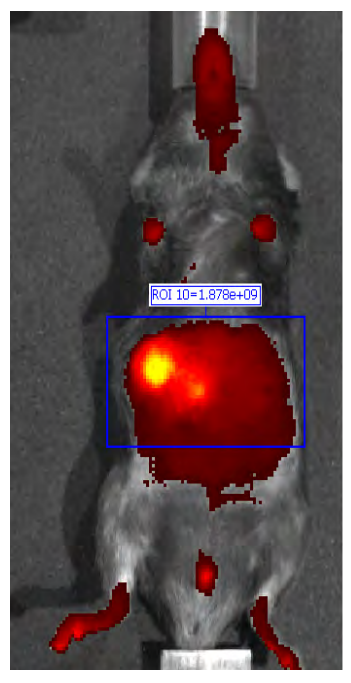

$E$

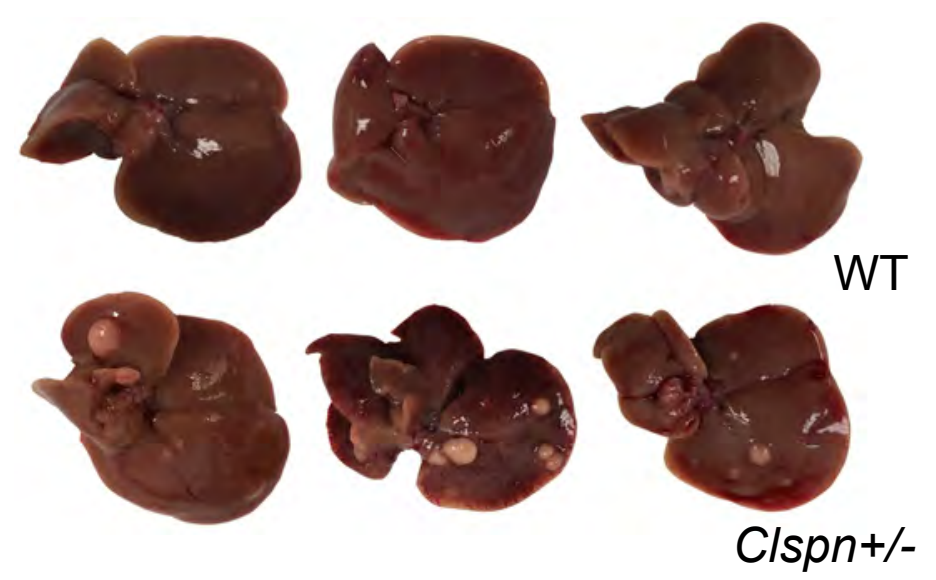

F

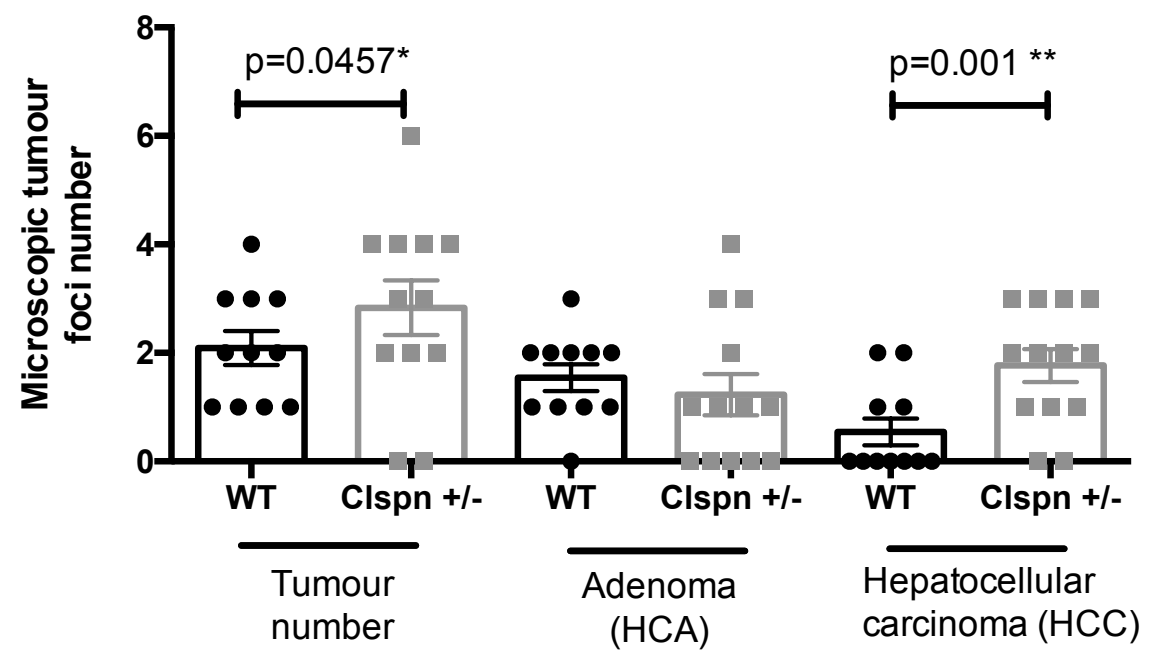


Hunter et al., Figure 8

\section{Cancer cells}

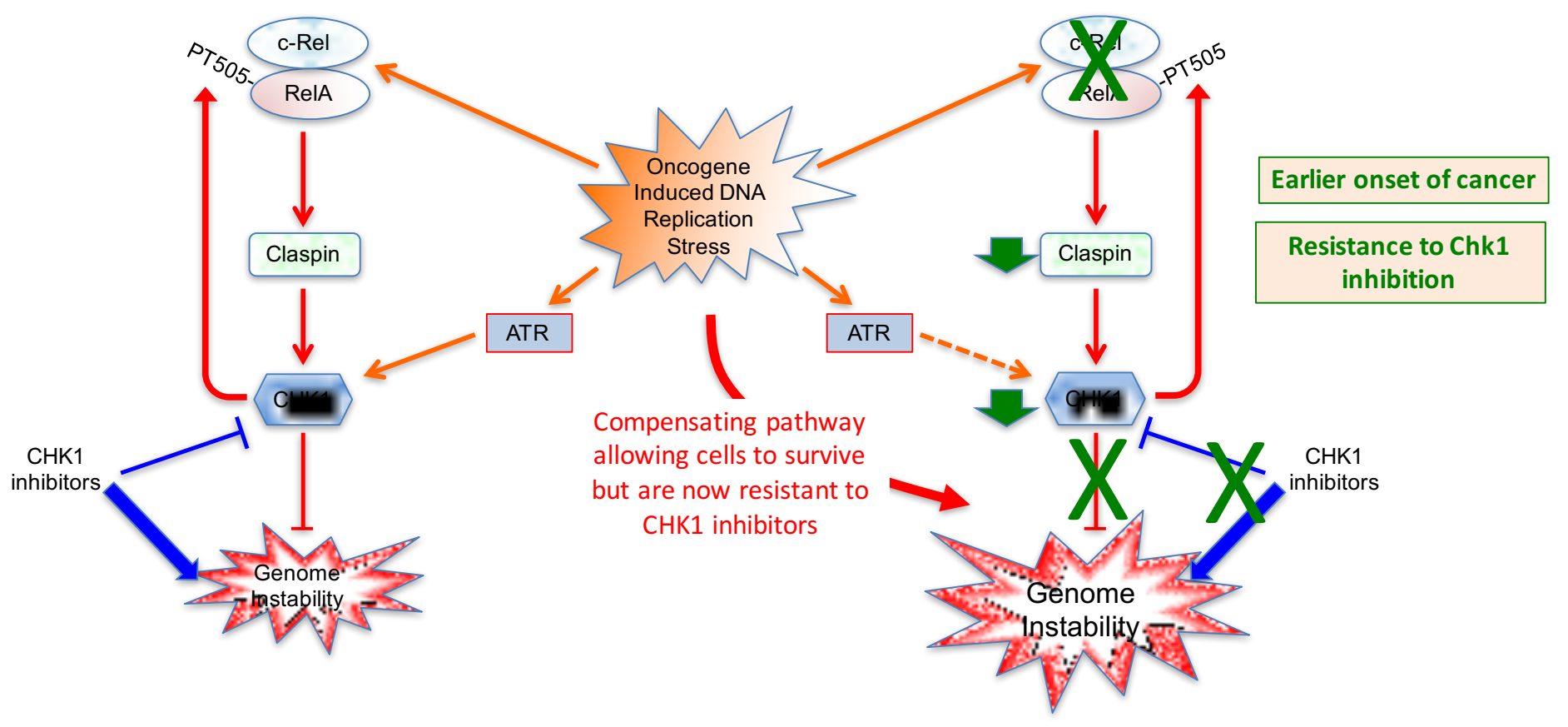




\section{Supplementary Table 1}

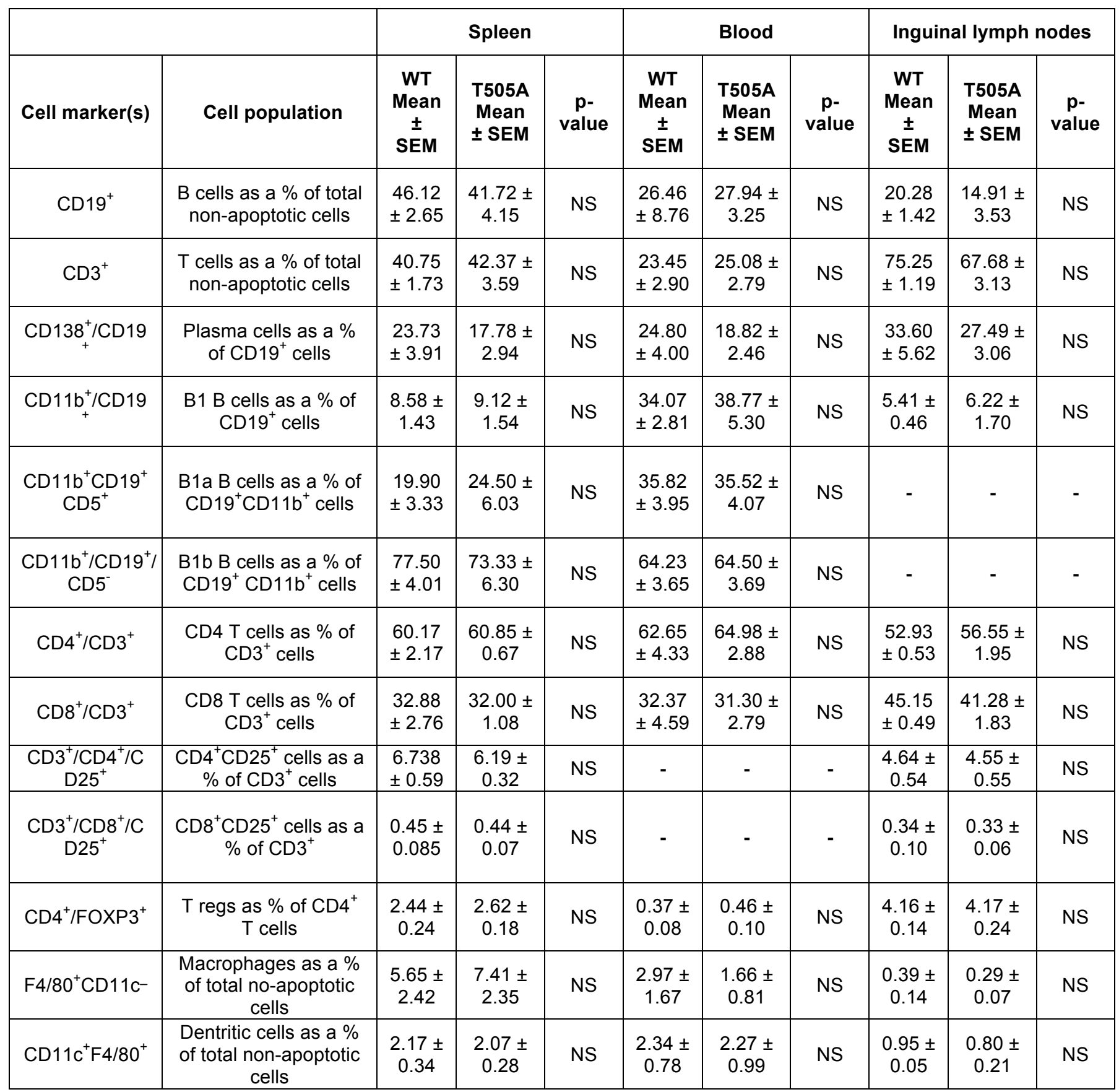

Table S1. Flow cytometric analysis of spleen, blood and inguinal lymph node cell populations of $6 \times$ WT and $6 \times$ T505A 12 week old male littermates. Peritoneal fluid control data is not shown. Data analysed using a two-tailed Students t-test. 


\begin{tabular}{|c|c|c|c|}
\hline \multicolumn{4}{|c|}{ Summary of CLSPN expression and cancer survival data (Human Protein Atlas, TCGA) } \\
\hline Tumour type & $\begin{array}{l}\text { CLSPN levels associated } \\
\text { with worse survival }\end{array}$ & $\begin{array}{l}\text { 5year survival low } \\
\text { CLSPN }\end{array}$ & $\begin{array}{l}5 \text { year survival } \\
\text { high CLSPN }\end{array}$ \\
\hline Glioma & No effect $(p=9.61 e-2)$ & NA & NA \\
\hline Thyroid & No effect $(p=1.73 e-1)$ & NA & NA \\
\hline Lung (total) & High $(p=3.99 e-3)$ & $47 \%$ & $44 \%$ \\
\hline Adenocarcinoma & High $(p=8.53 e-4)$ & $55 \%$ & $34 \%$ \\
\hline Squamous & No effect $(p=5.18 e-1)$ & NA & NA \\
\hline Liver & High $(p=1.18 \mathrm{e}-6)$ & $51 \%$ & $31 \%$ \\
\hline Pancreatic & $\operatorname{High}(p=8.71 e-6)$ & $48 \%$ & $0 \%$ \\
\hline Head and Neck & Low $(p=1.62 e-2)$ & $39 \%$ & $49 \%$ \\
\hline Stomach & Low $(p=4.92 e-4)$ & $30 \%$ & $45 \%$ \\
\hline Colorectal (total) & Low $(p=9.64 e-3)$ & $48 \%$ & $68 \%$ \\
\hline Colon & No effect $(p=9.66 \mathrm{e}-2)$ & NA & NA \\
\hline Rectum & Low $(2.53 e-3)$ & $0 \%$ & $70 \%$ \\
\hline Urothelial & No effect $(p=1.29 \mathrm{e}-1)$ & NA & NA \\
\hline Renal & High $(p=7.61 e-6)$ & $74 \%$ & $49 \%$ \\
\hline Prostate & High $(p=3.23 e-2)$ & $99 \%$ & $96 \%$ \\
\hline Breast & High $(p=4.75 e-2)$ & $88 \%$ & $80 \%$ \\
\hline Cervical & No effect $(p=1.01 e-1)$ & NA & NA \\
\hline Ovarian & Low $(p=1.63 e-2)$ & $26 \%$ & $36 \%$ \\
\hline Endometrial & High $(p=3.54 e-2)$ & $81 \%$ & $74 \%$ \\
\hline Melanoma & High $(p=2.08 e-3)$ & $58 \%$ (3 year) & $0 \%$ (3 year) \\
\hline
\end{tabular}

\begin{tabular}{|c|c|c|c|}
\hline \multicolumn{4}{|c|}{ Summary of CLSPN expression and cancer survival data (kmplot.com) } \\
\hline Tumour type & $\begin{array}{l}\text { CLSPN levels associated } \\
\text { with worse survival }\end{array}$ & $\begin{array}{l}\text { Upper quartile } \\
\text { survival (months) } \\
\text { Low CLSPN }\end{array}$ & $\begin{array}{l}\text { Upper quartile } \\
\text { survival (months) } \\
\text { High CLSPN }\end{array}$ \\
\hline Breast & Low $(p=5.4 e-6, H R=1.42)$ & 30 & 40.8 \\
\hline Mutant p53 & Low $(p=1.5 e-4, H R=3.57)$ & No data & No data \\
\hline Wild type p53 & High $(p=8.9 e-3, H R=2.94)$ & No data & No data \\
\hline ER positive & No effect $(p=1.5 e-1)$ & NA & NA \\
\hline ER negative & Low $(p=1.5 e-3, H R=1.64)$ & 22.37 & 36.44 \\
\hline HER2 positive & Low $(p=3.3 e-3, H R=2.63)$ & No data & No data \\
\hline HER2 negative & No effect $(p=3.3 e-1)$ & NA & NA \\
\hline Ovarian & High $(p=7.4 e-6, H R=1.57)$ & 19.98 & 12.23 \\
\hline Lung & High $(p=5.6 e-7, H R=1.58)$ & 89 & 42.38 \\
\hline Adenocarcinoma & High $(p=2.4 e-4, H R=1.62)$ & 117.33 & 61.3 \\
\hline Squamous & High $(p=5 e-2, H R=1.38)$ & 70 & 36.8 \\
\hline Gastric & Low $(4 \mathrm{e}-2, \mathrm{HR}=1.25)$ & 36.4 & 70.2 \\
\hline HER2 positive & No effect $(p=3.1 \mathrm{e}-1)$ & NA & NA \\
\hline HER2 negative & Low $(2.7 e-2, H R=1.35)$ & 36.4 & 79 \\
\hline Liver & High $(p=2.1 e-6, H R=2.26)$ & 71 & 27.9 \\
\hline
\end{tabular}

Table S2. Summary of CLSPN mRNA expression and cancer patient survival data. Data analysed from TCGA datasets at Human Protein Atlas (www.proteinatlas.org) and KM plotter (kmplot.com). All data presented was using best separation cutoff. No effect is defined as $p>0.05$. For kmplot, data obtained from microarray analysis is with Jetset best probe selected (apart from Liver data which was obtained by RNA Seq). 
Hunter et al., Supp Figure 1

A

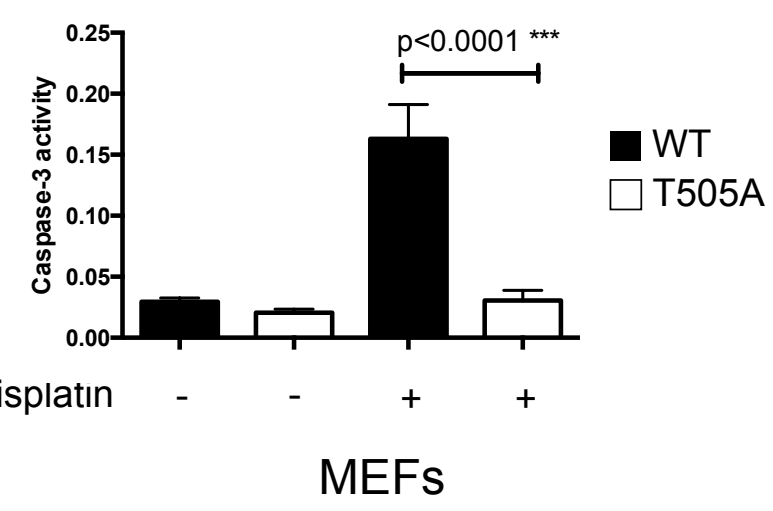

C Clonogenic survival (MEFs)

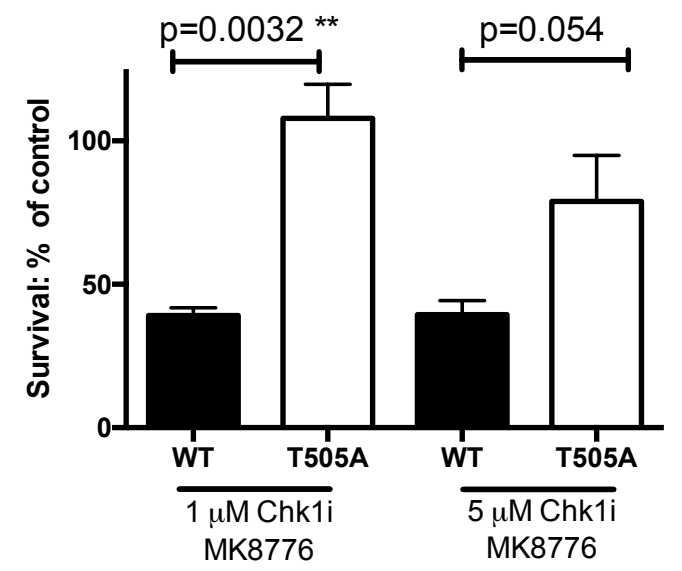

B

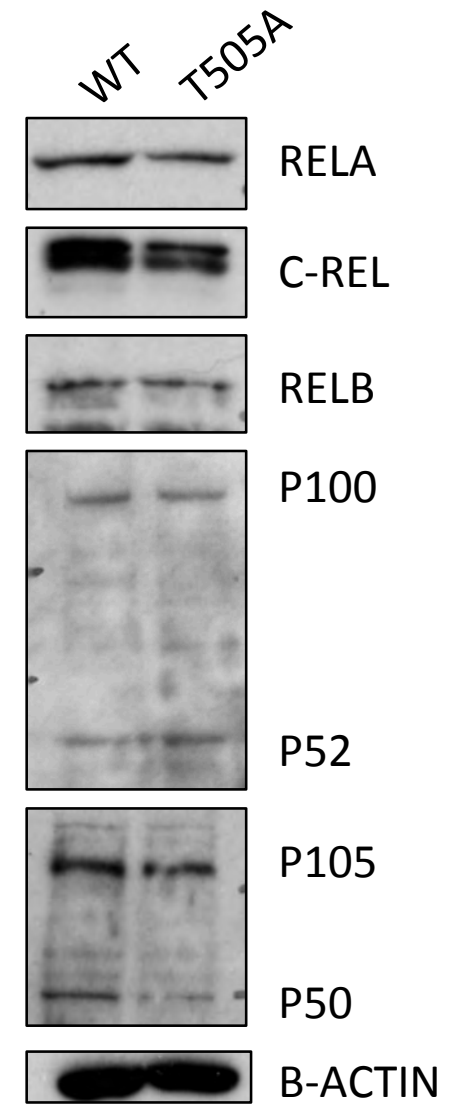

MEFs 
Hunter et al., Supp Figure 2

A

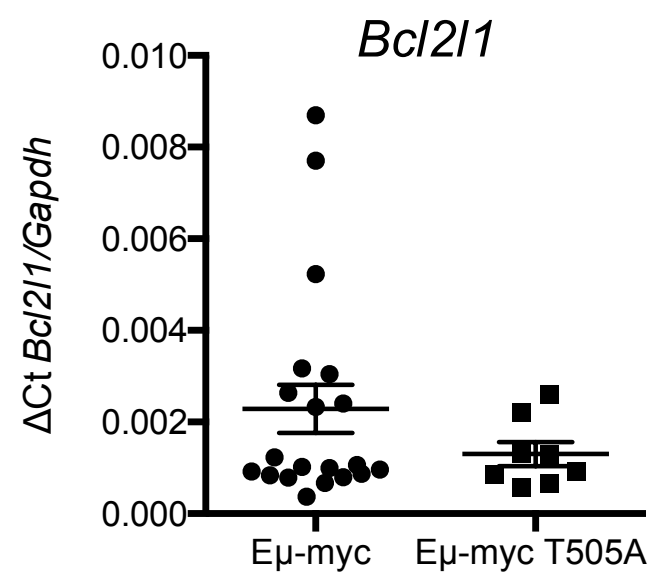

B

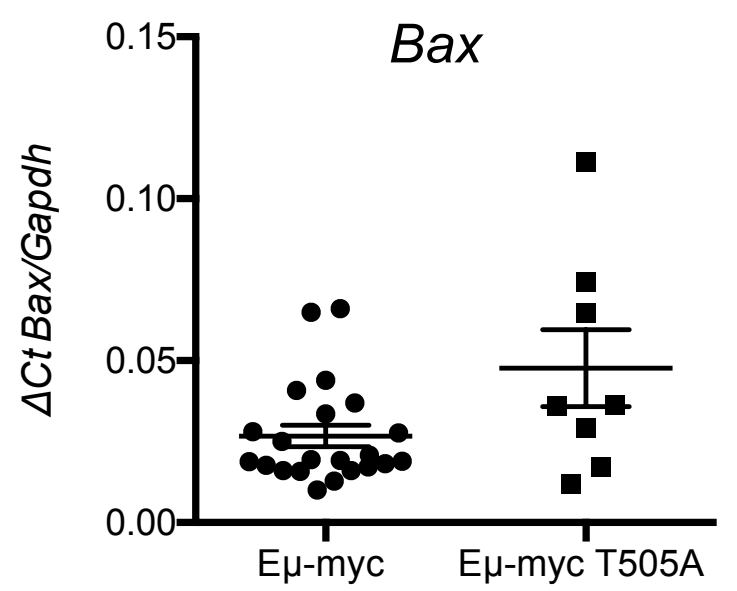

C

\begin{tabular}{|c|c|c|c|}
\hline \multirow{2}{*}{ Organ } & \multicolumn{2}{|c|}{ Mean cell count \pm SEM $\left(\mathbf{x} 10^{\circ}\right)$} & \multirow{2}{*}{-value } \\
\cline { 2 - 3 } & WT & T505A & \\
\hline Spleen & $46.00 \pm 3.425$ & $44.67 \pm 2.951$ & \multirow{2}{*}{ NS } \\
\hline Inguinallymph node & $2.367 \pm 0.2431$ & $3.133 \pm 0.4193$ & \\
\hline
\end{tabular}

D
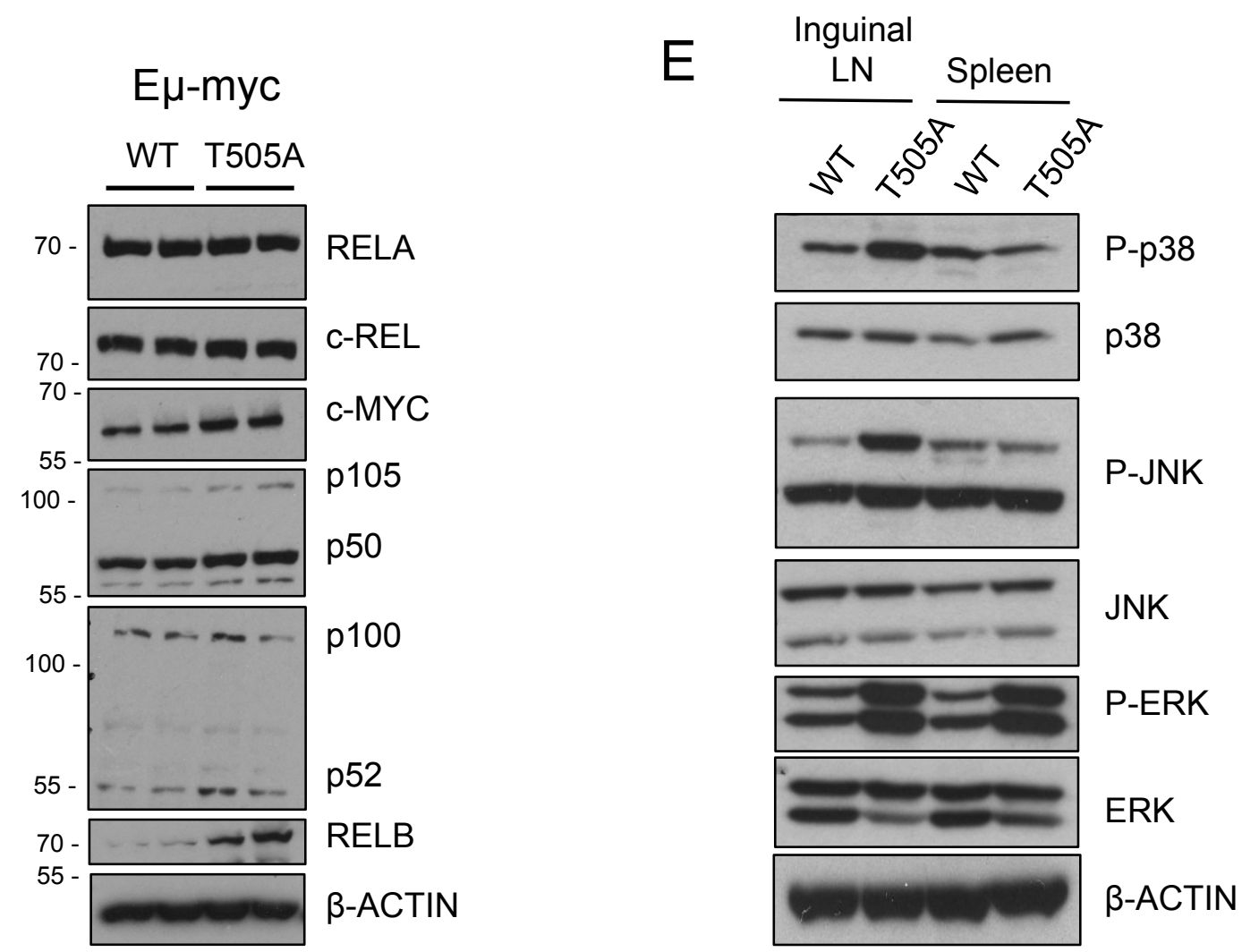
Hunter et al., Supp Figure 3

A

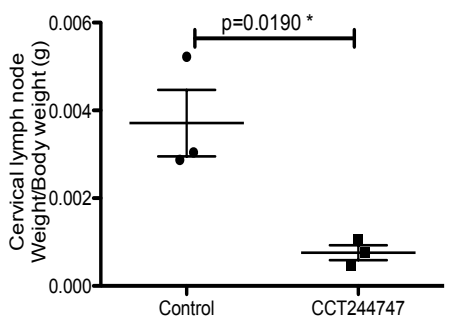

D

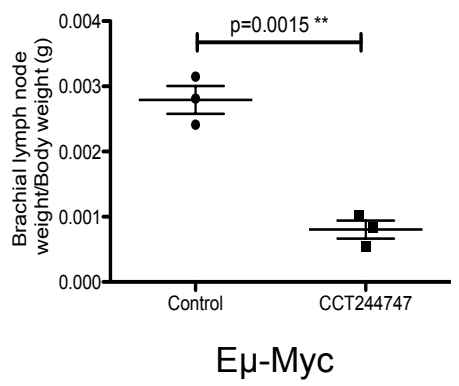

B

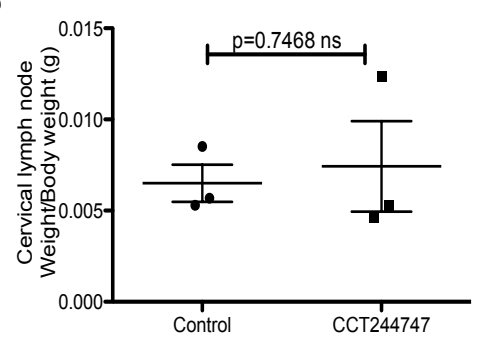

$E$

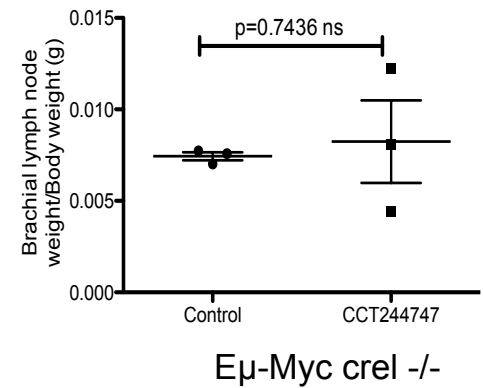

C

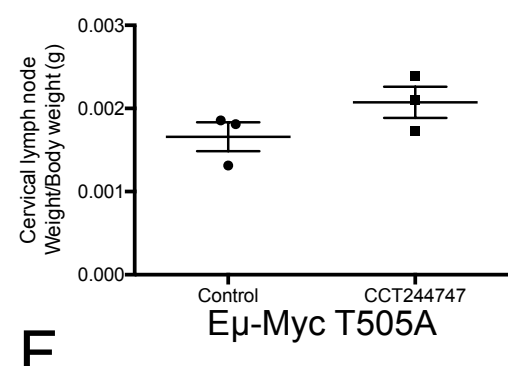

F

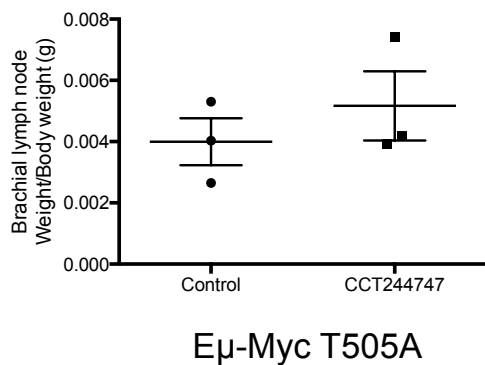



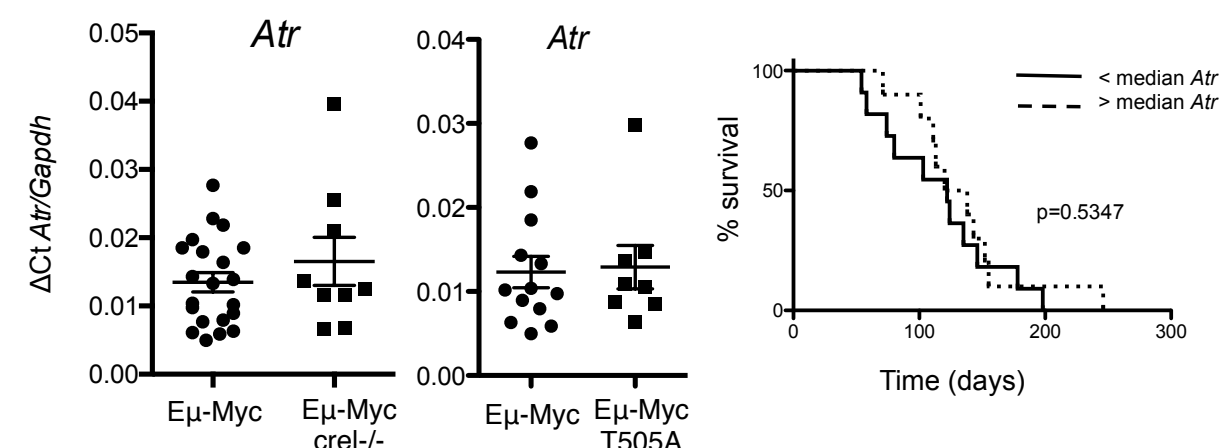

B
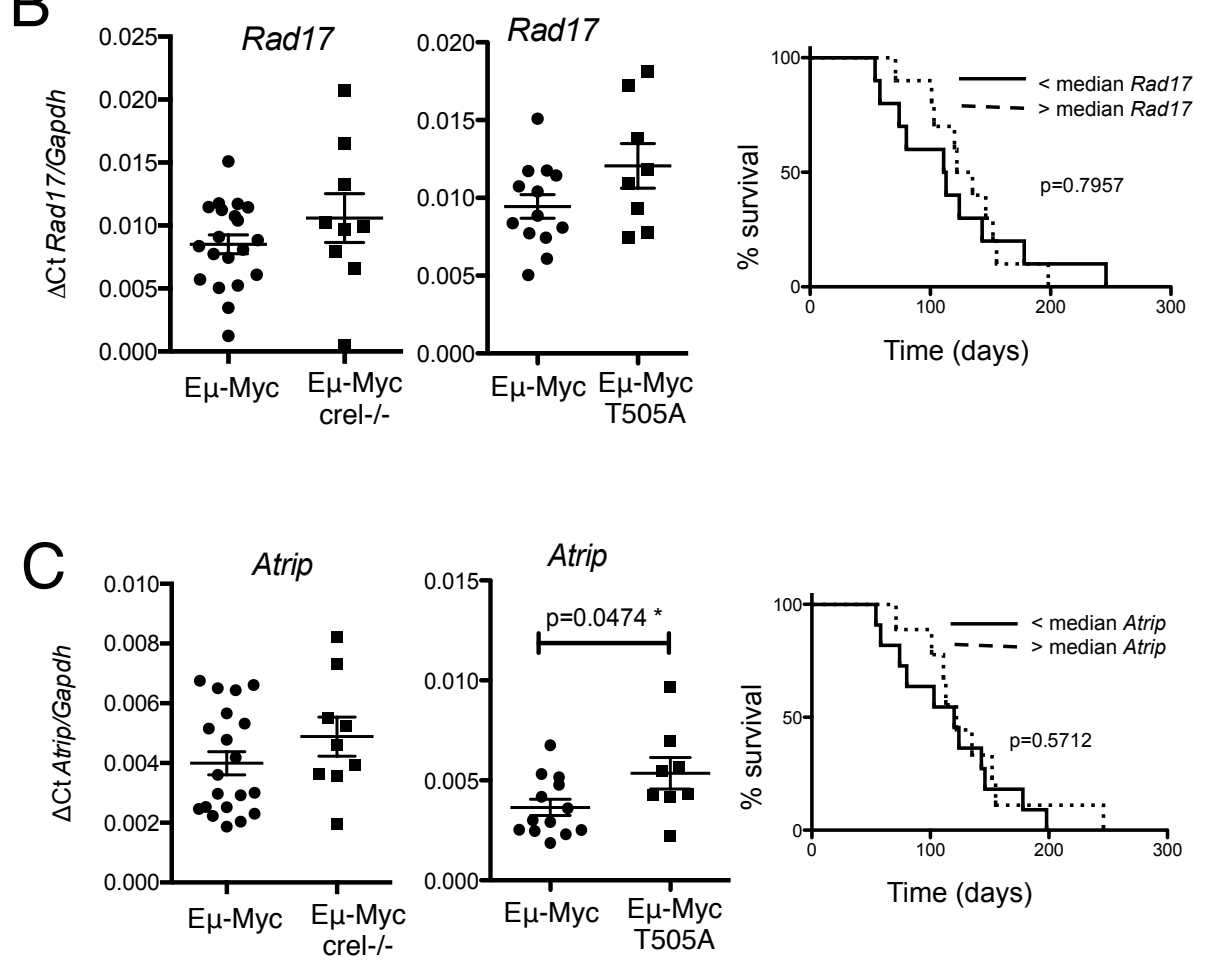

D
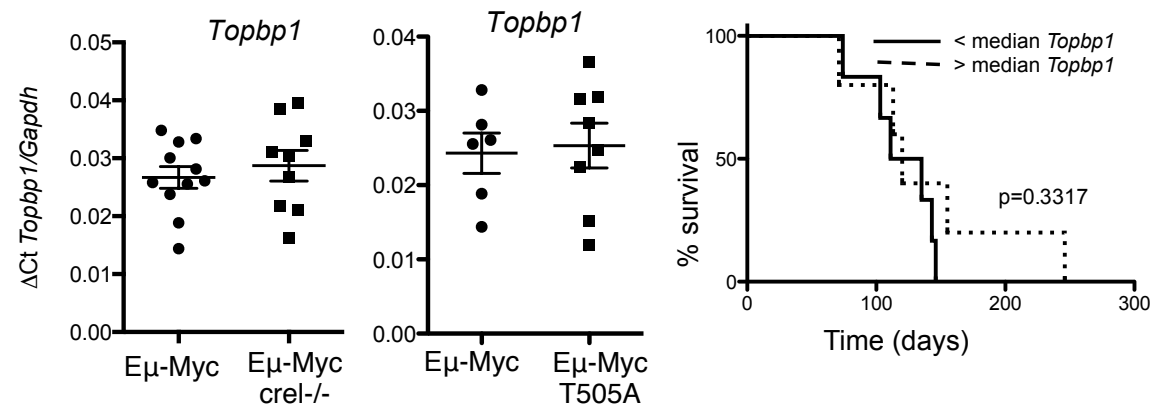

$E$
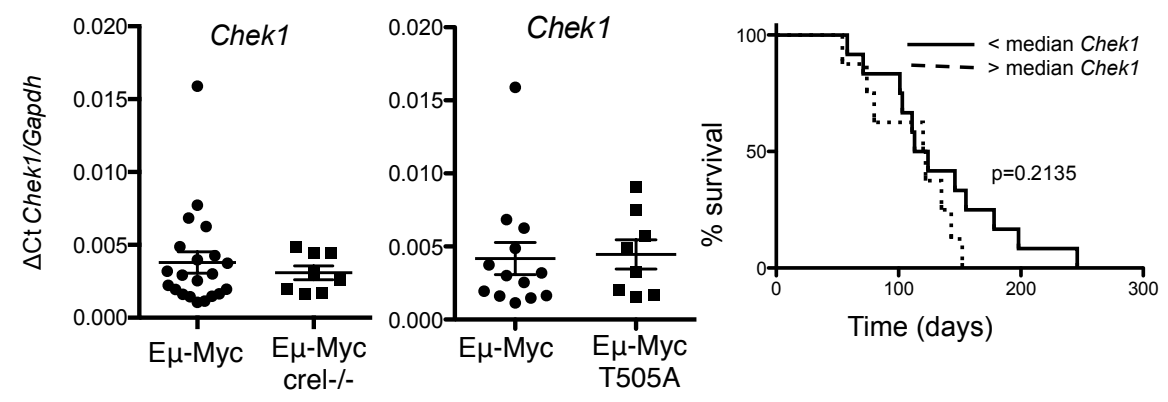
A

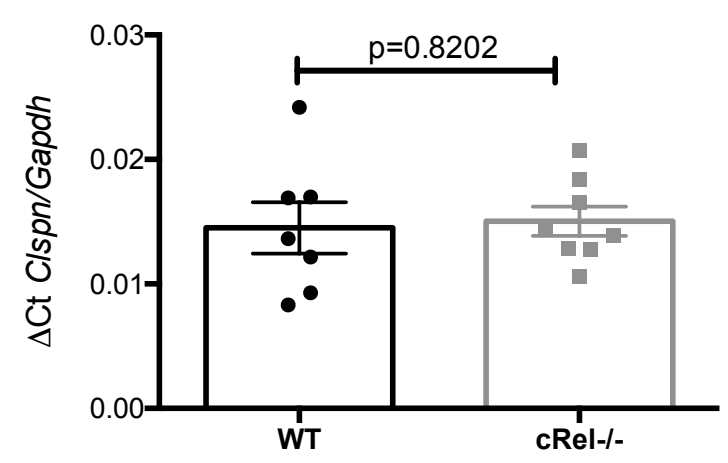

LCL cell line: GM12878

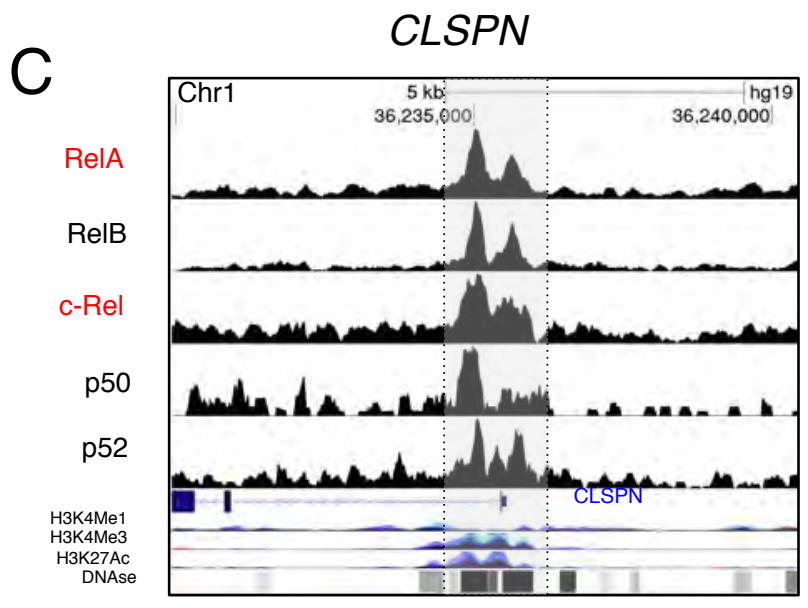

$E$

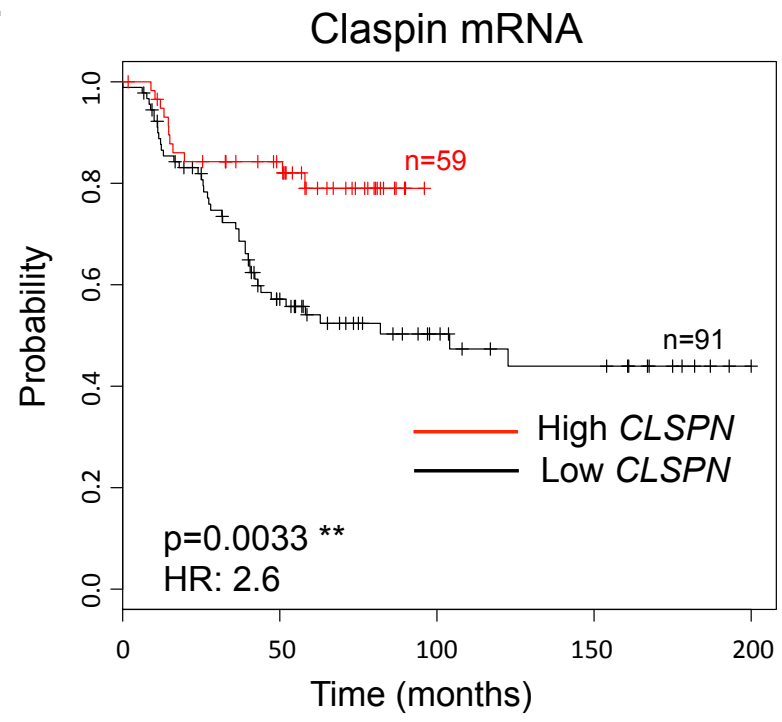

HER2 positive breast cancer
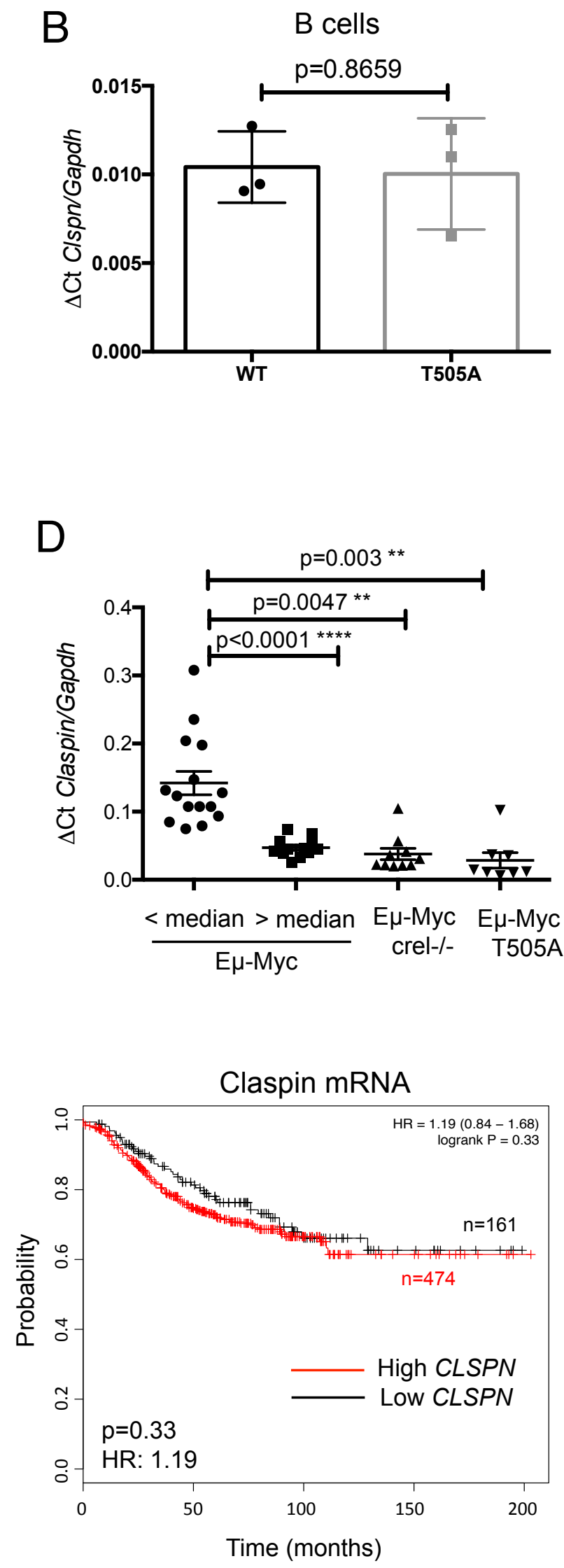

HER2 negative breast cancer 
Hunter et al., Supp Figure 6

A

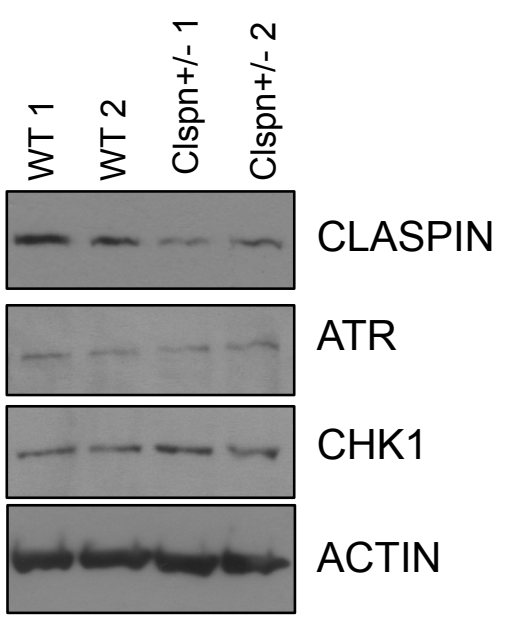

B

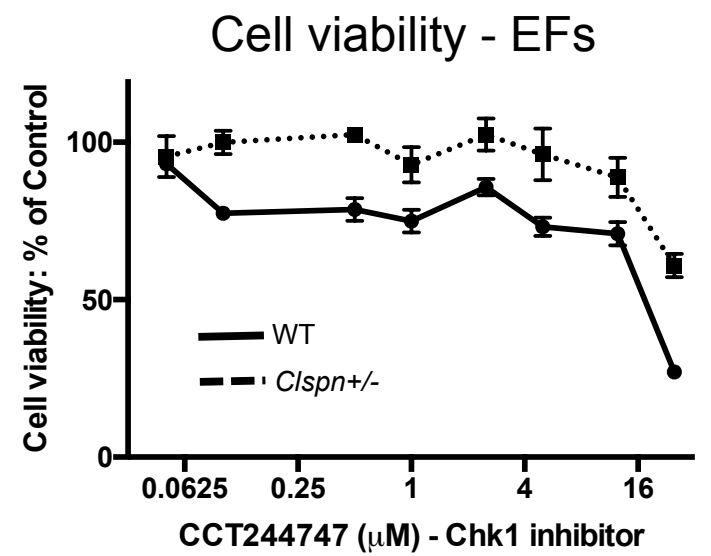

C

\begin{tabular}{|l|c|c|c|c|c|c|c|c|c|c|c|c|c|c|}
\hline \multirow{2}{*}{ SITE } & \multicolumn{10}{c|}{ WT } & \multicolumn{10}{|c|}{ TMOUR INCIDENCE } \\
\cline { 2 - 16 } & $\mathbf{1}$ & $\mathbf{2}$ & $\mathbf{3}$ & $\mathbf{4}$ & $\mathbf{5}$ & $\mathbf{1}$ & $\mathbf{2}$ & $\mathbf{3}$ & $\mathbf{4}$ & $\mathbf{5}$ & $\mathbf{6}$ & $\mathbf{7}$ & $\mathbf{8}$ & $\mathbf{9}$ \\
\hline & & & & & & $\mathrm{x}$ & $\mathrm{x}$ & & & $\mathrm{x}$ & $\mathrm{x}$ & $\mathrm{x}$ & & \\
\hline $\begin{array}{l}\text { Mesenteric LN } \\
\text { intestine/colon }\end{array}$ & & & & & & $\mathrm{x}$ & $\mathrm{x}$ & & & & & & & \\
\hline Inguinal LN & & & & & & & $\mathrm{x}$ & & & & & & & \\
\hline Brachial LN & & & & & & & $\mathrm{x}$ & & & & & & & \\
\hline Cervical LN & & & & & & & $\mathrm{x}$ & & & & $\mathrm{x}$ & & & \\
\hline Spleen & & & & & & & $\mathrm{x}$ & & & & & & & \\
\hline Thymus & & & & & & & $\mathrm{x}$ & & & & $\mathrm{x}$ & & & \\
\hline Pancreas & & & & & & & $\mathrm{x}$ & & & & & & $?$ & \\
\hline No cancer & $\mathrm{x}$ & $\mathrm{x}$ & $\mathrm{x}$ & $\mathrm{x}$ & $\mathrm{x}$ & & & $\mathrm{x}$ & $\mathrm{x}$ & & & & & $\mathrm{x}$ \\
\hline
\end{tabular}

D

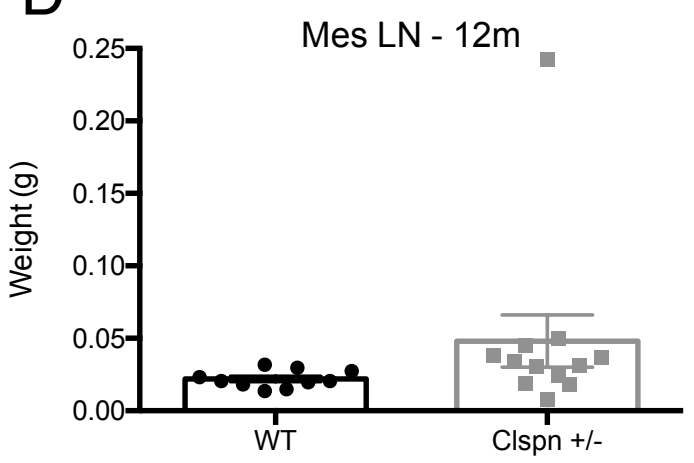

F

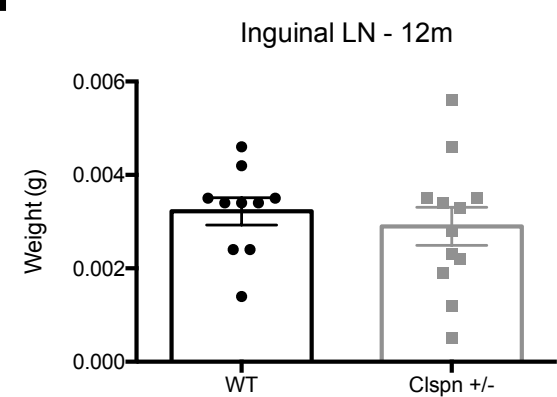

G
$E$
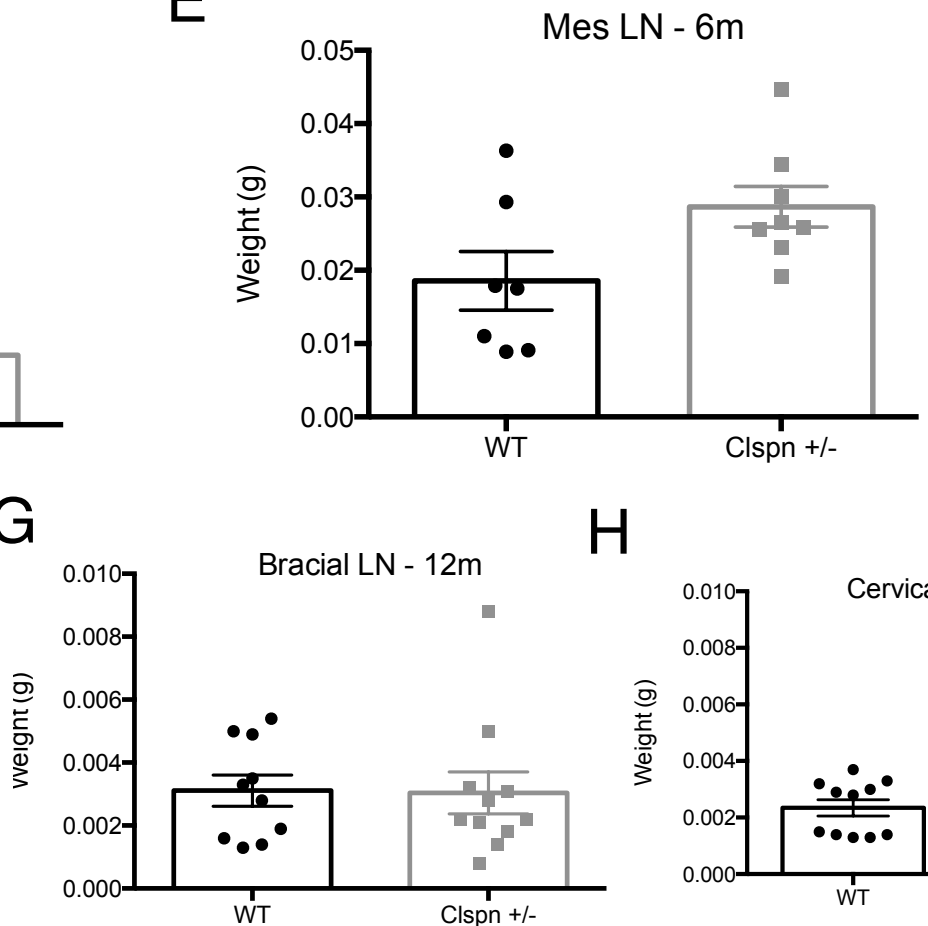

$\mathrm{H}$

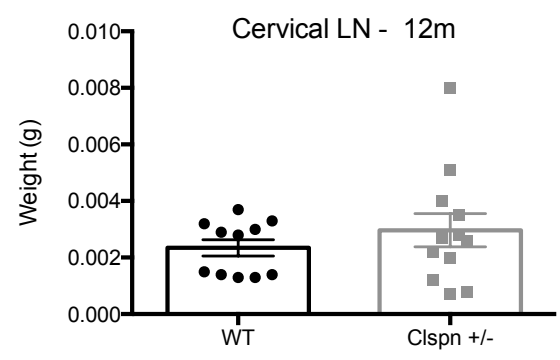


Hunter et al., Supp Figure 7
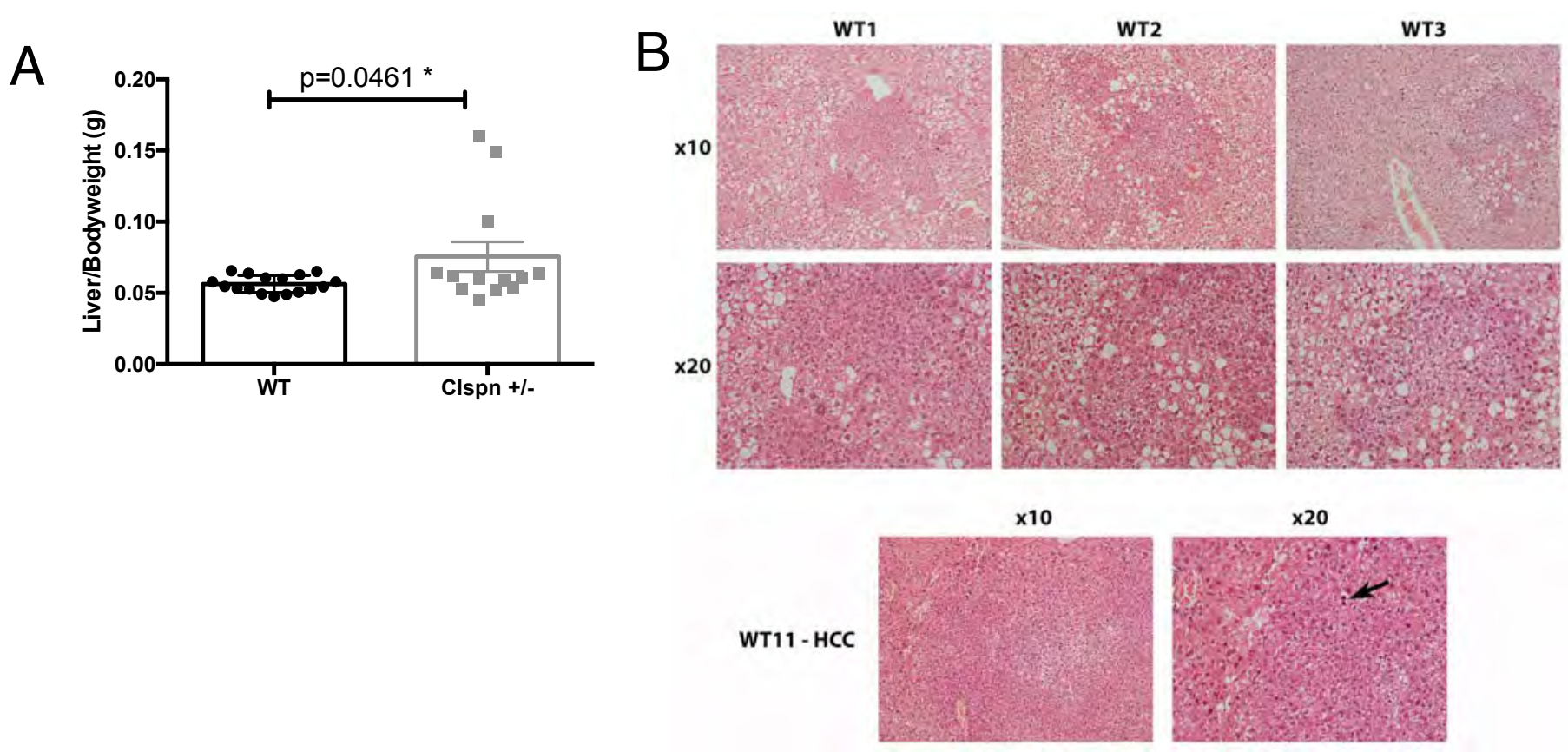

C
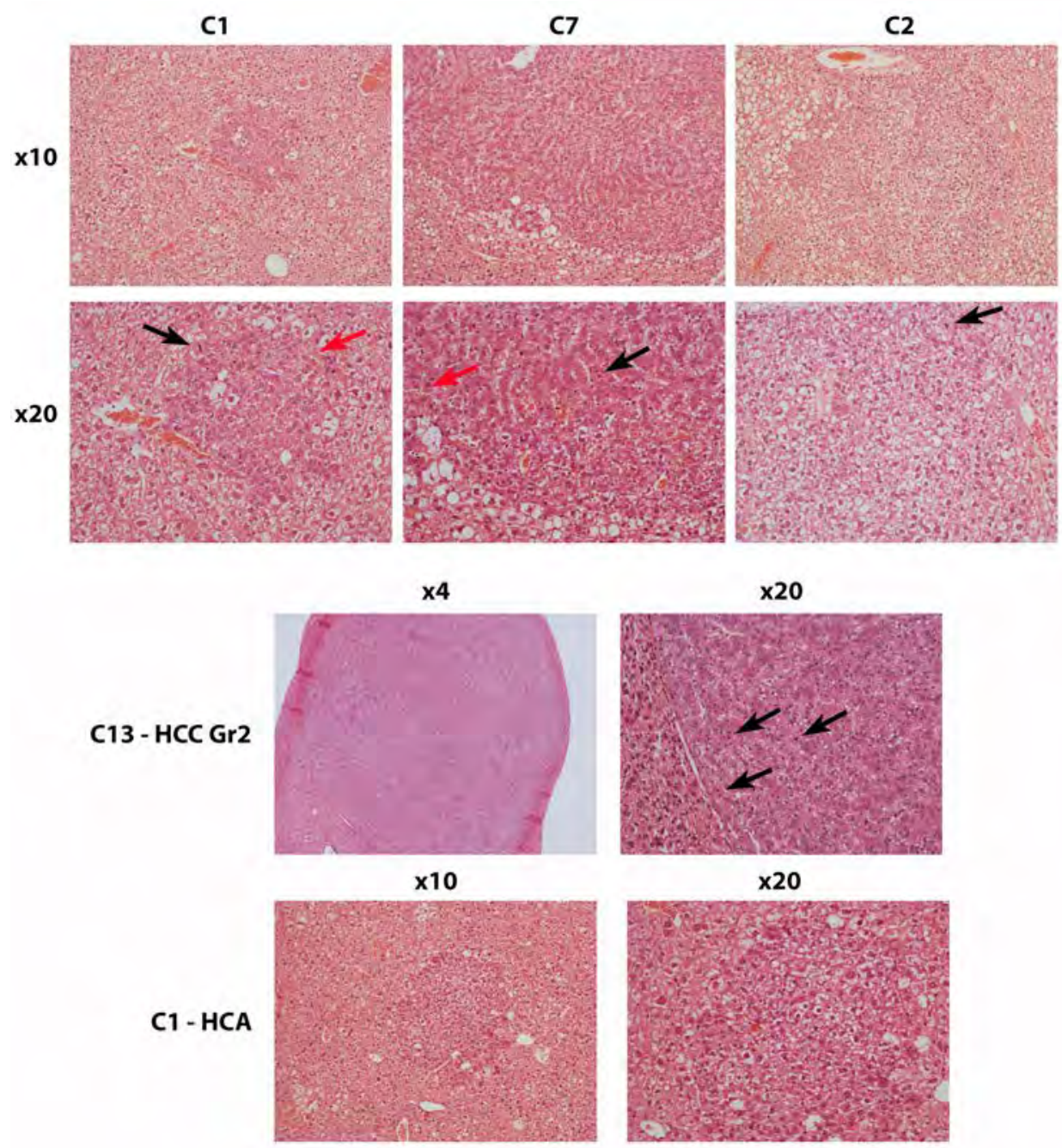

x20

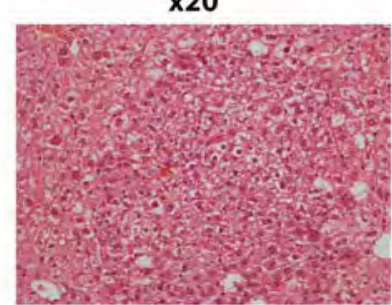

